\title{
Copyright
}

by

Belinda Boon

2006 
The Dissertation Committee for Belinda Boon Certifies that this is the approved version of the following dissertation:

\section{The Professional Development of Small Community Librarians in Texas: A Qualitative Study of the Female Experience}

\section{Committee:}

Barbara Immroth, Supervisor

W. Bernard Lukenbill

E. Glynn Harmon

Jo Lynn Westbrook

Diane L. Schallert 
The Professional Development of Small Community Librarians in Texas: A Qualitative Study of the Female Experience

by

Belinda Boon, B.A.; M.L.I.S.

\author{
Dissertation \\ Presented to the Faculty of the Graduate School of \\ The University of Texas at Austin \\ in Partial Fulfillment \\ of the Requirements \\ for the Degree of
}

Doctor of Philosophy

The University of Texas at Austin

May 2006 


\section{Dedication}

I wish to dedicate this work to my grandmother, Mrs. Velma Mitchell, who would have been very proud to see her belief in me come to fruition; and to the many non-MLS

library directors working in small Texas communities I have come to know and love over the years. Small community librarians are the unsung heroes of our profession. 


\section{Acknowledgements}

I would like to gratefully acknowledge the mentors without whose help this work would not have been completed: Barbara Immroth and Bill Lukenbill for their endless patience and tireless efforts spent helping me understand the research process, and for their support and encouragement over the many years I have been in the UT iSchool doctoral program; Veronica Covington for treating me as a colleague as well as a friend, and encouraging and inspiring me to become a better teacher; Shirley Lukenbill for all her support and guidance over the years; my parents, Carolyn and Herb Boon, my sisters Karen Montgomery, Sharon Bordenave and Rebecca Boon, and the rest of my family for their unwavering faith, love, and support; Suellen Adams and Stephanie Zurinski, peer reviewers whose critical comments helped me formulate a better research product; and my grandmother, Mrs. Velma Mitchell, whose faith in my abilities never wavered but who did not live to see me achieve my education goals. Finally, I would like to thank all of the small community librarians across the country whom I have learned from over the years, most especially the Texas librarians who agreed to take part in this study who cared enough to give freely of their time, thoughts, and feelings. All of you have my deepest and most heartfelt appreciation. 


\title{
The Professional Development of Small Community Librarians in Texas: A Qualitative Study of the Female Experience
}

\author{
Publication No.
}

\author{
Belinda Boon, Ph.D. \\ The University of Texas at Austin, 2006
}

Supervisor: Barbara Immroth

The purpose of this study is to explore elements in educational events, personal experiences, or job circumstances that a selected group of library directors without master's in library and information science (MLS) degrees working in small Texas communities believed to be significant in contributing to their professional development. The study may aid continuing education providers to develop training programs that better meet the needs of small community librarians, and may help promote understanding and collegiality between MLS and non-MLS librarians. A qualitative inquiry was conducted with 14 female library directors working in Texas communities of 25,000 or less with at least one participant from each of the ten Texas regional library systems. None of the librarians in the study have MLS degrees, and so are not considered by the field to be professional librarians. Study participants were selected using a random stratified sampling technique. Face-to-face interviews lasting between 30 and 60 minutes were conducted using open-ended questions, and interviews were recorded and 
transcribed for later analysis. Four archetype-like roles for librarians were identified from the interview data: the Mother/Caregiver, the Researcher/Detective, the Visionary Leader, and the New Professional. Four broad areas with sub-themes relating to the professionalization of non-MLS library directors also were identified from the data: job satisfaction (library work as spiritual salvation, librarianship and the ethic of caring, making a difference in the community, and pride in professional identity), professional development (hiring narratives, continuing education and lifelong learning, mentoring and professional development, and the importance of the MLS degree), challenges facing small community library directors (gender-based discrimination, resistance from local governing officials, and geographic isolation), and guidelines for success (understanding the community, becoming part of the community, making the library the heart of the community, business and managerial skills, and people and customer service skills). Conclusions relating to each finding are summarized and outlined in the final chapter. General conclusions are: (1) small community library directors approach their jobs as archetypal-like roles; (2) caring relationships and a need to make a difference both drive and inspire small community library directors; (3) continuing education and mentoring are essential to the professional development of small community library directors; and (4) many non-MLS library directors working in small communities exhibit traits associated with professional librarians, including knowledge of information sources and tools, research skills, business and management skills, and customer service skills. The study concludes with recommendations for practice and for further research in the area of small community librarianship. 


\section{Table of Contents}

List of Tables …........................................................................................ xii

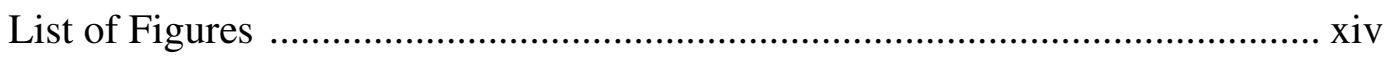

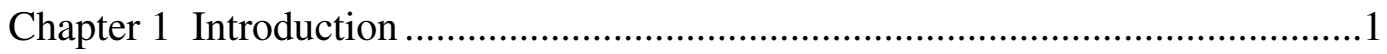

Background .................................................................................... 1

The Library Field .................................................................... 3

The Nature of Small Communities ...................................................4

Small Community Library Directors ............................................... 7

Librarianship as a Profession ........................................................8

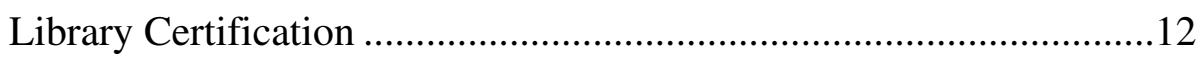

Computerization in Small Community Libraries..............................13

The Texas Library System ..............................................................16

Continuing Education and Adult Learning .....................................17

National Continuing Education Efforts .........................................21

The Small Library Management Training Program............................23

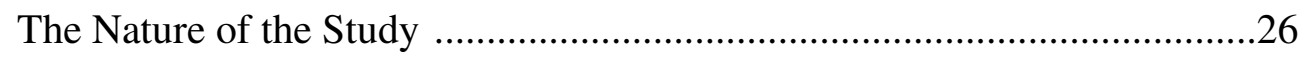

Statement of the Problem ............................................................26

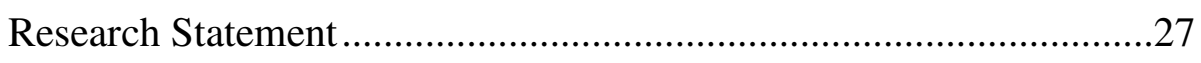

Significance of the Study ...............................................................28

Indicators of Evidence ............................................................ 30

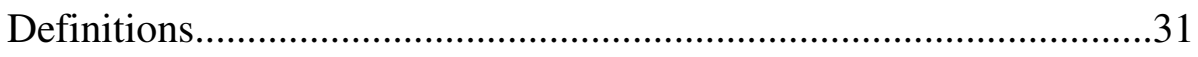

Research Question and Assumptions.............................................33

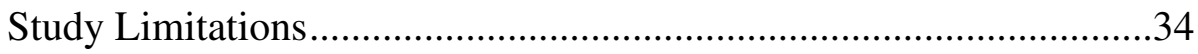

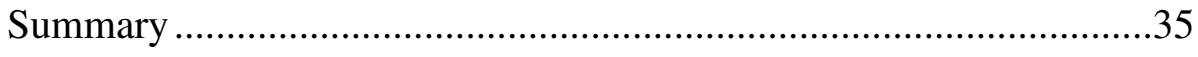

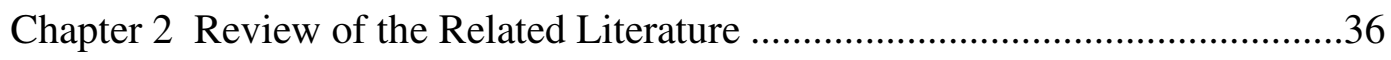

The Professionalization of non-MLS Librarians .......................................38

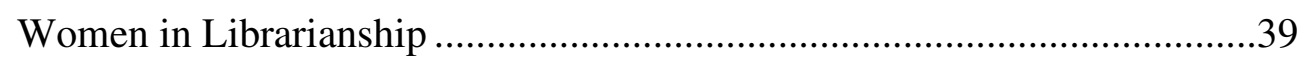

Gender-Based Discrimination.................................................41 


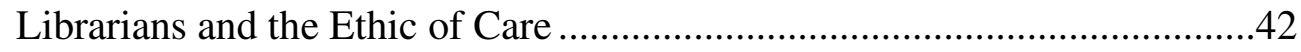

Challenges Faced by Small Community Library Staff ..................................44

The Role of Mentoring in Professional Development ....................................47

Summary of Relevant Literature..............................................................50

Chapter 3 Study Design and Description of Participants.....................................53

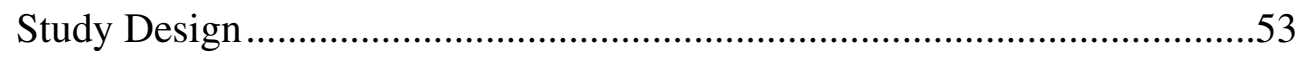

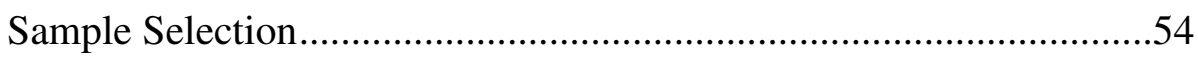

The Interview Process .....................................................................56

Data Compilation ............................................................................

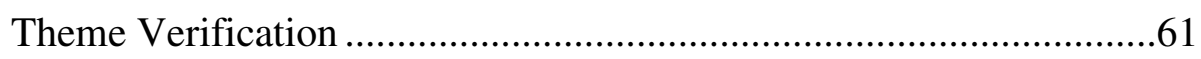

Description of Participants........................................................................62

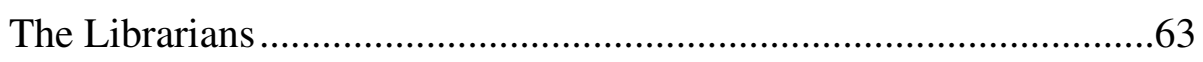

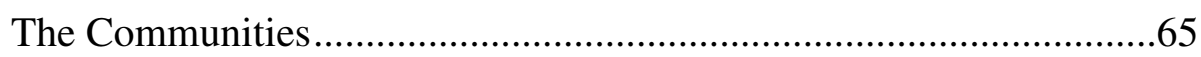

Texas Geographic Regions ...........................................................66

Geographic Distribution of Libraries in the Study ..............................69

Comparisons Between Libraries in the Study and Libraries of Similar

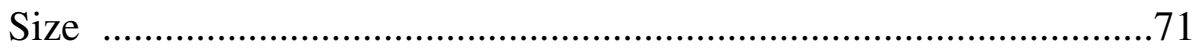

Chapter 4 Study Findings.....................................................................................78

1. Archetypal Management Roles for Library Directors ...............................80

The Mother/Caregiver......................................................................8

The Researcher/Detective .................................................................85

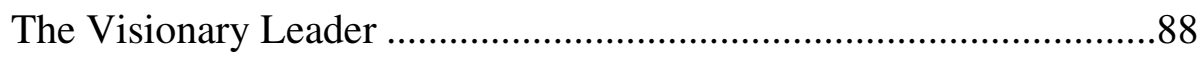

The New Professional .........................................................................91

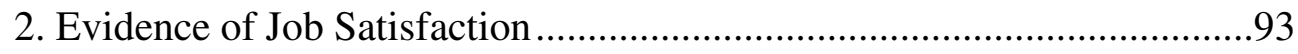

Library Work as Spiritual Salvation ..................................................94

Librarianship and the Ethic of Caring ..................................................97

Making a Difference in the Community .............................................101

Pride in Professional Identity - "It's the Library Lady!" .....................103

3. Positive Influences on Professional Development....................................105

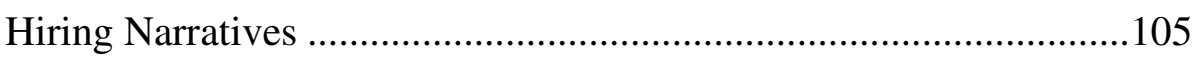


Accidental Librarianship ..........................................................106

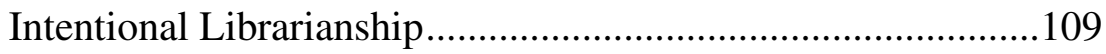

Continuing Education and Lifelong Learning ...................................111

Mentoring and Professional Development............................................113

Networking with Peers................................................................114

Regional Library System Consulting Staff .................................117

Other Mentoring Relationships.................................................118

Importance of the MLS Degree …………………………...............119

4. Challenges Facing Small Community Librarians ...................................124

Gender-Based Discrimination-Working within the Established Patriarchy 125

Resistance from Local Governing Officials .....................................129

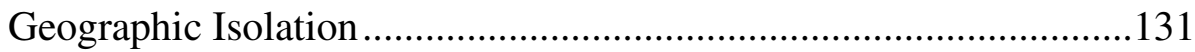

5. Guidelines for Success ......................................................................134

Understanding the Community ........................................................134

Becoming Part of the Community .....................................................136

Making the Library the Heart of the Community ……………….......138

Business and Managerial Skills ........................................................140

People and Customer Service Skills ...................................................142

Chapter 5 Summary, Conclusions, and Recommendations .................................145

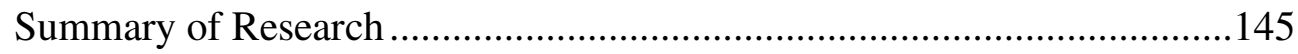

Archetypes as Metaphors for Library Management ...........................147

The Importance of Personal Relationships .........................................148

Positive Influences on Professional Development...............................151

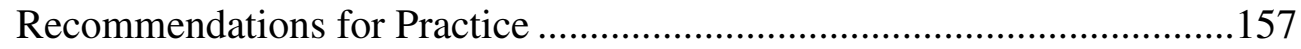

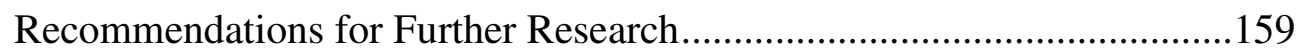

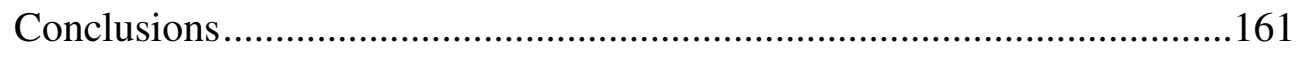


Appendix A Map of the Texas Library System .................................................166

Appendix B Map of the Texas Geographic Regions ..........................................167

Appendix C Informed Consent Form …………………...............................168

Appendix D Interview Protocol and Questions ..................................................171

Appendix E Theme Verification Form .........................................................173

Appendix F Participant Responses to Theme Verification Form .........................175

Appendix G Librarian Archetype Verification Form .........................................179

Appendix H Participant Responses to Archetype Verification Form with Researcher

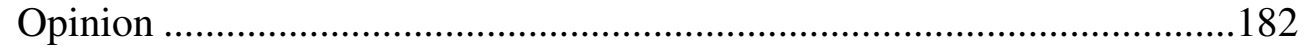

Appendix I Description of Study Participants ………………………..............183

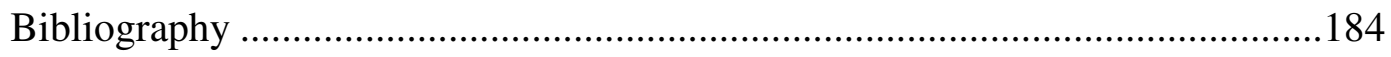

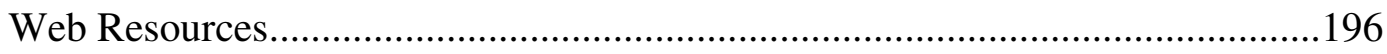

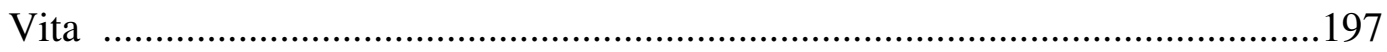




\section{List of Tables}

Table 1: $\quad$ Type of Jurisdiction, System, Geographic Distribution, Service Population, Age, and Education Levels of Libraries in the Sample by

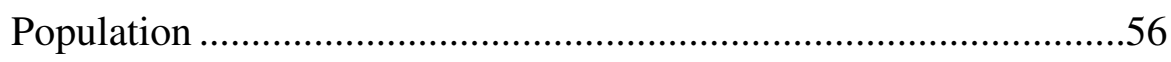

Table 2: Ethnic Distribution of Librarians Attending the Small Library management Training Program in 2005 .

Table 3: $\quad$ Small Community Library Membership in the Texas Library System

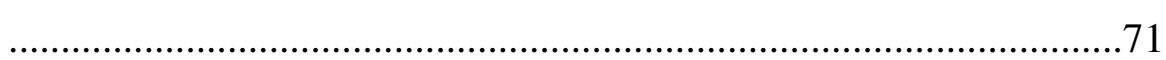

Table 4: $\quad$ Libraries by Population Served........................................................72

Table5: $\quad$ Average Total Operating Income........................................................73

Table 6: Average Collection Size ..................................................................74

Table 7: $\quad$ Statistics for Libraries Participating in the Study ................................75

Table 8: $\quad$ Percentage of Libraries Providing Internet Access.............................77

Table 9: $\quad$ Percentage of Libraries Providing Access to Electronic Services ....77

Table 10: Themes and Sub-theme Identified in the Study ................................126 


\section{List of Figures}

Figure 1: Geographic Distribution of Study Participants .............................56 


\section{Chapter 1: Introduction}

\section{BACKGROUND}

The current study identifies what elements in educational events, personal experiences, or job circumstances that a selected group of library directors without masters in library science (MLS) ${ }^{1}$ degrees working in small Texas communities believes to be significant in contributing to their professional development. Seventy-nine percent (79\%) of America's public libraries serve small communities, i.e., those with populations of less than 25,000 (Public Libraries in the United States: Fiscal Year 2001, 2002). In Texas, seventy-seven percent (77\%) of public libraries serve these areas. ${ }^{2}$ In both cases, women comprise more than ninety percent $(90 \%)$ of staff working in these libraries, including managerial staff and directors. Most of these women come into their jobs with little or no experience working in libraries or as managers, and few will pursue the master's level education required of professional librarians to improve their knowledge and skills. Instead, the task of training and educating small community librarians most often falls to continuing education staff in state library agencies. Yet, continuing education programs implemented by state library agencies do not adhere to any kind of national accreditation standards.

The process of professional development is key for library managers in all types of libraries, but particularly for small community librarians. Non-MLS library directors often work in geographically isolated areas without the support of colleagues and the

\footnotetext{
${ }^{1}$ In the current study the MLS degree is used generically to mean any professional master's program in librarianship, including the master's in library science (MLIS), master's in information studies (MIS), and master's of science in information studies (MSIS).

${ }^{2}$ See the Texas Public Library Statistics for 2003 at www.tsl.state.tx.us/ld/pubs/pls/2003/download.html (Accessed 4 Aug, 2005).
} 
larger profession, but as managers and librarians, they must still provide quality library services and handle complex management issues. The central research question guiding the current study is to discover elements in educational events, personal experiences, or job circumstances that a selected group of library directors without MLS degrees working in small Texas communities believed to be significant in contributing to their professional development, documenting the attitudes and perceptions of small community librarians.

Previous studies (Busch, 1990; Bushing, 1995) used qualitative case study methods to elicit experiences, opinions, and insights from individuals managing small community libraries. Bushing, in particular, focused on experiences influencing the professionalization of rural librarians in six states. The current research study considers themes identified in earlier studies in relation to small community librarians in Texas. This study also explores the role that archetypes play in the job approaches utilized by non-MLS library directors in small Texas communities. Further, it discusses the effects of widespread Internet connectivity and library automation after nearly a decade of implementation and training.

The following sections provide background information on areas of librarianship that affect the professional development of non-MLS library directors working in small Texas communities, and includes: 1) the library field, 2) the nature of small communities, 3) small community library directors, 4) the importance of archetypes, librarianship as a profession, 5) certification in librarianship, 6) computerization in small community libraries, 7) the Texas Library System, 8) continuing education and adult learning, 9) 
national continuing education efforts, and 10) the Small Library Management Training program developed by the Texas State Library and Archives Commission.

\section{The Library Field}

The field of librarianship has experienced myriad changes over the last 40 years. Even the name of the field has changed from librarianship to "library and information science" and, more recently, to "information services." The latter term is now widely used; it describes a field profoundly influenced by computerization and dominated by people anxious to distance themselves from the popular images of prim, unmarried and perhaps elderly women quietly and efficiently managing buildings stuffed with musty print materials. Many practitioners in the field prefer the monikers, "information specialist," "media specialist," "web architect," or even "data miner," to the "antiquated" title, librarian. In the past decade much space has been devoted to discussion of the "L" word in professional publications (Bates 2003, Berry 2000, Childers 1998, Crawford 1999, Cronin 2001, Ferguson 1996, Grossman 2006, Usherwood 1998), and former library schools in universities across the country have reinvented themselves as "schools of information." Yet, despite the changes in the field, public libraries continue to provide access to the latest materials and technology, as well as recreational reading materials, and a physical space for social interaction and formal or informal education. The preeminent leadership organization, the American Library Association, has made many efforts over the years to acknowledge and provide a forum for the wide diversity of the field. Yet, in addition to providing the latest technology available over the years- from LPs to videos to DVDs to the Internet—public libraries remain primarily physical 
locations that most people prefer to visit in person. Nowhere is this more evident than in small communities where "everybody knows everybody" and many people consider the library to be a community center for social interaction as much as, if nor more than, a place to go for information.

\section{The Nature of Small Communities}

Small communities tend to be relatively isolated and unchanging in their ways of life. In many instances, multiple generations of families live, work, and die in the same community. People who move into such communities can remain "outsiders" fifteen or twenty years after their arrival. Some small communities have experienced unprecedented growth and change over the last decade due to the urban sprawl of nearby metropolitan centers. In a relatively short period, many sleepy towns have become first bedroom communities, then suburbs of neighboring cities. The strain put on transportation networks, schools, and city services by mushrooming populations is immense, and older residents soon find themselves coping with the stresses of increased traffic brought by new housing developments, a faster and more impersonal pace of living, and the sight of unfamiliar faces among their neighbors.

A 1981 study conducted by the Center for the Study of Rural Librarianship (CSRL), an organization whose primary mission is to "extend the knowledge relative to the nature and role of rural libraries on a national and international basis," ${ }^{3}$ described the circumstances under which rural libraries operate. In this study, Vavrek (1982) surveyed 666 small community public libraries in Pennsylvania, Ohio, and New York to determine

\footnotetext{
${ }^{3}$ For more information, see the CSRL Website at http://jupiter.clarion.edu/ csrl/ (Accessed 23 July, 2005).
} 
the state of existing rural information services. Approximately one-third of the libraries surveyed (234) were rural libraries; i.e. libraries serving populations of less than $2,500 .^{4}$ The results of this study showed that by 1980 the average rural library:

1) Served a local population of approximately 1,255 people with a service area of nearly four times that population. ${ }^{5}$

2) Lay 53 miles away from a city of 25,000 or more individuals, and that some library users had to travel 12 miles for library services.

3) Had an annual budget of $\$ 28,000$, with federal funds providing only three percent of that total.

4) Operated for 25 hours per week and had a book collection of about 14,000 volumes.

5) Was the only library in its service area, other than a public or private school library that housed few additional resources.

6) Had a staff consisting of three salaried individuals, with only one in ten holding masters degrees in library science.

7) Had a staff consisting of $25 \%$ volunteers, and equipment consisted of a telephone (some even lacked phone service), typewriter, photocopier.

Further, Vavrek found that while four out of ten libraries surveyed were connected to the OCLC $^{6}$ system, each was almost entirely disconnected from the services provided by

\footnotetext{
${ }^{4}$ Although the study is now more than two decades old, many of the findings remain true in the present day as reflected in the NCES publication, Public Libraries in the United States: Fiscal Year 2001.

${ }^{5}$ Most municipal public libraries serve a designated population determined by the local tax base. However, most rural and small community libraries also serve people residing in other municipalities or in rural areas within the same county. To account for the lack in tax revenue, many small community public libraries charge an annual user fee to individuals or families living outside their taxation area.
} 
Dialog and other online database vendors (Vavrek 1982b, 23-25). Although Vavrek's

findings are more than two decades old, more recent data reveal that little has changed for the rural library. According to Texas Public Library Statistics 2003, the average Texas rural public library in the present day:

1) serves 1,407 people,

2) has an operating budget of $\$ 14,620$,

3) has a book collection consisting of about 15,000 volumes, and

4) is open 26 hours per week.

Small community libraries are as varied and unique as their communities. They may be vibrant, busy meeting places for local residents or still and empty for hours on end; noisy educational centers for the after-school crowds or quiet places of study for amateur genealogists and mystery book readers. The library's public access computers may be in use constantly hosting e-mailers, Web-surfers, and gamers of all ages and the meeting rooms booked solid with ESL and literacy classes; or local residents may make a habit of stopping by around 10:30 every morning the library is open because they know the staff are taking their coffee breaks. Elementary-age children may make a habit of watching videos at the library in the afternoons while business people routinely come by in the mornings to make copies and send faxes. In every case, people make up the character of the library, and the needs of the community drive the library's collection development practices and service provision. Further, a traditional, service-based

\footnotetext{
${ }^{6}$ Founded in 1967, OCLC Online Computer Library Center is a nonprofit, membership, computer library service and research organization dedicated to the public purposes of furthering access to the world's information and reducing information costs. In 2005 more than 50,540 libraries in 84 countries and territories around the world used OCLC services to locate, acquire, catalog, lend and preserve library materials. More information about the organization is available at http://www.oclc.org/about/default.htm.
} 
approach to librarianship dominates practice in small community libraries, where a professional library degree is seldom required of the library director.

\section{Small Community Library Directors}

Whatever the circumstances, small community public libraries tend to be managed by well-meaning and dedicated individuals - mainly underpaid women between the ages of 40 and 60 working part-time - who love to read, have a high regard for literacy and education, and enjoy helping others (Vavrek 1984, 12; Flatley 2000, 9). Most of these women have not obtained higher education or training in librarianship, although they often get their jobs because of their previous experiences in education, management, or with computers. In many instances, people still view the librarian's job as a sort of glorified clerk position in small communities; yet, non-MLS library directors are expected to perform professional work such as preparing and justifying budgets, hiring and managing staff, building and maintaining collections, and developing policies. These "nonprofessional" librarians also may have to handle materials challenges from individuals or groups in the community; confront inappropriate behavior or computer usage by children or adults; and navigate a hostile political environment when working with their board, city council, or county commissioners. Non-MLS small community library directors face similar challenges as their degreed counterparts working in large urban and suburban areas, but often lack the necessary professional knowledge and skills coming into the job.

In Texas, many non-MLS library directors seek out training and continuing

education opportunities provided by their regional library systems and the state library to 
gain the necessary competencies and skills. Often, a mentor or predecessor will informally train a non-MLS librarian in library procedures and operations. As a result, many small community library directors become competent librarians and managers without earning a master's degree in library science (MLS). Moreover, since many of these librarians were born or raised in the communities they serve, local residents perceive them as members of their communities - a friend and neighbor - as well as knowledgeable information providers. However, in the field of librarianship, their degreed colleagues do not consider non-MLS library directors to be professional librarians or even library professionals.

Many librarians in the current study noted the importance of a personal connection between the librarian and the community. The following quote is typical: "Be a part of your community. You may have worked for a place and know all about libraries. The most important thing you need to know is all about your community" (P12, L1449$1452^{7}$ ). This characteristic may be the most important quality for a small community librarian to have in addition to knowledge of library theory and procedures.

\section{Librarianship as a Profession}

The status of librarianship as a profession remains a topic of debate beginning with the field's formal inception in the late nineteenth century. What characteristics does the library field share with the traditionally recognized professions of law, medicine, and the clergy? What distinguishes the skilled work librarians do from the skilled work of

\footnotetext{
${ }^{7}$ Quotes from interviews with small Texas community librarians are referenced throughout the study by the order in which each participant was interviewed (e.g., P01 for Participant 1, P02 for Participant 2) and the numbered transcript lines where each quote appears (e.g., L34-48 for lines 34-48). See Table 2 and Appendix G for a complete list of study participants.
} 
auto mechanics and plumbers? Most agree that understanding the abstract theory supporting practice is the distinguishing element that places professionals apart from other skilled laborers. Abbott (1998) concedes that "if auto mechanics had that kind of abstraction...they would, for my purposes, be a profession" (Abbott 1998, 430), and elaborates on this theory in his landmark book, The System of Professions. Proponents of professional status and their detractors have argued the issues repeatedly; perhaps it is time to move forward from these discussions and concentrate instead on how to effectively work in and manage libraries.

The American College Dictionary and The Random House Unabridged Dictionary both define a profession as "a vocation requiring knowledge of some department of learning or science" and a professional as one who follows "an occupation as a means of livelihood or gain" or one who is "engaged in one of the learned professions.” Bates (1999b) expands on this definition, stating that:

A profession develops a body of knowledge around roles and activities that a society values. Professional skill then involves mastering that body of knowledge and developing experience applying it to situations where the knowledge is relevant... a profession always requires developed judgment. There are complexities, subtleties, and variations from situation to situation that require experienced judgment in order to apply the professional knowledge properly (Bates 1999b, 1).

An online tutorial on professionalism developed for non-MLS librarians

(Todaro 2000) lists the major elements of a profession as:

1) An articulated philosophy that is both oral and written.

2) A body of knowledge or professional literature. 
3) Leaders or philosophers who once were considered to be those who wrote about the profession but who now include writers, practitioners, and role models in active service.

4) Guidelines for behavior; i.e., codes, guidelines, creeds, oaths, commitment statements, belief statements - such as statements on ethics and professionalism that are content-oriented.

5) Professional organizations and associations that provide professional development opportunities outside the work environment.

6) Certification and licensing requirements.

Librarianship meets all of the above criteria. For more than 100 years, the library field has developed a philosophical basis for its functions and services, as well as a rich body of knowledge reflecting both the practice and theory guiding its members. The field has a multitude of leaders representing various areas of study and practice in the international, national, regional, state, and local arenas. Ethical codes include commitments to access; the freedom to read, listen to, and view print and electronic materials; statements and laws concerning the confidentiality of information and services; and acceptable use policies for online computer usage. National and state associations and organizations provide the basis for professional direction, service statements, and some accreditation of professional requirements for local to international activities. Although licensing and certification requirements vary from state to state, all require some form of certification, testing, educational levels, and continuing education. 
The idea of professionalism in librarianship has been attacked as an affliction, a type of mania that "promotes self-centeredness, which in turn breeds an air of selfimportance and self-delusion" (Kehde 1999, 43). Citing a transformation in service taking place in over the last thirty years, Kehde laments that academic libraries are no longer efficient and frugal operations staffed by librarians - whose main purpose was to get the books on the shelves and help the patrons find them. Instead, these libraries have evolved into convoluted environments requiring, among other things, an "astronomical number of committees, team managers, and continuous meetings that thwart the real aims of a library" (Kehde 1999, 43). Further, he believes that young university and college librarians yearn for a renaissance that will return them to the "good old days" helping patrons find the books they need simply and efficiently (Kehde 1999, 43).

One outstanding characteristic that removes all doubt about the professional status of the library field is its ability to renew itself to meet the needs of the time and place in which it exists. While one could argue that auto mechanics also must change to keep up with new developments in their field, those changes are never met with the hue and outcry, the endless debate and argument, and the diametrically opposed viewpoints that rage throughout the field of librarianship. Ultimately, perhaps the defining element of the library profession is not the presence of abstract theory, but its very existence as a dynamic, living organism that cannot be clearly defined but continuously grows — with accompanying pains — mutates, and reinvents itself in relation to other fields and the world in which it exists. Abbot (1988) describes librarianship as enjoying "a vibrantly 
real but highly elusive existence, qualities that make it both worthwhile and impossible to discuss objectively" (Abbot 1998, 432).

\section{Library Certification}

"Paraprofessional" is a term commonly used to describe anyone working in a library who does not have a master's degree in library science (MLS). However, the term usually is applied to staff employed in urban or suburban libraries working in jobs with narrow and specific duties, such as shelving or manning the circulation desk. In contrast, managers of small community libraries usually carry a number of job responsibilities, including shelving, working the circulation desk, providing reference services, presenting library programming, providing outreach services, and doing both administrative and custodial work. The term "non-MLS library librarian" appears throughout this study, and is used to distinguish non-degreed library directors working in small communities from what the profession considers to be paraprofessionals.

The MLS degree has become the standard entry-level degree for professional librarians working in the United States. Yet, the MLS is seldom required in communities of less than 25,000, and an attitude of superiority can exist on the part of degreed librarians toward their non-degreed counterparts working in small towns. One of the librarians in the current study commented on the prevalence of professional elitism in her own experience:

I'm a little bit surprised at how the line is drawn within the library profession among MLS and non-MLS because I really see that non-MLS, we, we stick together and we are more forthcoming. And it's almost as if - now this is not - this is a general statement. This is not everybody 'cause there are-I have seen exceptions to the rule on both sides, but 
there seems to be a little line drawn that MLS is over here and if I'm not MLS, over here (P13, L-307-312).

The current study identifies elements in the process of professional development of nonMLS librarians that may promote understanding and collegiality between professional librarians and their non-degreed colleagues.

\section{Computerization in Small Community Libraries}

The effects of widespread and rapidly changing technology on librarians in small community libraries cannot be overlooked. For example, in the decade following Bushing's 1995 study of rural librarians, state and local agencies undertook massive efforts to connect rural American schools and libraries to the Internet. Most of the librarians in the current study oversaw the installation of Internet access computers during this period. Many small public libraries received their first computers with the advent of the Internet, as most did not have existing automated catalogs or circulation systems. Over the last ten years, state, federal, local, and private grant programs have allowed even the most rural communities to gain access to the Internet through DSL, ${ }^{8}$ cable, broadband, or wireless technologies. These programs were instrumental in putting computer hardware and software into small community libraries. In many cases, small community public libraries became the first public venues to offer Internet access in their communities, as well as the first places to offer training on Internet searching, email, and word processing programs.

\footnotetext{
${ }^{8}$ Digital Subscriber Line: A method for moving data over regular phone lines that is much faster than a regular phone connection, but uses the same wires coming into the subscriber's premises (copper wires) used for regular phone service. DSL is currently a popular alternative to Leased Lines and ISDN, faster than ISDN and less costly than traditional Leased Lines.
} 
Since 1996, the E-Rate program ${ }^{9}$ funded by the federal government has allowed public and public school libraries up to a ninety percent (90\%) discount on telecommunications lines and phone bills based on the level of poverty of the community. ${ }^{10}$ In Texas, the Telecommunications Infrastructure Fund (TIF) provided more than $\$ 25$ million to rural schools and libraries for computer hardware and telecommunications lines during that same period. Through a series of nationwide grants provided between 1997 and 2003, the Gates Foundation provided more than 47,000 computers with Microsoft operating systems and educational software to more than 11,000 public libraries in all 50 states. ${ }^{11}$ Virtually overnight, geographically isolated communities became part of the "Information Superhighway" with access to the World Wide Web, electronic mail, and online databases. As use of digital information technology mushroomed, countless challenges - including learning how to use email systems to learning new word processing software and learning online database search techniques - presented themselves to small community librarians, many of whom had never touched a computer before. One librarian in the current study summed up the rapid technological changes for her small library:

We went from virtually having no computers [to] over 30 in the building now, and we have 13 public access computers for the Internet. We have three of the Gates computers that we basically use for children's computers for the games and we have the staff computers. So it's, it's

\footnotetext{
${ }^{9}$ For more information about this program, visit the Universal Service Administrative Company's Web site at http://www.sl.universalservice.org/ (Accessed 23 July, 2005).

${ }^{10}$ The number of children taking part in the local school district's free lunch program determines the level of poverty for any community. This number also determines the percentage of the library's telecommunications and phone bill discount.

${ }^{11}$ For more details about the Gates Foundation Library Grant Program visit their Web site at http://gatesfoundation.org/Libraries/USLibraryProgram/Grants/default.htm (Accessed 27 Aug, 2005).
} 
incredible over the space of time how much has kinda gone 'hwwwwt!'(P05, L56-61).

Small community libraries, in many ways a microcosm of the larger culture, have experienced extraordinary changes wrought by computerization in the last ten years. Non-MLS librarians have grappled with the same rapid changes affecting collections, procedures, and services that their counterparts in larger, more urban settings have encountered, but often are handicapped by lack of education and management experience. A significant percentage of small and rural library managers are older than 65 , and therefore have the added disadvantage of not having worked with computers before encountering them in the library. One of the library directors in the current study — the only paid staff person in a library run by more than 20 volunteerscommented on this phenomenon in her library: "We have these computers ... and the volunteers hate to do anything with them because all our volunteers are in their sixties, have all retired, and so, the technology ... it kinda scares them" (P11, L92, 95-96). Small community librarians have had to deal with electronic connectivity to the Internet, and with the procedural, behavioral, and access issues inherent in providing public access to online resources. At the same time, many have had to learn basic computer functions, such as using a mouse and point and click technology, as well as database and Web searching skills. Most of the librarians in the study gained these skills from hands-on training and consulting services provided by the Texas State Library and Archives Commission and the Texas Library System. 


\section{The Texas Library System}

The Texas Library System comprises ten regional library systems established throughout the state and funded by contract with the Texas State Library and Archives Commission (TSLAC). Nearly every public library in the state is a member of the Texas Library System. Member libraries receive many benefits from the system including consulting and continuing education services, and support for such projects as literacy, English as a Second Language programs, and library automation. ${ }^{12}$

The Library Systems Act, adopted in 1969, enabled the TSLAC to establish a network of public library systems funded through contracts with TSLAC (System Orientation Manual, 1999). While the Act enabled the TSLAC to encourage and assist in the establishment of individual public libraries, the TSLAC is not authorized or required to establish libraries; instead, the TSLAC is authorized to bring existing public libraries together in a system formed to improve statewide library service and to serve, collectively, the entire population of the state. To accomplish this, the Act authorized the TSLAC to divide the state into geographic regions, each including at least 4,000 square miles, and to designate a large public library in each region as a Major Resource Center (MRC). The TSLAC also was authorized to establish standards as a prerequisite for voluntary system membership. Within each region, libraries that apply for membership in the Texas Library System and that meet accreditation standards are attached to the regional MRC for system services. Contracts made between the MRCs' municipal governments and the TSLAC fund the regional library systems.

\footnotetext{
${ }^{12}$ More information about the Texas Library System is available at http://www.tsl.state.tx.us/ld/pubs/libsysact/index.html (Accessed on 14 August, 2005).
} 
Texas public libraries depend almost entirely on local support, most of which comes from city or county governing bodies through appropriation of local public funds. Historically, many local governments have been reluctant to appropriate funds for library support in Texas, substantially hindering library development at the local level. To accomplish its objective of improving statewide library service through a state system, the TSLAC first had to encourage an increase in local library support, since local support efforts are necessary for libraries to meet system membership accreditation standards. System membership also provides essential services that, in many cases, could not be afforded at the local level. One of these essential services is library continuing education provided at no cost to the participating librarians.

\section{Continuing Education and Adult Learning}

Continuing education refers to activities and efforts by an individual to upgrade her knowledge, abilities, competencies, and understanding in a field of work or specialization to become a more effective professional and be able to handle responsibilities of greater scope and accountability (Weingand 1992, 394). Continuing education encompasses both formal and informal education that goes beyond academic programs offered by educational institutions and helps the library professional:

1) become more effective and successful,

2) develop professionally,

3) meet degree, licensure and certification requirements,

4) update knowledge and skills,

5) share experiences and concerns, and 
6) become acquainted with colleagues and peers (Jensen 1997, 1).

In its broadest sense, continuing education includes workshops on general or specific topics, degree and certificate programs, participation in professional organizations, training courses and seminars, videotapes and films, lectures and panel presentations, synchronous or asynchronous online courses, information shared on listservs and discussion groups, and journal and newsletter articles.

Lifelong learning - the ability of a living organism continuing to gain awareness, or learn, throughout its lifespan - is an inherent part of continuing education. Research has shown that learning how to learn is as important to adult learners as the skills and competencies acquired (Asp et al. 1985, 55; Knowles 1994, 12; Laird 1985, 9). Also prevalent in the literature is the idea of self-directed learning—an individual's personal responsibility to take an active role in determining his or her own professional development needs. To be most effective, library education or training must be guided by a thoughtful, studied approach that includes:

1) assessing skills and competencies,

2) developing an individual plan for professional development.

3) setting objectives for learning,

4) identifying available resources,

5) gaining some evidence of accomplishment or recognition, and

6) evaluating experiences to determine if goals were met (Asp et al. 1985, 61). Adult learners favor self-directed learning methods through which they are allowed to define and explore their own education and training needs. Studies also have 
shown that adults share several learning motivations or content areas. According to Asp et al. (1985) and Laird (1985), adults are motivated to seek continuing education offerings when the training:

1) Includes relevant content based on their actual needs,

2) relates directly to their jobs,

3) gives a feeling of growth in job competence,

4) is of high quality,

5) has practical application (i.e., there is an opportunity to use the new knowledge on the job),

6) provides a chance to network with other library professionals, and 7) meets certification requirements ${ }^{13}$ (Asp et al. 1985, 67-71; Laird 1985, 125126).

One of the aforementioned criteria stands out, particularly for non-degreed public library directors in small communities: the chance to network with other librarians in similar situations. This accounts for much of the success of on-site workshops and seminars, even when other factors in the training effort (e.g., low quality, not relevant to job) are lacking. The opportunity to discuss issues with colleagues and to learn how they handle similar problems is a powerful factor in assessing the overall success of the training offering. In contrast, barriers to seeking continuing education tend to be contextual and driven by outside factors. These include accessibility and convenience

\footnotetext{
${ }^{13}$ In Texas, this certification requirement for public library staff is known as County Library Certification.
} 
(lack of time or inconvenient location), travel expense, and hostility or reluctance of administration (Asp et al. 1985, 71).

Many factors influence individuals to seek out opportunities for continuing education. Presently, MLS degrees have a short life if they are not enhanced with continuing professional education, and academic programs rely on employers to provide practical job skills for new hires. At the same time, employers-even in small communities — are demanding a wide array of skills and competencies for entry-level positions. These factors, along with the rapidly changing character of LIS and the demands of an increasingly technologically sophisticated and more demanding clientele, are steadily increasing pressures on continuing education providers to diversify and expand their existing programs.

Until recently, ${ }^{14}$ few small community librarians have pursued master's degrees from accredited university library programs; hence, the burden of training and education falls on the state library agency continuing education (CE) staff. In 2002, more than $\$ 5$ million was spent in Texas to fund continuing education programs specifically targeted for small community library staff. This funding includes 1) monies from the Library Services and Technology Act (LSTA) funding provided by the Institute of Library and Museum Services (IMLS) to the Texas State Library and Archives Commission (TSLAC) and channeled to the ten regional offices in the Texas Library System, and 2)

\footnotetext{
${ }^{14}$ Since the mid-1990s, online master's programs — such as those offered through the University of North Texas School of Library Studies and the School of Library and Information Studies at Texas Woman's University - have allowed geographically isolated Texas library staff to earn professional degrees from ALA-accredited programs.
} 
Texas Infrastructure Fund (TIF) grant money provided by legislative mandate to TSLAC for the establishment of a statewide videoconferencing network.

\section{National Continuing Education Efforts}

For almost three decades, the LIS profession has called for the formation of a national, formal structure for continuing education that would "provide relevant content of high quality that addresses the actual needs of practicing librarians" (Smith 1999). In 1974, Elizabeth Stone proposed the development of an ALA Center for Continuing Education. The result was the formation of the Continuing Library Education Network and Exchange Round Table (CLENERT), a unit of the American Library Association that offers workshops at ALA annual conference and produces publications, but does not govern the continuing education efforts of other organizations in the United States (Smith 1999). Many states, including Texas, have ongoing continuing education programs specifically designed to provide knowledge of and skills for library management.

Given the small number of small community public library staff who hold MLS or equivalent degrees and the reasons discouraging them from pursuing formal library education, it is not surprising that the bulk of the responsibility for job skill and competency education falls on state library agencies. In 2001 the Western Council of State Librarians (WCSL) Education Task Force commissioned a survey of national library education and continuing education programs currently available for support- and paraprofessional public library staff. Intended to support and guide efforts by the WCSL to develop a comprehensive and consistent nation-wide continuing education program, the study's authors reviewed pertinent professional literature, summarized trends for 
library staff education, described selected certification programs, and suggested competencies and delivery methods for consideration by the WCSL Education Task Force (Madden and Grover 2001). Study findings included the following:

1) library work is becoming more complex,

2) the roles of all library staff are changing,

3) educational and certification programs for library support staff exist in many forms, and in many kinds of organizations, but are not organized according to any common systems of competency standards or institutional accreditation systems,

4) the professional literature asserts that there should be unified systems for recognition of competency standards,

5) library paraprofessionals are forming sophisticated organizations designed to address their unique needs,

6) educational institutions are providing increasingly varied forms of education related to Library and Information Science (LIS), and

7) technology has allowed LIS education to be delivered through more sophisticated means, particularly in the delivery of distance learning (Madden \& Grover 2001).

The Madden and Grover report does not include descriptions of the many library skills education programs operated by state library agencies, such as the UPLIFT program in Utah, the Library Skills Institute in Missouri, or the Small Library Management Training Program in Texas. After continuing education staff at these state libraries drew attention to these omissions, the WCSL grant development team invited 
Jan Elliot, the CE Consultant at the Arizona State Library, to become a member of their team.

Perhaps the most useful result of this study is the development of a list of core competencies and technical standards related to different aspects of library work, from youth services to reference to technical services to technology planning and implementation. This detailed list of competencies presents a guide for developing a comprehensive, national training program, one that would incorporate existing continuing education and formal education programs, the completion of which would include a standard form of library certification. The following section describes the Small Library Management Training Program (SLMTP), an ongoing continuing education program developed for non-MLS library directors in Texas. The SLMTP is one continuing education program considered for inclusion in the larger WCSL effort.

\section{The Small Library Management Training Program}

The Library Development Division of the Texas State Library and Archives Commission developed the Small Library Management Training Program (SLMTP) in 1994 in response to requests for ongoing basic library skills education from librarians in small communities, regional library system staff, and library advocates, all of whom recognized that consistent statewide education could best be provided by the state library. Only librarians working in communities of 25,000 or less who do not have MLS degrees are eligible to participate in the SLMTP. The program was modeled on two successful library skills education programs that had been operating for at least ten years: the UPLIFT program developed by the Utah Department of Library Services, and the Library 
Skills Institute developed by the Missouri State Library. The SLMTP consists of five two-day workshops spread out over a period of two and one-half years for a total of ten days of training. During the first cycle of the program from 1994-1996, TSLAC presented each workshop at six sites around the state. This number dropped to five sites in the 1997-1999 cycle and to four in the 2000-2002 cycle, reflecting a drop in the number of eligible participants as the training progressed. In 2003, the program was opened to all non-MLS public library staff, and the number of workshop sites was increased to five to accommodate the growing numbers of attendees.

Loosely based on the core coursework required for a master's degree in library science, and reflecting topics included in other state library agency programs, SLMTP training topics include 1) Administration and Planning; 2) Advanced Management Issues (policy development, and legal and personnel issues); 3) Collection Development; 4) Reference Services; and 5) Technology Planning and Automation. Directors and staff who attend all five sessions receive a certificate of achievement from the TSLAC. All participants earn continuing education credit that may count toward county library certification or other certification requirements.

While many states offer weeklong training institutes for non-MLS library staff, two aspects of the Texas training program are unique. First, the program includes two days of training on one topic rather than a weeklong institute format. Program developers assumed that participants would have enough time to assimilate and apply the skills and information learned before attending the next workshop four to six months later. Further, training takes place at several locations around the state, rather than one central location, 
to accommodate the state's geographic size and to encourage participation. Several overriding factors emerged early in the planning process resulting in this structure. First, most small community librarians are unable to leave their libraries for several days at a time to attend a more traditional weeklong training institute. Second, due to the geographic distances in Texas, there is no convenient central workshop location. In addition, some of the participants are not reimbursed for their travel expenses by their funding institutions, while a few are unwilling or unable to travel alone. These parameters dictated that the program be offered at several locations and for a shorter period. Given these constraints, the program still has to provide participants with enough information to understand the topics theoretically, and to apply new knowledge practically during the day-to-day operations of their libraries.

TSLAC continuing education staff assumes that the two-day training sessions successfully provide ten to twelve hours of instruction while allowing the participants to assimilate what they have learned. Participants have approximately six months between sessions in which to apply both theory and practice to their jobs. Completing the entire program — ten full days of training — is roughly equivalent to attending a two-week institute. Spreading the training topics out (two topics per calendar year) helps prevent participants from being overwhelmed with information so that they cannot assimilate or apply it in meaningful ways in their everyday work. An evaluation form comment from a 1996 SLMTP program participant supports this assumption: "The two days are adequate and not a problem to plan for. The information offered is comprehensive. The time span 
between sessions gives us time to implement new knowledge before learning another topic."

\section{THE NATURE OF THE STUDY}

\section{Statement of the Problem}

Since the inception of public librarianship in the mid-nineteenth century, librarians have worked collectively and individually to establish the professional status of the field. To become a professional librarian, one must earn a master's degree in library and science (MLS), preferably in a program of higher education accredited by the American Library Association. Yet, in small communities of 25,000 or less-which constitute seventy-nine percent (79\%) of America's public libraries—an MLS degree is not required of library directors. Most small community library directors are women who grew up and now reside in their communities. Non-MLS female library directors may have a high school, college, two-year business school, or master's degree in another field, and generally are expected by their governing entities to work part-time for lower pay in what their governing agency considers to be a clerk's position.

Although state library agencies in most U.S. states are responsible for the professional training and education of small community librarians through continuing education events and programs, participation by the librarians is voluntary and not mandated by law. Further, training programs are developed by individual state library agencies and do not conform to any national standards. Consequently, the professional development process for non-MLS library directors working in small communities is inconsistent, and little is known about the elements that influence this process. To date, 
only one non-published qualitative study (Bushing 1995) has attempted to define the formal and informal elements that contribute to the professional development of nonMLS female library directors; however, participants in that study worked in rural communities with populations of 2,500 or less. ${ }^{15}$ The current study provides data based on the results of the personal experiences of 14 Texas public library directors working in small communities, including some rural areas. These data may aid library consultants at the regional and state level to develop more effective continuing education events, and can provide useful information to other women considering a career as a small community library director.

\section{Research Statement}

The current study attempted to discover what elements in educational events, personal experiences, or job circumstances that a selected group of library directors without MLS degrees working in small Texas communities believes to be significant in contributing to their professional development. Based on prior experience as a continuing education consultant, I anticipated that external influences—-such as challenges related to authority and competence faced by female directors of small community public libraries as a result of their gender and their positions as library directors - would emerge during the interviews as significant factors in some participants' professional development. In addition to external influences, I assumed that internal influences such as the librarians' personal characteristics - learner motivation, perseverance, determination, and self-

\footnotetext{
${ }^{15}$ Rural libraries constitute forty-four percent (44\%) of the total number of public libraries in the United States according to the National Center for Education Statistics publication, Public Libraries in the United States 2003 available at http://nces.ed.gov/pubs2005/2005363.pdf (Accessed 23 Aug, 2005).
} 
confidence_-also would influence the study participants' professional development. I also anticipated that librarians in the study would demonstrate their agency and authority in a number of ways, such as choosing to participate in continuing education workshops and programs in an effort to achieve some level of professional certification.

\section{Significance of the Study}

The latest statistics available from the National Center for Education Statistics (2003) indicate that small community libraries constitute $78.6 \%$ of the total number of libraries in the United States. This number is down slightly from the 1993 statistics showing $79.4 \%$ of libraries serving populations of 25,000 or fewer. Still, warnings that the rural library "will become an unpopular, unused entity" and "before long, the library will be shut down" (Luchs 2001, 53-54) because the librarians who manage them do not have or are unable to earn MLS degrees have yet to be proven. Further, according to Texas Public Library Summary Statistics provided by the Texas State Library and Archives Commission, the number of small community libraries in Texas increased from 418 to 434 between 1999 and 2004. Both nationally and statewide, women comprise more than $90 \%$ of staff working in small community libraries, including managerial staff and directors.

Under the rules governing the establishment of Texas libraries in the Library Laws of Texas, communities with populations of less than 25,000 are not required to hire librarians who hold MLS or equivalent degrees. Although the master's degree in library science (MLS) has become the standard form of accreditation for librarians working in the United States, this degree seldom is required of librarians working in communities of 
fewer than 25,000 people by the governing entities. The professional status of non-MLS library directors often is questioned in the larger profession, and state and national library associations, state library agencies, and local governments perennially debate mandating an advanced degree for librarians working in small communities. Yet, many small community library directors who might consider earning an MLS degree face barriers such as geographic distance, time constraints, low prestige, and low pay. Bushing (1995) summed up the situation succinctly when she stated:

The question then, is not how to provide the MLS to rural librarians, but how to provide appropriate and effective educational and professional development experiences in order to meet the needs of rural librarians and to assure the best possible public library service given the demographic, economic, cultural and political realities of rural communities (Bushing 1995, 141-142).

Non-MLS library directors in small communities constitute twenty-five percent (25\%) of public library staff, but suffer from a lack of professional recognition within the field. Further, continuing education and professional development opportunities for small community librarians vary in scope and quality from state to state, making it difficult to determine a standard level of professionalization. Most small community librarians do not participate in the professional activities of the larger library field, such as national conferences and professional memberships, in part due to their inability to identify with the larger profession, and a collegial gap exists between these librarians and their MLS counterparts working in larger cities. The attitudes and perceptions of non-MLS rural librarians towards libraries and the library profession have been measured in both qualitative (Bushing 1995) and quantitative (Flatley 2000) studies; yet, no studies have explored factors affecting the professionalization of small community librarians in Texas. 
Findings from the current study may aid continuing education providers to develop programs that better meet the needs of small community librarians, and help to promote more collegiality between non-MLS librarians and their degreed counterparts.

\section{Indicators of Evidence}

The following indicators of evidence summarize the themes emerging from the interview process, and were used to support the research question and form the basis of the study inquiry:

1) Archetypal Management Roles for Library Directors - How women managing small community public libraries perceive themselves in relation to their work and their roles as librarians in ways that reflect archetype-like roles.

2) Evidence of Job Satisfaction - Factors that have contributed to the personal and professional satisfaction of women managing small community public libraries.

3) Positive Influences on Professional Development - The experiences women managing small community public libraries perceive as having contributed to their professional development.

4) Challenges Facing Small Community Librarians - The nature of the challenges facing women managing small community libraries, including gender-based discrimination related to the women's authority.

5) Guidelines for Success - Qualities and characteristics that women managing small community libraries believe are essential for successful librarianship. 


\section{Definitions}

The following definitions explain terms and phrases used throughout this study. Most of these definitions come from the Library Systems Act and Rules for Administering and the National Council for Educational Statistics (NCES) Web site.

1) Accreditation standards - criteria established by the Texas State Library and Archives Commission that a library must meet to be accredited and eligible for membership in the Texas library system.

2) County Librarian Certification - a certificate of qualification issued by the Texas State Library and Archives Commission to a librarian managing a public library designated as a county library. County libraries and municipal libraries that receive county funding are not eligible for membership in the Texas Library System unless the library director has earned her county library certification.

3) Governing body - the entity having the power to authorize a library to participate in, or withdraw from, a library system. Generally, the governing body of a Texas public library is a municipal or county government or, in the case of 501(c)(3) nonprofit organization, a library governing board.

4) Library director - a person hired by the governing body to direct the fiscal and operational management and personnel of a public library. This term is used interchangeably with the term librarian throughout this study.

5) Library system - two or more public libraries cooperating in a system approved by the Texas State Library and Archives Commission to improve library 
service and to make their resources accessible to all residents of the area the libraries serve.

6) Non-MLS librarian - a person employed as a librarian who does not have a master's degree in library science (MLS).

7) Professional development - The process of utilizing formal or informal training to enhance skills, knowledge, and ability, including study, travel, research, workshops or courses, sabbaticals, internships, apprenticeships, residencies or work with a mentor (Young 2004, 49). This term is used interchangeably throughout the study with the term, professionalization.

8) Public Library - a library established under state enabling laws or regulations to serve a community, district, or region, and provides at least the following: (a) an organized collection of printed or other library materials, or a combination thereof; (b) paid staff; (c) an established schedule in which services of the staff are available to the public; (d) the facilities necessary to support such a collection, staff, and schedule; and (e) is supported in whole or in part with public funds.

9) Regional Library System - a network of library systems established under section 441.122 of the Texas Public Library Systems Act.

10) Rural library - a public library serving a population of fewer than 2,500 people. ${ }^{16}$

11) Small community library - a public library serving a population of less than 25,000 that is a member of a library system interrelated to a major resource center.

\footnotetext{
${ }^{16}$ Source: the U.S. Census Bureau (www.census.gov) accessed multiple times between 14 August 2005 and January 5, 2006.
} 


\section{Research Question and Assumptions}

The following assumptions, about small community librarians, consulting services provided by the Texas library systems and Texas State Library, the library profession, and research design, serve as the basis for the research conducted in this study.

1) Many small community librarians will seek out opportunities to improve their knowledge, skills, and abilities related to librarianship through continuing education events, communication with peers, and hands-on assistance from regional library system other mentors.

2) The professional development of non-MLS librarians working in small communities will have a positive effect on the quality of library services available in these communities, the personal and professional development of the librarians, and the library profession as a whole.

3) Continuing education and consulting services provided by staff of the Texas regional library system offices and the Texas State Library and Archives Commission are essential to the professionalization of non-MLS librarians working in small communities.

4) The qualitative research design using a multiple case study derived from a randomly selected stratified purposeful sample assumes that the experiences of the librarians in the study highlight issues that can guide future study and sampling to permit logical generalization to the whole population of non-MLS librarians working in small communities in Texas. Although the individuals participating in this study may or may not represent "typical" small community librarians, it is assumed that their approaches to their jobs, challenges faced, and perceptions of accomplishment and satisfaction related 
to the job demonstrated by the librarians in this study might be representative of nonMLS librarians serving populations of 25,000 or less.

\section{Study Limitations}

1) Study population - The study population was limited to female public library directors without MLS degrees serving populations of 25,000 or less in Texas. Texas was the only state represented in the study, due to My experience and familiarity with the librarians, communities, and regional library system and Texas State Library staff and operations.

2) Ethnic distribution - The stratified random purposeful sampling technique used to select the study participants resulted in a group of 14 Caucasian and Hispanic librarians, but did not include librarians of other ethnicities (African-American, American Indian, Asian, or Pacific Islander). With the exception of African-American women, who constitute one percent (1\%) of the small community library directors in Texas, the ethnic distribution of the study sample is representative of the total population.

3) Population served - Service populations between 2,500 and 5,000 seem underrepresented in the study compared to the percentage of overall representation in Texas; however, thirty-six percent (36\%) of the libraries included in the study are embedded in communities in this population range.

4) Interview sample - The number of librarians interviewed (14) was representative of all Texas geographic regions. Though small, the sample provides a cross-section of population sizes, education levels, age groups, ethnicity, rural and urban areas, and years of experience. 


\section{Summary}

This chapter examines areas of librarianship that have a bearing on the professional development of non-MLS library directors working in small Texas communities, such as library certification, computerization, and continuing education programs developed by state and national organizations. The chapter concludes with statements defining the research problem, definitions of terms used throughout the study, and indicators of evidence that I used to determine if the research question has been answered. 


\section{Chapter 2: Literature Review}

The current research study concerns the professional development of non-MLS female library directors working in small Texas communities. This chapter presents a review of the literature addressing the role of professionalization in small community librarianship and women's involvement in librarianship in the United States. Theoretical issues related to the professional development of non-MLS librarians, the female ethic of caring, challenges faced by small community librarians, gender-based discrimination, and the role of mentoring in professional development are considered in terms of their relevance to non-MLS library small community directors in Texas.

I conducted a number of literature searches using the electronic databases listed below, available through resources provided by the University of Texas at Austin general libraries. Each of the following sections includes the keyword search terms used by I:

- American Sociological Review, through January 2006. Keywords:

Discrimination, Women, Gender, Archetype, Professional, Professional Development, Professionalization, Career, Caring Behavior.

- Gender Studies Database, through January 2006. Keywords: Mentoring, Discrimination, Librar*, Caring Behavior, Archetype, Professional, Professional Development, Professionalization, Career.

- Library and Information Science Abstracts, through January 2006. Keywords:

Mentoring, Women, Female, Public Libraries, Librar*, Discrimination, Archetype, Berrypicking, Continuing Education, Rural Libraries, Small Libraries, Challenges, 
Leadership, Professional, Professional Development, Professionalization, Caring Behavior, Career, Library Management.

- Library Literature and Information Science Full-Text, through January 2006.

Keywords: Mentoring, Women, Female, Public Libraries, Librar*, Discrimination, Archetype, Berrypicking, Continuing Education, Rural Libraries, Small Libraries, Challenges, Leadership, Professional, Professional Development, Professionalization, Caring Behavior, Career, Library Management.

- PsycARTICLES, through January 2006. Keywords: Archetypes,

Discrimination, Women, Female, Profession, Professional Development, Professionalization, Mentoring, Caring Behavior, Librar*, Career.

- PsycINFO, through January 2006. Keywords: Archetypes, Discrimination, Women, Female, Profession, Professional Development, Professionalization, Mentoring, Caring Behavior, Librar*, Career.

- Social Services Abstracts through January 2006. Keywords: Archetypes,

Discrimination, Women, Female, Profession, Professional Development, Professionalization, Mentoring, Caring Behavior, Librar*, Career.

- Sociological Abstracts through January 2006. Keywords: Archetypes,

Discrimination, Women, Female, Profession, Professional Development, Professionalization, Mentoring, Caring Behavior, Librar*, Career.

This review is intended to be exploratory rather than exhaustive. Search results were limited to English language publications including books, journal articles, peer-reviewed journal articles, Web publications, and conference papers. 


\section{The Professionalization of Non-MLS Librarians}

Professionalization - the process of becoming a professional - is by nature a "continuing dynamic process" of becoming during which an individual is transformed, as opposed to simply learning tasks and procedures (Bushing 1995, 12). According to this definition, true professionals are more than mere practitioners of an occupation because they act in accordance with a set of ethical standards in addition to any technical guidelines. In her 1995 dissertation, Bushing points out the current literature concerns "the extent to which particular individuals are or are not professionals" rather than a debate about whether specific occupations qualify as professions (Bushing 1995, 12). In her study, Bushing interviewed 26 librarians working in rural communities (serving populations under 2,500) in six states to discover significant factors contributing to the development of the participants' professional identity and their self-confidence as librarians. She investigated four areas influencing professional identity including 1) events in the participants' careers; 2) activities or elements in educational events, such as continuing education workshops; 3 ) necessary attributes of effective librarians identified by the participants; and 4) characteristics of being a librarian used by participants to define their roles. Bushing identified several themes and sub-themes contributing to small community librarians' perceptions of themselves as professionals, which include:

- help from others, such as mentors, and networking with peers;

- relevant continuing education topics;

- experienced educators with good communication skills and knowledge of circumstances in a small community library;

- support from local government and community; and 
- organizational skills, self-confidence and assertiveness.

Bushing used qualitative case study methods to determine the attitudes and perceptions of the librarians in her study, all of whom lacked the MLS degree that would designate them as professional librarians in the eyes of the larger profession. Conducting on-site interviews allowed her to probe deeply into the motivations, perceptions, and experiences of the study participants in a more in-depth manner than survey instruments would allow. Bushing's research findings centered on the concept of what it means to be a librarian "both as defined by the participants and experienced by them" (16). The study also explored personal characteristics and attributes contributing to the success and effectiveness of small community librarians.

\section{WOMEN IN LIBRARIANSHIP}

The idea of a public lending library is a uniquely American phenomenon originating with Benjamin Franklin in the late eighteenth century. By the mid-1800s, the concept of a free public library was well established in the U.S. as an institution that common people could use to educate themselves, thereby improving their social and economic standing. Enoch Pratt, first director of the Baltimore Public Library expressed

this idea succinctly, "The library is... a place for all, where races, ages and socioeconomic classes mingle and people can educate themselves — and without cost”. Soon after the concept of a free public library was established in the mid-nineteenth century, Melvil Dewey $(1886,1978)$ proclaimed librarianship to be uniquely suited to the talents and abilities of "college-bred" women, whom he believed were more detail-oriented and patient than their male colleagues: 
There is almost nothing in the higher branches which she cannot do quite as well as a man of equal training and experience; and in much of library work women's quick mind and deft fingers do many things with a neatness and dispatch seldom equaled by her brothers (Dewey 1886, $1979 ; 10)$.

In the early twentieth century the women's suffrage movement generated lively discussions among library professionals about the role of women in librarianship whose tone ranged from patronizing (Chennell 1902, 1976) to supportive and inspirational (Fairchild, 1904, 1976, Gilbert, 1915, 1976). While academic librarianship in particular was considered too rigorous for women, many in the field recognized that women would work more cheaply than men. Though this fact was not lost on perennially impecunious public libraries, women were relegated to entry-level and clerical jobs and to the newly emerging specialization of children's librarianship in the early days of the profession because they were not expected to keep working after they married (Chennell 43; Dewey $1886,1979 ; 11)$.

By the early 1970s, the influence of the women's movement was evident in the literature on library management (Friedman 1970, Garrison 1972, Heim 1982, Lowenthal 1971, Ward 1966), and continues to be a subtle force in present day literature (Baum 1992). Early researchers debated the future of the library field through the lens of feminist thought, predicting great strides forward for women in terms of pay, authority, and positions of management. By the 1980s, however, researchers were lamenting the tendency of many women to adopt masculine modes of dress and behavior in order to achieve positions of authority and management (Heim 1982, 4-5). Trends in the current library literature include management challenges focusing on gender and ethnic diversity 
in the workplace, the graying of the library profession, and the role of mentoring for career professionals, signaling a shift away from the issue of women as librarians toward change management and the inclusion of many types of people in the library profession.

\section{Gender-Based Discrimination}

The issue of gender inequality in librarianship, specifically in library administration positions, is a frequent topic in the literature (Bergman, 2005, Brand, 1983, Brugh and Beede 1976, Coats, Goodwin, and Bangs 2000, Cooper 1984, Fisher 1997, Hoadley 1999, Kaufman 1993, Kennedy and Okrent 1993, McDermott 1994, Poland, Curran and Owens 1996, Rigs and Sykes 1993, Rooks 1994, Sable 1969, Schiller 1976, Somerville 1995, Voelck 2003, Yapp 2000). A little over a decade ago Kaufman (1993) pointed out that "ours is still a highly feminized profession in which men continue to hold most of the leadership positions" (Kaufman 1993, 109). Melvil Dewey, an outspoken advocate of female librarians, considered women to be handicapped by their poorer health, lack of business knowledge, tendency to leave work after marriage, and physical disadvantages compared to men who can "lift a heavy case, or climb a ladder to the roof or in case of accident or disorder can act as fireman or do police duty" (Dewey, 1886, 1979; 10-11). Dewey cites each of these qualities as factors contributing to women's lower pay scales compared to those of men. A study conducted in the late 1960 s concluded that "it was impossible to determine whether the low salaries were responsible for the presence of all the women" in librarianship, "or whether women were responsible for the low salaries" 
(Hildenbrand 2000,54). Yet, the circumstance of unequal pay based on gender persists in the present day in small communities, evidenced by the study findings on p. 113.

Traditionally, librarianship has been considered a feminine, and therefore less rigorous, profession almost since its inception. In the nineteenth century, men held most of the jobs and society still frowned on the idea of women working outside the home. In most cases, women did not own property, and their actions were strictly governed by first their fathers and later their husbands. The legal system of the time essentially defined women as chattel, which allowed men not only to physically abuse their wives, but also to regulate their lives with impunity (Pessen 1978, 49). Librarianship offered women a way to break into the professional and business world dominated by men. At the same time, librarianship provided an opportunity for women to use acculturated skills such as establishing social contacts and caring for others in their work. More will be said about caring in the section following.

\section{LIBRARIANS AND THE ETHIC OF CARE}

Librarianship is a caring profession that relies on human contact and interaction. The role of caring in librarianship is even more evident in small communities where library patrons are also neighbors, friends, and even relatives. The prevalence of female librarians in small communities may arise as the consequence of low pay and the perception of librarianship as unskilled labor by local governments, but this prevalence 
also may be the result of people's perceptions that women librarians are more caring than men are, and therefore better able to fill a public service role.

Women's moral and ethical development has been described as being based in caring for others (Gilligan 1979, 1982 and Nodding 1984). The state of caring has been delineated as a relationship between the "one-caring" and the "one-cared for," and it has been suggested that women "define themselves in terms of caring and work their way through moral problems from the position of one-caring" (Nodding 1984, 4, 8). Caring behavior involves putting others' needs first and acting to enhance the welfare of others before oneself:

When we care, we consider the other's point of view, his objective needs, and what he expects of us. Our attention, our mental engrossment is on the cared-for, not on ourselves. Our reasons for acting, then, have to do both with the other's wants and desires and with the objective elements of his problematic situation... To act as one-caring, then, is to act with special regard for the particular person in a concrete situation. We act not to achieve for ourselves a commendation but to protect or enhance the welfare of the cared-for (Nodding 1984, 24).

Although caring behavior is not the sole dominion of women, women generally

are acculturated to care for others. Further, "independence, achievement, and dominance are more important components of men's self-concepts than women's and...intimate relations are a more important component of women's self-concepts than men's" (Woods et al. 1997, 524). Gilligan (1979) goes further to explain women's caring behavior:

...women not only define themselves in a context of human relationship but also judge themselves in terms of their ability to care. Woman's place in man's life cycle has been that of the nurturer, caretaker, and helpmate, the weaver of those networks of relationships on which she in turn relies (Gilligan 1979, 440). 
The idea of caring for others instead of oneself in a library setting also was promoted in an 1899 article encouraging women to obtain business and management skills in order to be effective librarians: “...the best chance of happiness lies in forgetting our own individuality altogether and living for others" (Ahern 1899, 1979; 24).

According to Nodding, caring behavior is based not on a set of rigid principles, but rather on an ability to adapt one's behavior to a particular situation based on the needs of the one-cared for. Nodding proposes that flexibility in judgment and action by the onecaring centers on "human affections, weaknesses, and anxieties" eschewing rule-bound moral action prescribed by laws and edicts (Nodding 1984, 25). The one-caring is internally motivated to serve those being cared for; that is, her motivating energy is put "at the service of the other" (Nodding 1984, 33). Further, an "attitude of warm acceptance and trust is important in all caring relationships" for "when this attitude is missed, the one who is the object of caretaking feels like an object. He is being treated, handled by formula" (Noddings 1984, 65).

\section{ChaLlenges FaCED by SMALl COMmunity LibRaRians}

Since Texas librarians working in small community libraries usually are not required to have master's degrees in library and information science, many of these library directors come to their jobs with no formal knowledge of library procedures and principles or management techniques. Library directors and staff working in small communities face many challenges, including lack of knowledge-i.e., experience or education - about how to manage or operate a library, a sense of isolation from colleagues, and the perception of low prestige from both the public and funding entities. 
Additionally, female directors often find that male colleagues in other departments who participate in a "good ol' boy" network often receive precedence from the governing entity for limited local tax revenues (Vavrek 1984). This phenomenon remains prevalent more than twenty years after Vavrek gathered his data, evidenced by findings in the present study.

Women working in small community public libraries, particularly those in positions of authority, face challenges related to their gender and to their lack of professional knowledge and competency. However, the environment and circumstances in small communities engender a different set of challenges that library staff of both genders face daily. Vavrek (1984) points out that the biggest challenges facing library staff in small communities are:

1) attempting to provide information services in a community where the public library may be the only cultural institution, and also — perhaps — the only community meeting space,

2) residing in a community that lacks "meaningful" local bookstores,

3) having no widely circulating (state or national) daily newspaper available other than USA Today,

4) having only a single movie theatre in town that eventually receives first-run films, but the limited screening space prevents the community from enjoying the variety of films available to their urban and suburban counterparts, and

5) the likelihood that there are a number of individuals in a small community who have a strong sense of community involvement and more people willing to volunteer 
their time for civic activities in an environment where traditional families and religious participation are still vitally important (Vavrek 1982, 271).

Each of the restrictions listed above limits the quality and type of information available to people living in small communities and, Vavrek contends, contributes to an insular atmosphere reflecting narrow and provincial viewpoints.

In a 1984 study, Vavrek attempted to shed further light on why small libraries are all but ignored by the mainstream profession; i.e., urban and large public libraries whose staff regularly participate in state and national library association programs and activities. After pointing out the positive trends in support of small and rural libraries during the early 1980s, Vavrek (1984) lists the factors contributing to what he views as the obscurity of the rural library from the larger library profession. First on his list is the small library staffs' lack of participation in state and national library organizations - such as the Texas Library Association and the American Library Association — and related national conferences and meetings. Further, staff of these libraries rarely contributes to the library literature. Even the Center's publication, Rural Libraries, which was created as a forum for rural library staff, more often than not contains contributions from state agency staff rather than librarians in the field. Vavrek equates this deficit in participation and vocalization with a lack of political leverage and power to institute change (Vavrek 1997, 37). This professional silence and absence of voice may also constitute evidence that the women who work in these libraries perceive themselves as having little or no agency in either their local arena or the larger library community. Vavrek (1984) also criticizes what he perceives as a "haughtiness" shown toward staff of small libraries by other 
librarians. Finally, he concludes that the geographic isolation inherent in small and rural public library settings contributes to the sense of remoteness and distance from the larger library profession (Vavrek 1997, 38). Often, librarians working in geographically isolated communities will seek advice and instruction from other individuals.

\section{The Role of Mentoring in Professional Development}

Mentoring of librarians and information professionals has become a frequent topic in American, British, and Australian library literature since 1980, particularly in the last few years (Appleton 2004, Bell 2003, Bonnette 2004, Burrington 1993, Chatman 1992, Farmer and Campbell 1998, Field 2001, Fisher 1994, Fisher et al. 1997, Golian 1996, Hunt and Michael 1984, Law 2001, Nankivell et al. 1997, Regan 2003, Studwell 2002). Mentors "can have a tremendous impact on personal development," and have the ability to "inspire enthusiasm for the work and the library, and encourage those they mentor to develop the skills they need for making their full contribution to developments in libraries and librarianship" (Burrington 1993, 226).

Much of the literature relates mentoring to the professional development of MLS librarians who have plateaued in their current jobs and wish to advance to higher positions in their present organization or take higher-level management jobs in other organizations (Bonnette 2004, Burrington 1993, Chatman 1992, Law, 2001, Nankivell et al. 1997). No literature exists on the role of mentoring in the professional development of small community or non-MLS librarians. Early library literature on mentoring in librarianship (Hunt and Michael 1984) draws from the business management field where the male-to-male, patriarchal form of mentoring remains a common way to groom bright 
young adults for management positions. Mentoring roles for men are variously described as sponsors, godfathers, and parent-like figures, and the mentoring association is described as a father-son relationship (Hunt and Michael 1984, 80). Traditional mentoring models cast the mentor as an older person in a position of authority who:

1) can introduce their younger protégé into a professional network, a key element in the younger person's professional development;

2) is secure enough in a position of power that they are not threatened by the younger person's potential to exceed or surpass them; and

3) is a powerful, knowledgeable, and influential individual interested in gaining more status in the eyes of their supervisors and peers by taking on a number of protégés (Chatman 1992, Hunt and Michael 1984).

In contrast to older literature more closely related to business management practices, more recent literature identifies qualities such as personal interaction, friendship, helping behavior, mutual respect, and a willingness to share information and skills as being essential for successful mentoring relationships (Field 2001, Law 2001, Nankivell et al. 1997, Studwell 2002). The less formal term "mentee" now is preferred over the more formal term "protégé," indicating a shift from an apprentice style association to a relationship based on guiding and coaching between people who are closer in age and social status (Field 2001, 270). Law prefers the term "partners" to describe the reciprocal learning relationship involved in mentoring (Law 2001, 147), and further deconstructs the mentoring process by distinguishing between training, coaching, and mentoring: 
I determined that I would use training for situations that were targeting at the development of specific skills, coaching for activities that were aimed at building on and improving existing skills, and mentoring for activities that were focused on broadening a person's perspective (Law 2001, 146).

Twenty years ago, female-to-female mentoring relationships were undocumented in the library literature. While they are not specifically discussed in the present day, much of the current library literature mentions programs in which both men and women participate in mentoring relationships. Other national and international qualitative studies have linked mentoring to the professional development of women in other fields.

Gustafson (2005) explored the effects of mentoring on nursing practice, finding that:

Novice nurses evaluated their mentors as confirming, which is understood as a key factor for novice nurses' positively reinforced self-relation (perception of themselves) and self-knowledge linked to improved competencies in nursing practice such as more secure and motivated to nurse (Gustafson 2005, 312).

Further, mentoring was instrumental in helping these nurses to develop their abilities of verbalization, reflection, and evaluation in nursing and patient situations, encouraging nurses to perceive patients as individuals and to view patient care from a holistic perspective. Gustafson concluded that "mentorship enabled novice nurses to nurse in a more reflective and holistic way" and helped these nurses to develop self-relation, which she considers "a crucial ingredient for maintaining quality standards in nursing in the future" (Gustafson 2005, 320-321).

Chovwen (2005) investigated the influence of mentoring on the professional growth of Nigerian women working in corporate and other work environments. His findings confirmed that: 
Although protégé/mentoring relationship was not formally constituted in most organizations it was found to be a significant predictor of growth and participants with mentors perceived they experienced higher growth than those without mentors (Chovwen 2005, 131).

\section{SUMMARY OF RELEVANT LITERATURE}

The library literature reviewed for this research study elaborates on the roles women have played in librarianship throughout its history, and documents the ongoing struggles for equality with male librarians related to compensation and the level of regard they receive from the public and governing officials. Business and management skills, attention to detail, research skills, and public service skills remain high on the list of desirable qualities identified by researchers and practitioners. Other studies, particularly those conducted by the Center for Rural Librarianship, have helped to establish the character of small community life and the challenges facing libraries embedded in small communities through quantitative means. Yet, studies conducted on rural libraries focus more on the nature of the communities and services provided by the libraries rather than on the people who manage them.

Many articles discuss the process of library professionalization and its importance for non-MLS librarians, but only one research study deals specifically with the professional development of non-MLS librarians managing libraries in rural communities, and none have explored the topic in relation to small community libraries in Texas. Fewer than a dozen qualitative studies rely on interview data to inform the field about the perceptions and beliefs of librarians working in any venue exist, and only two of these studies deal with the 
concerns of small community and rural librarians in particular. Library literature and literature from the fields of sociology and psychology provide information about the importance of mentoring in professional situations, particularly for women. Yet, no studies discuss mentoring as a tool for the professional development of small community librarians.

The literature of psychology and education reveals how women's moral development stems from an ethic of caring behavior. Librarianship often is described as a "helping profession" or a "service profession," but there is little in the library literature concerning the gender-specific qualities of caring embodied by women in the field. The current study shows how the women who manage small community libraries draw on an ethic of caring to provide personal service to the people in their communities. This ethic of caring is the source of most of the personal and professional satisfaction expressed by the librarians in the current study.

Although they account for the leadership of nearly eighty percent $(80 \%)$ of the libraries in the U.S., non-MLS librarians managing small community libraries remain an almost invisible population in the literature and in the larger profession. Small community librarians often become active in their state library associations, but rarely participate in national meetings and events. Many professional librarians - those who have earned an MLS degree - tend to view their non-MLS counterparts as paraprofessional or clerical staff rather than equals in the field of library management. Research conducted with this 
population tends to rely on survey data, and mainly concerns library operations, and services rather than the beliefs and perceptions of the librarians themselves.

The current study uses qualitative case study methods to identify important elements influencing the professional development of non-MLS librarians working in small communities, but goes beyond the existing body of library literature to incorporate theories from the fields of management, psychology, education, and sociology. This study focuses on the perceptions and beliefs of people; specifically, it elicits input on the issues and concerns facing women library directors, many issues of which received attention in the earliest library literature. For example, the current study elaborates on the issues of unequal pay and animosity toward female librarians because of their gender. In addition, a historical review of discussions about the qualities women should develop in order to be effective librarians shows that little has changed from the early days of the profession. Additionally, the current study draws on the fields of organizational management and psychology to discover the archetypes embodied in the management styles of small community librarians, a topic heretofore not applied to librarianship in general, to non-MLS librarians working in small communities, or to women in librarianship. The resulting study offers new insights into the motivations and perceptions of small community librarians. 


\section{Chapter 3: Design of the Study and Description of Participants}

The central research question guiding the current study was to discover elements in educational events, personal experiences, or job circumstances that a selected group of library directors without MLS degrees working in small Texas communities believed to be significant in contributing to their professional development. The study identifies concepts associated with the process of self-efficacy and attitudes related to identity and job satisfaction for small community librarians. A qualitative case study using multiple cases (14) was designed to permit logical generalization and maximum application of information gathered to other cases (Miles \& Huberman 1994, 28). I used a combination of categorical and holistic analysis (Rossman \& Rallis 2003, 273-274) to determine meaningful categories and define the salient themes emerging from the interviews.

\section{STUDY DESIGN}

The study was conducted over a five-month period between April and September, 2005. A stratified random sampling technique (Miles \& Huberman 1994, 32) was used to identify two library directors from each of the ten regional library systems constituting the Texas Library System. Data indicating libraries with service populations of less than 25,000 and managed by directors without MLS degrees were obtained from current (2003) statistics provided by the Texas State Library and Archives Commission. Criteria used to select these individuals were:

1) no formal education in librarianship (no MLS or equivalent degree),

2) currently employed as the director of a public library with a service population of 25,000 or less, 
3) employed in a library that is currently a member in good standing in the Texas Library System, and

4) Willing to participate in a single interview of 30 to 45 minutes and to provide follow-up information and evaluation as requested.

\section{Sample Selection}

The state library data were organized by library system, resulting in ten Excel spreadsheets. Using the Excel random number function, each library was assigned a random number between zero and one in a separate column and each spreadsheet was sorted according to the random number column. I contacted the two librarians listed first and second in each spreadsheet after the sorting process, either by email or through the U.S. mail with an invitation letter, or by telephone with a verbal invitation followed with a written communication. In a few instances, library directors who had been randomly selected using this procedure declined to be interviewed, verbally expressed resistance to an on-site visit ("I'm just too busy," "We're building a new library and I don't know when I'd have time"), or did not respond to emails or telephone calls after agreeing to participate in the study during the initial contact. These directors were not used as participants; instead, the corresponding spreadsheet was resorted and the librarian appearing first in the resulting list was invited to participate in the study.

Using this method, I developed a pool of participants providing representation of the following geographic regions: west Texas, Panhandle, north Texas, central Texas, east Texas, and south Texas (see Figure 1 and Appendix B). These geographic regions are described in detail later in this chapter. Each of these regions includes one or more of 
the ten regional library systems (Appendix A). In instances where the randomly selected libraries in each regional system were located close to each other, the corresponding spreadsheets were resorted to elicit broader geographic coverage in the sample. Although each regional library system is represented in the sample, geographic distribution dictated that some systems had only one representative while others had two. Table 1 shows the geographic distribution, system, type of jurisdiction, and service populations of libraries in the sample, and the ages and education levels of the directors (see also Appendix I). Saturation was achieved after fourteen interviews with non-MLS library directors.

Table 1: Type of Jurisdiction, System, Geographic Distribution, Service Population, Age, and Education Levels of Libraries in the Sample by Population.

\begin{tabular}{|c|l|l|l|r|r|l|}
\hline $\begin{array}{c}\text { Interview } \\
\text { Participant }\end{array}$ & $\begin{array}{c}\text { Type of } \\
\text { Jurisdiction }\end{array}$ & $\begin{array}{c}\text { Regional } \\
\text { System }\end{array}$ & $\begin{array}{c}\text { Geographic } \\
\text { Region }\end{array}$ & $\begin{array}{c}\text { Service } \\
\text { Population }\end{array}$ & $\begin{array}{c}\text { Librarian } \\
\text { Age }\end{array}$ & $\begin{array}{c}\text { Librarian } \\
\text { Education } \\
\text { Level }\end{array}$ \\
\hline P04 & Municipal & STLS & South & 969 & $70+$ & Bachelor \\
\hline P08 & County & TTPLS & West & 1,727 & $60+$ & High School \\
\hline P06 & County & TTPLS & West & 2,211 & $30+$ & High School \\
\hline P11 & Non-profit & AALS & South & 5,067 & $40+$ & Bachelor \\
\hline P07 & County & WTLS & West & 6,892 & $40+$ & Bus. School \\
\hline P02 & Municipal & CTLS & Central & 7,207 & $60+$ & Bachelor \\
\hline P05 & Municipal & HALS & East & 7,830 & $50+$ & Masters \\
\hline P10 & County & TPLS & Panhandle & 8,075 & $50+$ & High School \\
\hline P12 & Municipal & NTRLS & North & 8,174 & $50+$ & Bachelor \\
\hline P03 & County & BCLS & Central & 8,766 & $70+$ & Bachelor \\
\hline P13 & Municipal & NETLS & North & 11,239 & $40+$ & Bachelor \\
\hline P14 & Multi & STLS & South & 12,811 & $50+$ & Bachelor \\
\hline P01 & Municipal & CTLS & Central & 16,196 & $50+$ & Some College \\
\hline P09 & County & WTLS & Panhandle & 22,838 & $50+$ & Some College \\
\hline
\end{tabular}


Figure 1: Geographic Distribution of the Study Participants.

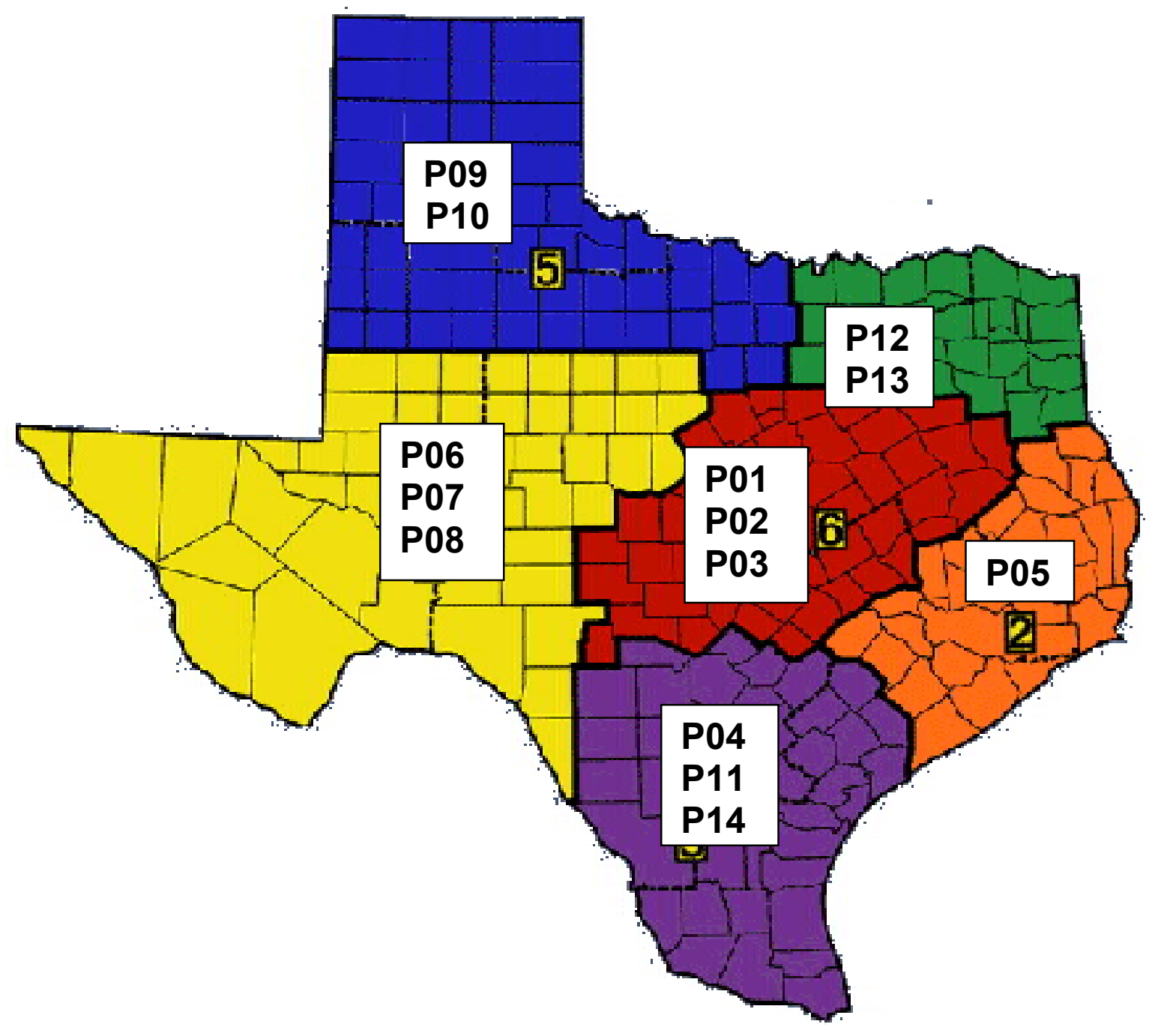

The Interview Process

After the initial contact to verify interest in the study, I contacted each library director again by email or telephone to arrange a 30- to 45-minute interview. All interviews were conducted on-site at the participants' respective libraries either before the library opened, on a day the library was closed, or during the librarian's lunch period. All of the library directors randomly selected for the study were acquainted with I- some 
for as little as one or two years and others for ten years or more- through her work as a continuing education consultant with the Texas State Library and Archives Commission, or as an independent trainer and library consultant. This established acquaintance allowed for immediate rapport with the study participants, and helped elicit their friendly, honest, and in some cases enthusiastic participation during the interviews. I attempted to establish a comfort level with the interview participants by dressing casually, allowing the librarians to be interviewed on their "home turf" and to control the setting of the interview, and by discussing personal and trivial topics outside of the formal interview. Yet in some instances, my status as an authority figure might have been perceived as a social threat to the interview participants, causing them to provide what they supposed to be the "right answers" rather than a frank response to the questions. Many of the participants seemed flattered to be taking part in the study. A few worried that they would not make good interview candidates, and one protested with typical west Texas modesty that she "wasn't interesting at all." The richness of the resulting narrative proved her fears wholly ungrounded.

Interview sites ranged in distance from 40 miles to over 450 miles from my home base. Two or three interviews were conducted over the course of two days in each region of the state to reduce the travel time and expense needed to reach distant areas. All of the interviews were preceded by a tour of the library and, when available, an introduction to library staff, patrons, and in one instance, the resident library cat. Most of the on-site visits also included an informal lunch or dinner with the library director, her friends or family. At least one visit included a tour of the community and surrounding area, and 
another a visit to the librarian's newly inherited home accompanied by an excited account of her future renovation plans. All of the participants extended an open invitation for me to revisit them and their libraries, and most expressed a sincere desire to keep in touch via telephone or email in order to exchange personal and social news after the interviews.

Before each interview began, I explained the confidentiality and audio recording provisions in the informed consent form (Appendix C) required of human research subjects by the university. Each participant signed the consent form and received a copy of it for her records. During the interviews, the participants were asked to respond to six open-ended questions that explored their job history, their experiences in the community related to gender, the value of continuing education programs and consulting assistance offered by state library and regional System staff, their satisfaction with their job, and their perceptions of what it means to be a librarian. One additional question prompted participants to add other information they considered important to the study. Questions were constructed to be open-ended to encourage the participants to tell me what they considered important without restricting them to a narrow range of answers, and to provide them with an opportunity to revisit and elaborate on previously stated issues later in the interview. Interview questions elicited data about the study participants' experiences related to their work as directors of small community libraries in several areas: job history, continuing education, job satisfaction, challenges and frustrations, and essential characteristics. Interview questions were developed in part from my prior extensive experience working with small community librarians in continuing education and consulting contexts. The interview questions were: 
- Tell me how you became a librarian, and how you became the director here.

- Describe what it is like to be a woman in a position of authority in your community.

- How has your job has given you a sense of personal or professional satisfaction or accomplishment?

- What has contributed most to your professional development?

- What advice would you give to someone coming into a small community library as a director?

- What does being a librarian mean to you?

- Is there anything else I should have asked, or anything else you would like to share?

Probe and follow-up questions were interjected when study participants gave short answers or seemed to have difficulty articulating what they intended to say. Both the responses to these diverse questions and the form of the responses when later analyzed, formed the basis of the data set used to develop a list of archetypes that embodied the job approaches most often articulated by small community librarians. The response forms I considered included 1) the choice of words and phrases used, 2) the rate of speed with which they were delivered, 3) and the participants' voice inflections.

The interviews were recorded to ensure exactness during the analysis phase of the study, using either a digital recorder or analog audiotape machine. An independent transcriber later transcribed all 14 recordings, and I reviewed and edited these transcriptions for accuracy and to add notes, thoughts, and impressions. I also took field notes during the interviews, used later to summarize her impressions and insights about 
the participants, and developed contact summary sheets summarizing the dominant themes and concepts articulated during each interview.

An interview protocol (Appendix D) provided a structured and consistent approach to each interview, while allowing me to interject probing questions where necessary to elicit responses that were more detailed, or to clarify or summarize points made by the participants. The interview questions were deliberately ordered from the general to the more specific to allow participants first to relate a variety of experiences they felt were important to mention, then to focus their answers on particular aspects of their work, helping to distill their perceptions into cardinal points. This interview technique facilitated the transition from what were primarily storytelling narratives into more succinct expressions of beliefs and opinions.

\section{Data Compilation}

As each interview was completed, I transcribed my field notes and created a contact summary sheet within one week while my impressions were still vivid. An independent transcriber transferred the recorded interviews into print format in batches of three or four, after which I reviewed and edited the transcriptions. Themes and concepts began to emerge immediately as I reviewed each interview, noting similarities and differences in responses and response forms. After repeated reviews of both audio and print interview formats, I used Microsoft Word to create codes to identify each theme based on the content of the research findings. I then entered quotations from each interview under their corresponding codes. Lists of dominant themes and job approaches 
(archetypes) were developed and compiled for each interview, and these data were later distilled into two distinct documents: Interview Themes and Librarian Archetypes.

\section{Theme Verification}

I used a model developed by Bushing $(1995,61)$ to generate a Theme Verfication Form consisting of five major themes and three related components: 1) personal characteristics of successful small community librarians, 2) challenges and frustrations facing small community librarians, and 3) elements relating to job satisfaction. Both documents - the Interview Themes Verification Form (Appendix E) and the Librarian Archetypes Verification Form (Appendix F) — were sent to each librarian either in electronic form delivered via email or in print form delivered via U.S. mail, as were the transcripts of their interviews. Study participants were instructed to indicate whether they agreed or disagreed with the five themes and related components based upon their individual knowledge and experiences, and to provide, on a separate sheet, additional themes or salient points for each area of interest explored in the interviews - job history, continuing education, job satisfaction, challenges and frustrations, and essential characteristics.

Study participants were further instructed to add additional information in writing to the interview transcripts, and to indicate their first and second choices of librarian archetypes that best expressed their approaches to their jobs. Participants also were encouraged to develop alternative archetypes and indicate these in writing on the Librarian Archetypes form. Allowing the study participants to review and respond to the interviews, themes, and archetypes provided both theme verification and a process of 
triangulation for the study while giving the librarians an opportunity to verify, comment on, and modify My initial analysis. I modified the themes based on participants' input.

More than half (sixty-four percent) of the study participants responded with feedback. Only one participant disagreed with the theme, "Becoming a small community librarian/library director often happens by accident or through serendipitous circumstances, but it eventually becomes a vocation.” Another librarian disagreed with the statement, "Continuing education is valuable when it is practical and applicable to the small library situation." This librarian included margin notes on the theme verification form and called me to explain that she felt any continuing education opportunity could be beneficial to small community librarians, whether or not it specifically addressed the needs of small libraries. Two respondents disagreed with the statement, "Working at the library can become a kind of 'spiritual salvation,' giving direction and purpose to one's life after the loss of a loved one." I later realized that responses to the Theme Verification Form did not clearly indicate whether the librarians agreed that a theme might be true in general, or if their agreement reflected only the study participant's personal experiences. Participants responses to the Theme Verification Form appear at the end of this document in Appendix F. Participant responses to the Archetype Verification Form with my opinion of each of their roles appear in Appendix H.

\section{Description OF STUdy Participants}

The librarians included in the study are intimately bound to communities they serve and the geographic regions they live in. In the interviews, each librarian identified herself strongly with her library's regional system and most spoke highly of the 
mentoring they received from system staff. Many of the participants also emphasized the importance of getting to know and becoming part of the communities they served. Therefore, while the study participants are described as individuals, descriptions of their communities and geographic regions also are included in this section.

\section{The Librarians}

The library directors interviewed for this study are as diverse as the regions they represent. They range in age from their late 30 s to nearly 80 , and their education levels include high school, business school, some college, and in one case, a master's degree in theatre. Two of the fourteen study participants are Hispanic, reflecting the statewide percentage of Hispanic small community library directors in Texas (15\%) identified in a pilot study I conducted in 2004 (Table 2).

Table 2: Ethnic Distribution of Librarians Attending the Small Library Management Training Program in 2005.

\begin{tabular}{|c|c|c|c|c|}
\hline $\begin{array}{c}\text { African- } \\
\text { American }\end{array}$ & Hispanic & Caucasian & $\begin{array}{c}\text { Asian or Pacific } \\
\text { Islander }\end{array}$ & Other \\
\hline $1 \%$ & $15 \%$ & $84 \%$ & N/A & N/A \\
\hline
\end{tabular}

The remaining participants are Caucasian. All but two librarians were born or raised in the communities they now work in, and all but one had been a librarian for more than five years. Some participants have husbands and young children; others are widowed, divorced, or single. The personalities expressed in the interviews were gregarious, outgoing, friendly, warm, reticent, detail-oriented, scattered, unassuming, proud, engaging, abrasive, funny, serious, energetic, and apathetic, making it impossible to generate a stereotype of a "typical" small community librarian. Nevertheless, with one 
exception all of the librarians shared three outstanding qualities — sensitivity to the needs

of a small community:

Well, small communities are completely different than, like, a large town, so I would say that you definitely have to make it personable. You can't just be, just, "Okay, here's your book. Here, check this out." And, you know, you do have to make it a personal place to come (P01, L609-702).

Dedication to their job:

You gotta put a lot into it. You've got to put a lot, a lot of thought, a lot of feeling, and a lot of caring into it. You can't just do it without that. One of the ladies, uh, said something about 2 o'clock in the morning, she said, "you were down at the library at 2 o'clock in the morning?" I said, "Yes." Any hour that I didn't, that was over 40 hours, not really paid hours, I don't begrudge that because it's given me the rewards (P01, L804-805, 807-810).

Well, being crazy helps a whole lot $<$ Laughs $>$ to start out with 'cause you don't mind working yourself to death, and you like what you're doin' (P03, L721-722).

And an enormous feeling of gratification from helping others:

And so you get such a sense of satisfaction, you know, such a gratification from people. It is a reward you know, every day because if nothing else you've helped someone learn to read. You've helped someone get that GED. You've helped someone...just be able to talk to people (P001, L284-287).

It's a chance to make a difference...Y You never know who you're gonna touch or where they're gonna go (P03, L924).

Everybody is an enrichment to me-everybody. No matter if they're even surly and angry, you know, they're offering me something. I really, truly, feel that way and, actually, people that if they're, you know, whatever it is they're, they're bringing me an enrichment (P13, L797-800).

Originally, seventeen librarians were interviewed for this study; however, three of them had MLS degrees, a fact I was unaware of ct until the interviews were well underway. All three of the MLS librarians were participants in the Small Library 
Management Training Program (SLMTP). Since only non-MLS library directors are

eligible for the program, I presumed from their participation in the SLMTP that they did not hold MLS degrees. Each of the three small community library directors with MLS degrees expressed a willingness to work for less pay in exchange for the opportunity to "make a difference in" and "give back to" people living in a small community. Each of these librarians had held her job for more than six years and attested that she gained immense personal satisfaction from her work. Additionally, two of these librarians had left higher paying — but less satisfying — professional jobs in large, urban libraries for the opportunity to manage libraries in smaller communities. Some data from one of these interviews is included in the study findings as anecdotal evidence. The rest of the data is taken from interviews with the fourteen remaining study participants.

\section{The Communities}

The small communities in which the study participants' libraries are embedded range from small and isolated - a population of 428 and one of only eight towns in a county spanning 4,776 square miles (more than twice the size of Rhode Island) with a total population of 16,800 people - to those that have all but disappeared into their surrounding urban environments. Predictably, smaller, geographically isolated townssuch as those in the west Texas and Panhandle regions - were slower paced and had fewer restaurants, retail shops, and recreation centers than larger communities or those lying near or within large, urban areas. 


\section{Texas Geographic Regions}

Texas spreads across 259,000 square miles in the center of the continental United States. The state's climate, geography, and topography are among the country's most diverse, ranging from coastal beaches and piney woods of east and southeast Texas to the high plains and deserts of the western regions. Population density and economic development are equally diverse. The eastern regions are densely populated and include the large, metropolitan areas of Houston, San Antonio, Austin, and the Dallas-Fort Worth metropolitan area. In contrast, it is not unusual to find counties with only one town and economies driven by agriculture rather than business or service industries in the western regions of the state. Spanish-speaking populations are prevalent in the west, central, and south Texas regions, but also are present in large numbers in other regions.

Following are detailed descriptions of each geographic region represented in the study with a representation of the corresponding regional library Systems (Appendices A and B):

West Texas - Includes the Texas Trans-Pecos Library System (TTPLS), the West Texas Library System (WTLS), and the Big Country Library System (BCLS). This region in far west Texas borders New Mexico in the west, Mexico in the south, the Panhandle in the north, and the central and south Texas regions in the east. The western half of this vast region is desert with an arid climate, and the economy relies mainly on ranching, wind farming, and oil and natural gas production. Three towns in this area with public libraries - Marfa, Alpine, and Fort Davis - lie unusually close to one another in a triangle 60 miles apart but reside in separate counties. Communities generally are few, 
small, and geographically isolated, although the towns listed above have seen an influx in recent years of new residents from metropolitan regions of Texas and other states. These newcomers have established a thriving artist community in Marfa and boosted business and economic development in Alpine, which also is the home of Sul Ross State University. Another institution of higher learning, the University of Texas-El Paso, lies more than 200 miles away. The eastern half of the region includes the metropolitan areas of Midland and Odessa. The geography of this area includes both arid, desert topography in the south and lush cotton fields in its central and northern reaches. Large-scale farming, oil and gas production, and service industries make up the bulk of the region's economic development. Inhabitants in this region tend to be self-reliant as many routinely drive long distances (up to 200 miles) for amenities such as shopping malls and chain restaurants.

Panhandle - This region includes the West Texas Library System (WTLS) and the Texas Panhandle Library System (TPLS), and lies due north of the west Texas region. It borders New Mexico in the west, Oklahoma in the north, and north Texas in the east. Farming and cattle ranching dominate the economy, and the largest cities, Amarillo and Lubbock, lie closer to Denver, Colorado than they do to Austin, the Texas capital. Lying in the southern part of the Great Plains, the region is flat—with the exception of the awe-inspiring Palo Duro Canyon 30 miles south of Amarillo-and there are few trees or shrubs outside of populated areas. Many small communities in this region have experienced sharp declines in population and revenue over the last decade. 
North Texas - Includes the North Texas Regional Library System (NTRLS) and the Northeast Texas Library System (NETLS). This region borders Oklahoma in the north, Arkansas in the east, the Panhandle region in the west, and the central and east Texas regions on the south. The geography is mainly flat with some rolling hills, but there are densely wooded areas in the eastern reaches. Three major interstate highways intersect the region-Interstate 35 running north to south and Interstates 20 and 30 running east to west. Although this region includes the Dallas-Fort Worth metropolitan area, much of the area is agricultural and laced with small communities. Many of the small communities around the Dallas-Fort Worth metropolitan area have been or are in the process of being absorbed into the urban sprawl of these cities. Exploding populations in these areas are causing drastic changes in the pace of life and the expectations for library services.

Central Texas - Includes the Alamo Area Library System (AALS), the Big Country Library System (BCLS), the Central Texas Library System (CTLS), and the southern edge of the Northeast Texas Library System (NETLS). This area is surrounded by the north, east, south, and west Texas regions. The region boasts some of the most popular recreation areas in the state, including the rolling Texas Hill Country, the Highland Lakes chain on the Colorado River, and the Austin metropolitan area. Many small towns in this region have experienced explosive growth and developed into bedroom communities for people living in Austin and San Antonio.

East Texas - This region includes the eastern counties in the Central Texas Library System (CTLS) and the entire Houston Area Library System (HALS), and 
borders Arkansas and Louisiana on the east, north Texas on the north, central Texas on the west, and the Gulf Coast on the south. Houston is the major metropolitan area in the southern part of the region, which is heavily wooded from the coastal areas to the northern reaches. The region also is densely populated with small communities that lie on average 15 miles apart. Towns lying up to 60 miles around Houston have experienced a population explosion over the last two decades, as many of them have become bedroom communities.

South Texas - Includes the South Texas Library System (STLS) and the Alamo Area Library System (AALS), and is bordered by the central Texas region to the north and Mexico to the south and west. Although it includes the greater San Antonio metropolitan area, sparsely populated areas devoted to farming and ranching dominate this region. The rich Rio Grande Valley area along the Mexico border is more densely populated, and many small communities have experienced an upsurge in population as retirees and people from colder climates—often called "winter Texans"- have relocated to areas they formerly visited for recreation. The resulting populations are mixtures of long-time local residents and new settlers from out-of-state who are accustomed to and demand a high level of library services.

\section{Geographic Distribution of Libraries in the Study}

Table 3 shows the number of small community libraries that are members of the Texas Library System and their populations. The Texas Library System is comprised of ten regional library systems across the state funded with IMLS monies through contracts with the Texas State Library and Archives Commission. Nearly every public library in 
the state is a member of the Texas Library System. Member libraries receive many benefits from the system including consulting and continuing education services, and support for such projects as literacy, English as a Second Language programs, and library automation. To maintain membership in the Texas Library System, libraries serving populations between 10,001 and 24,000 must:

1) maintain per capita support of at least $\$ 1.50$,

2) maintain a materials collection of at least one item of library materials per capita or expend at least $25 \%$ of local expenditures on the purchase of library materials,

3) maintain a minimum of 7,500 materials,

4) be open to the public not less than 30 hours per week, and

5) have a head librarian who is employed in library duties at least 30 hours per week and who completes at least 20 hours of continuing education over a two-year period. Membership criteria for libraries serving populations of 10,000 or less are the same as above, with the exception of hours open to the public (20 per week) and hours worked by a head librarian (20 per week). ${ }^{17}$

Table 3: Small Community Library Membership in the Texas Library System.

\begin{tabular}{|lc|ccccccc|}
\hline & Total & $1-$ & $1,000-$ & $2,500-$ & $5,000-$ & $10,000-$ & \multicolumn{2}{c|}{ Totals } \\
System & Libraries & 999 & 2,499 & 4,999 & 9,999 & 25,000 & $\#$ & $\%$ \\
\hline AALS & 46 & 1 & 7 & 7 & 12 & 10 & 37 & $78 \%$ \\
BCLS & 43 & 2 & 8 & 18 & 10 & 2 & 40 & $93 \%$ \\
CTLS & 78 & 4 & 13 & 9 & 15 & 25 & 66 & $85 \%$ \\
HALS & 72 & 2 & 5 & 8 & 19 & 17 & 51 & $71 \%$ \\
NETLS & 108 & 1 & 12 & 19 & 18 & 23 & 73 & $68 \%$ \\
NTRLS & 74 & 1 & 5 & 16 & 15 & 18 & 55 & $74 \%$
\end{tabular}

\footnotetext{
${ }^{17}$ Summary criteria for membership in the Texas Library System are listed on the Texas State Library and Archives Commission Web site at http://www.tsl.state.tx.us/ld/pubs/libsysact/criteria.html (Accessed on 14 August, 2005).
} 


\begin{tabular}{|lc|ccccccc|}
\hline & Total & $1-$ & $1,000-$ & $2,500-$ & $5,000-$ & $10,000-$ & \multicolumn{2}{c|}{ Totals } \\
System & Libraries & 999 & 2,499 & 4,999 & 9,999 & 25,000 & $\#$ & $\%$ \\
\hline STLS & 54 & 1 & 3 & 6 & 13 & 15 & 38 & $72 \%$ \\
TPLS & 31 & 6 & 6 & 8 & 5 & 5 & 29 & $94 \%$ \\
TTPLS & 16 & 2 & 3 & 5 & 1 & 2 & 13 & $81 \%$ \\
WTLS & 36 & 1 & 5 & 13 & 6 & 5 & 31 & $86 \%$ \\
\hline Totals & 571 & 21 & 67 & 109 & 114 & 122 & 433 & $76 \%$ \\
\hline
\end{tabular}

Comparisons Between Libraries in the Study and Libraries Serving Populations of Similar Size

I compared demographic, statistical, and financial data about each library included in the study to the most up-to-date state and national data sets available from the Texas State Library and Archives Commission (2003) and the National Center for Educational Statistics (2001). The tables following illustrate comparisons between libraries included in this study and state and national public libraries and branches serving populations of 25,000 or less. It is important to note that "population served" does not necessarily describe the population of the community where each library is embedded. State and federal guidelines assign countywide populations to public libraries that receive funds from their county governments. Although this study did not differentiate between city, county, or other library designations, it included six city libraries, six county libraries, one non-profit library, and one city-county library (see Table 2). 
Table 4: $\quad$ Libraries by Population Served.

\begin{tabular}{|c|c|c|c|c|c|c|}
\hline \multirow[t]{2}{*}{$\begin{array}{c}\text { Service } \\
\text { Population }\end{array}$} & \multicolumn{2}{|c|}{$\begin{array}{c}\text { U.S. Public } \\
\text { Libraries }\end{array}$} & \multicolumn{2}{|c|}{ Texas Public Libraries } & \multicolumn{2}{|c|}{ Libraries in Study } \\
\hline & Total \# & $\begin{array}{l}\% \text { of } \\
\text { Total }\end{array}$ & Total \# & $\begin{array}{l}\% \text { of } \\
\text { Total }\end{array}$ & Total \# & $\begin{array}{l}\% \text { of } \\
\text { Total }\end{array}$ \\
\hline $1-999$ & 1,041 & $15 \%$ & 19 & $4 \%$ & 1 & $7 \%$ \\
\hline $1,000-2,499$ & 1,621 & $22 \%$ & 67 & $16 \%$ & 2 & $14 \%$ \\
\hline $2,500-4,999$ & 1,305 & $18 \%$ & 107 & $25 \%$ & 0 & $0 \%$ \\
\hline $5,000-9,999$ & 1,443 & $20 \%$ & 111 & $26 \%$ & 7 & $50 \%$ \\
\hline $10,000-25,000$ & 1,767 & $25 \%$ & 123 & $29 \%$ & 4 & $29 \%$ \\
\hline Totals & 7,177 & & 427 & & 14 & \\
\hline
\end{tabular}

The statistics for service populations between 2,500 and 4,999 represented in Table 4 seem to indicate that no libraries serving those populations were included in the study. In actuality, several participating libraries assigned countywide populations are embedded in towns whose population falls into a lower range. Consequently, more than half of the libraries included in the study fall into the service population range of 5,000 to 9,999 . Other service population ranges represented in the study reflect percentages similar to those represented by state and national data.

Table 5 below shows the total operating income for libraries in the study compared with libraries of similar size in Texas and in the U.S. With one exception, Texas ranks below the national standard in all population categories. In the population ranges 5,000 to 9,999 and 10,000 to 25,000 , the average total operating income in Texas public libraries is only half the national average. Libraries in the sample rank below the Texas averages in all but 1,000 to 2,499 population category, where average total operating income nearly matches the national average. 
Table 5: Average Total Operating Income.

\begin{tabular}{|l|ccccc|}
\hline & & $1,000-$ & $2,500-$ & $5,000-$ & $10,000-$ \\
& $1-999$ & 2,499 & 4,999 & 9,999 & 25,000 \\
\hline Libraries in the Study & $\$ 15,157$ & $\$ 42,523$ & N/A & $\$ 98,101$ & $\$ 114,441$ \\
Texas Public Libraries $<25 \mathrm{~K}$ & $\$ 22,097$ & $\$ 33,526$ & $\$ 62,071$ & $\$ 105,427$ & $\$ 222,200$ \\
U.S. Public Libraries $<25 \mathrm{~K}$ & $\$ 19,793$ & $\$ 45,882$ & $\$ 93,974$ & $\$ 205,897$ & $\$ 489,940$ \\
\hline
\end{tabular}

Texas public libraries—and those libraries participating in the study—with service populations under 2,500 have much larger collections on average than their U.S. counterparts, illustrated in Table 6. Libraries in the study serving between 1,000 and 2,499 have almost double the national average of materials. This strong showing may be attributed, at least in part, to the assistance that regional library system staff provide for their smallest libraries. These libraries often are the most needy in terms of librarian education, collection, staffing, and facilities. As the library director working in a community of less than 1,000 emphatically put it: "We'd've never made it without [the system coordinator] and her staff" (P04, L667). A librarian working across the state from the first in another library system echoed this sentiment when she said, "We couldn't survive without our system staff!" (P07, L241).

Public libraries also receive collection development monies from the regional systems, and many small community public libraries in Texas seek out grant monies from private foundations such as the Meadows Foundation and the Tocker Foundation. The latter organization in 2005 awarded more than $\$ 500,000$ to Texas public libraries with service populations under 12,000 , and routinely provides travel stipends to participants in the Small Library Management Training Program. Founded in 1995, the mission of the Tocker Foundation is to distribute funds principally for the support, encouragement, and 
assistance of small rural libraries in Texas. Funding provided by Tocker provides library shelving and furniture, funds automation projects, and purchases books and other library materials in libraries serving populations of fewer than 12,000 people. Another major source of collection development and project funds for small community libraries in the last decade is money provided through Texas Book Festival grants. Since 1996, this annual festival has raised $\$ 1.65$ million for 550 Texas libraries, half of which reside in small communities.

Table 6: Average Collection Size.

\begin{tabular}{|l|ccccc|}
\hline & & $1,000-$ & $2,500-$ & $5,000-$ & $10,000-$ \\
& $1-999$ & 2,499 & 4,999 & 9,999 & 25,000 \\
\hline Libraries in the Study & 9,153 & 23,644 & N/A & 27,040 & 35,620 \\
Texas Public Libraries $<25 \mathrm{~K}$ & 13,468 & 15,600 & 20,026 & 27,475 & 42,042 \\
U.S. Public Libraries $<25 \mathrm{~K}$ & 8,904 & 13,697 & 20,832 & 32,878 & 58,562 \\
\hline
\end{tabular}

Comparing the collection size and circulation data in Table 7 reveals an interesting story. For example, a non-profit library in a brand new and spacious facility with a budget of just over $\$ 50,000$ - all donations - in a community full of active retirees circulates more than its total collection every year. In another part of the state, a wellestablished but poorly maintained county library with a collection more than twice the size of the first—and embedded in a dying community that has seen its population decrease steadily over the last ten years - struggles to circulate even half of its inventory. The circulation and collection size data also indicate that a multi-type, county library annually circulates only one-third of its collection; however, the library does not open until 3 p.m. Monday through Friday, and resides in a decrepit and crowded building. 
Table 7: Statistics for Libraries Participating in the Study by Population Served.

\begin{tabular}{|l|l|r|r|r|r|}
\hline Jurisdiction & $\begin{array}{c}\text { Geographic } \\
\text { Region }\end{array}$ & $\begin{array}{c}\text { Service } \\
\text { Population }\end{array}$ & $\begin{array}{c}\text { Total } \\
\text { Operating } \\
\text { Income }\end{array}$ & $\begin{array}{c}\text { Collection } \\
\text { Size }\end{array}$ & $\begin{array}{c}\text { Annual } \\
\text { Circulation }\end{array}$ \\
\hline Municipal & South & 969 & $\$ 15,157$ & 9,153 & 7,542 \\
\hline County & Panhandle & 1,727 & $\$ 33,638$ & 15,535 & 7,500 \\
\hline County & Panhandle & 2,211 & $\$ 51,408$ & 31,753 & 35,120 \\
\hline Non-profit & Central & 5,067 & $\$ 53,811$ & 6,038 & 6,616 \\
\hline County & West & 6,892 & $\$ 105,394$ & 38,372 & 56,201 \\
\hline Municipal & Central & 7,207 & $\$ 140,572$ & 29,503 & 50,358 \\
\hline Municipal & East & 7,830 & $\$ 268,746$ & 47,096 & 56,805 \\
\hline County & West & 8,075 & $\$ 40,143$ & 9,823 & 2,364 \\
\hline City & North & 8,174 & $\$ 121,200$ & 28,785 & 40,714 \\
\hline County & North & 8,766 & $\$ 97,413$ & 29,664 & 20,500 \\
\hline City & North & 11,239 & $\$ 83,342$ & 29,367 & 24,118 \\
\hline Multi-type & South & 12,811 & $\$ 67,324$ & 24,700 & 7,296 \\
\hline Municipal & Central & 16,196 & $\$ 194,895$ & 37,126 & 42,714 \\
\hline County & West & 22,838 & $\$ 112,203$ & 51,287 & 64,514 \\
\hline
\end{tabular}

In 1996 only 47\% of U.S. public libraries with service populations between 5,000 and 25,000 had Internet connectivity. ${ }^{18}$ Just five years later, in 2001, that percentage had doubled as state, federal, and private grant programs began providing funding for computer hardware and software, connectivity, and training for library staff. Texas public libraries also experienced a rapid surge in public Internet access over that same period.

One librarian in the study described how rapid computerization has changed the nature of her work:

I would like to make this comment that in the years that I've been in this library, the nature of my work has changed because when I first came, I was, there was a, just me and one other person. And I did all the frontline stuff as well as whatever administrative duries were required of me. As the

\footnotetext{
${ }^{18}$ Bertot, John Carlo, Charles R. McClure, and Patricia Diamond Fletcher. 1997 National Survey of U.S. Public Libraries and the Internet: Final Report. American Library Association, 1997. http://research.umbc.edu/ bertot/figures/figure7.html (retrieved on August 15, 2005).
} 
Internet and computers and you know, all the expectations of that came into our favor...I spend less and less time doing the things I truly love (P13, L828-833).

Table 8 shows that while the percentage of Internet connectivity for Texas public libraries lags behind the national average in all but the smallest population category, the percentage of Internet connectivity for public libraries represented in the study far exceed the national average. The data in Table 9 reflects a similar lead for libraries in Texas and in the study over the national averages. All but one of the libraries in the study provided access to electronic services, and all but one - a non-profit library founded 2000 and still using a dial-up connection - provided public Internet access. The most recent statistical data available at the time of the study reflects three different fiscal years (federal data 2002, state data - 2003, study data - 2005), which may account for differences in percentages.

Table 8: Percentage of Libraries Providing Internet Access.

\begin{tabular}{|l|ccccc|}
\hline & & $1,000-$ & $2,500-$ & $5,000-$ & $10,000-$ \\
& $1-999$ & 2,499 & 4,999 & 9,999 & 25,000 \\
\hline Libraries in the Study & $100 \%$ & $100 \%$ & N/A & $93 \%$ & $100 \%$ \\
Texas Public Libraries $<25 \mathrm{~K}$ & $89 \%$ & $96 \%$ & $94 \%$ & $94 \%$ & $93 \%$ \\
U.S. Public Libraries $<25 \mathrm{~K}$ & $81 \%$ & $96 \%$ & $98 \%$ & $99 \%$ & $99 \%$ \\
\hline
\end{tabular}

Table 9: Percentage of Libraries Providing Access to Electronic Services.

\begin{tabular}{|l|ccccc|}
\hline & & $1,000-$ & $2,500-$ & $5,000-$ & $10,000-$ \\
& $1-999$ & 2,499 & 4,999 & 9,999 & 25,000 \\
\hline Libraries in the Study & $100 \%$ & $93 \%$ & N/A & $100 \%$ & $100 \%$ \\
Texas Public Libraries $<25 \mathrm{~K}$ & $74 \%$ & $71 \%$ & $82 \%$ & $79 \%$ & $86 \%$ \\
U.S. Public Libraries $<25 \mathrm{~K}$ & $69 \%$ & $86 \%$ & $90 \%$ & $93 \%$ & $97 \%$ \\
\hline
\end{tabular}

The statistical data only hint at the diversity of the libraries participating in the study, their location in the communities they serve, and the state of preservation or 
disrepair of each facility. The data do not indicate the almost overwhelming smell of mold in a library housed in a building so "historical" it was literally falling down, or the bustling activity generated by enthusiastic children and interested adults participating in another library's summer reading program on a Saturday afternoon. These statistics do not reveal the nature of the women who devote their waking lives to managing, developing, and maintaining small community libraries in Texas. The stories told by these librarians and analyses of these women's experiences as library administrators are the subjects of Chapter 4 . 


\section{Chapter 4: Research Findings}

The current study answers the research question: what contributes to the professional development of a selected group of library directors without MLS degrees working in small Texas communities? The study explores elements in educational events, personal experiences, or job circumstances that a selected group of library directors without MLS degrees working in small Texas communities believed to be significant in contributing to their professional development. I analyzed the experiences of these librarians - recounted during 14 one-on-one interviews - to identify patterns or factors contributing to the professionalization of non-MLS librarians working in small Texas communities. The interview questions defined the indicators of evidence in the study related to the general research question:

1) Archetypal Management Roles for Library Directors - How women managing small community public libraries perceive themselves in relation to their work and their roles as librarians in ways that reflect archetype-like roles.

2) Evidence of Job Satisfaction - Factors that have contributed to the personal and professional satisfaction of women managing small community public libraries.

3) Positive Influences on Professional Development - The experiences women managing small community public libraries perceive as having contributed to their professional development.

4) Challenges Facing Small Community Librarians - The nature of the challenges facing women managing small community libraries, including gender-based discrimination related to women's authority. 
5) Guidelines for Success - Qualities and characteristics that women managing small community libraries believe are essential for successful librarianship.

I developed a naturalistic study using qualitative research methods to obtain narrative data that addressed the research objectives. Data emerging from 14 one-on-one interviews with non-MLS librarians working in small Texas communities indicated many common attitudes, experiences, and perspectives shared by the study participants despite circumstantial differences relating to their geographic region, economic status, educational background, job experience, professional development and involvement with professional organizations, and local government and community support. I derived approximately 250 quotations relating to the research objectives from twenty hours of recorded interviews and coded them into tables. Some of the statements in this chapter have been modified for the sake of clarity, economy, or to protect the identities of the study participants, but the initial meanings of these statements have not been altered. Italics indicate individual words and phrases emphasized by the participants.

Findings in the current study lead to new conclusions about the caring behavior and archetypal manifestations of female librarians. Further, this study supports Bushing's (1995) conclusions that the concept of being a librarian arose not only from the selfperceptions of non-MLS librarians working in rural communities but also from "the various definitions, expectations and stereotypes imposed by family, friends, communities, and others in the library community—peers, MLS librarians, consultants, and educators" (Bushing 1995, 74). For example, the library directors interviewed in 
Bushing's study perceived the following factors as contributing to the process of their professionalization:

- help from others (such as mentors) and networking with peers,

- relevant continuing education topics,

- experienced educators with good communication skills and knowledge of circumstances in a small community library,

- support from local government and community, and

- organizational skills, self-confidence and assertiveness.

Participants in the current study identified at least four of these factors - help from others and networking, continuing education, support from the community and local government, and personal qualities such as organizational skills - as contributing to their professional development. I identified and developed a list of archetype-like roles, or job approaches, articulated by the study participants when describing their feelings toward their work as librarians. Archetypes I identified include the Mother/Caregiver, The Researcher/Detective, the Visionary Leader, and the New Professional. The numbered sections following correspond to indicators of evidence listed on pp. 30, 78, and 79.

\section{ARChetypal MANagement Roles for LibRaRy DiRectors}

Central to the work of psychiatrist Carl Jung, archetypes are "innate structures which play a large part in determining the way we perceive the world around us and which organize and give meaning to the multitude of information which our senses receive every second of our lives" (Knox 2003, 12). One way to view library management roles is through this idea of archetypes as it is defined by the fields of psychology and mythology. Although they may represent one key to understanding the 
dynamics of professional development, until now, archetypal management roles have not been explored in the library literature. With one exception, all of the librarians interviewed in the current study described their approaches to their work in personal terms that implied archetye-like management roles.

In the last twenty years, management practices have incorporated the use of archetypes to promote understanding of people's motivations in the work environment. The terms "personality type" or "psychological type" are commonly associated with the model of personality development created by Isabel Briggs Myers, the author of the personality test most widely used in the business world, the MBTI or Myers-Briggs Type Indicator ${ }^{\circledR}$. Myers and her mother, Katherine Briggs, based their inventory of personality traits on the ideas and theories of psychologist Carl Jung, a leading exponent of Gestalt personality theory. Myers and Briggs extended Jung's model with the development of the MBTI in the 1940s, translating Jung's concepts into language a layperson could understand. More recently, Carol Pearson introduced hero archetypes popularized by mythologist Joseph Campbell into modern business practice in her publications, Awakening the Heroes Within: Twelve Archetypes to Help Us Find Ourselves and Transform Our World and The Hero Within: Six Archetypes We Live By. Through her management methods targeting CEOs and other managers, Pearson promotes the idea that ordinary people must become aware of and incorporate archetypal patterns into business and every day life so that everyone can "realize our highest powers of creativity and effectiveness" (Archetypes 2003). According to Pearson, "very often we don't even know we have an archetype, we're just going around acting a certain way and seeing the 
world out of a certain lens. They [archetypes] determine how we see the world" (Archetypes 2003). In this section, the term "archetype" is used as a metaphor to describe various job approaches articulated by the study participants.

Early in the interview process, I noticed that words and phrases included in each narrative gave clues to how the individual study participant viewed her role as a small community librarian. Phrases like, "I'm the mother of it all!" and "You've got to look at the library as a business," indicate a deeper inclination on the part of each librarian to relate to her work in an archetypal role. I originally developed a list of eight library director archetypes based on the interview data, but narrowed these to four after receiving input from the study participants on the Archetype Verification Forms: the Mother/Caregiver, The Researcher/Detective, the Visionary Leader, and the New Professional. Although four study participants indicated the Social Conscience as their preferred archetype, I felt that the pertinent characteristics of that role would be better exemplified in the section, Librarianship and the Ethic of Caring (p.97). Although it was not selected by any of the librarians on the Theme Verification Form, I included the New Professional role because I felt it more strongly exemplified two of the study participants who selected the Social Conscience role.

\section{The Mother/Caregiver}

Motherhood is the quintessential caring role assumed by women. The Mother/Caregiver is a prevailing archetypal role emerging from the interviews, characterized by: 
1) feelings of responsibility for the establishment, organization, or operation of the library,

2) contributing one's own resources to purchase materials or furniture for the facility,

3) feelings of responsibility and concern toward patrons, especially children,

4) close identification with the library and its services, and

5) reluctance to retire or turn over the reins to a new director who would not a)

know the history of how the library was built up over the years, and/or b) understand the extent or the significance of the current librarian's contributions.

Having a nurturing or caring nature also is not a requirement for embodying the Mother/Caregiver archetype. Rather, personal identification with and a sense of ownership of the "baby" - whether it is an organization, community, or project — are the outstanding qualities of this personality type. Mother/Caregivers invest of themselvestheir time, energy, resources, thought, and feeling - in their projects, and feel devastated or fearful if anyone else tries to take over or make changes to it.The Mother/Caregiver archetype is emphatically expressed in the following quotes from an elderly librarian in one of the smallest communities represented in the study as she explained her perception of her role as the library director:

Well, [the library]...it's, see, it's nearly the world to me because I started when it wasn't anything...nothing but some old books that $I$ didn't even really care about reading, and we gradually got rid of those, got all new books (P04, L786-787).

Because after all, I was the one that started, got all the books. I'm, I'm the mother of it all...I did it all myself, you know. And I even bought the prizes and everything 'cuz they didn't have money set up for that... And I 
feel like I've got to hang on 'cause the next person wouldn't know all this history. They wouldn't know how it started out and how you had to work and work to get to this point (P04, L23-24, L1223-1225).

In the statements above, the librarian identifies herself as the mother of her library, the person who in essence "gave birth" to the library's services. Her phrase "you had to work and work to get to this point" is reminiscent of labor pains that eventually resulted in a new entity; in this case, the library. To take the mother/child metaphor further, under the librarian's nurturance the library grew from a fledgling organization into a flourishing public institution with state of the art computer access and up to date materials. Her willingness to spend her own resources to develop the collection from scratch, and the fact that she almost solely operates the library, give her a sense of ownership and pride for the organization as a parent might have for a child. Her sense of ownership and responsibility is evident in the phrase, "I feel like I've got to hang on 'cause the next person wouldn't know all this history. They wouldn't know how it started out..." It is difficult for the "mother" to let go of her "child."

The Mother/Caregiver archetype was the first choice of nearly half of the study participants to describe their approaches to the job. Even librarians who spoke at length in their interviews of their abilities as businesswomen or who demonstrated the skills of a storyteller in their use of metaphor and command of narrative language admitted on their Archetype Verification Forms (Appendix G) that they saw themselves as the Mother or Caregiver for their community in their role as the librarian. Others selected this archetype as their second choice after choosing a different archetype to describe their most compelling tendencies. 
Three of the librarians in the study who identified with this archetype-like role spoke with pride of their accomplishments, and each one had gathered photographs and newspaper articles illustrating milestone events as evidence of these accomplishments. These pictures and news stories documented the history of the library—as well as the librarian's involvement—in events like community fundraisers, awards ceremonies, and groundbreaking ceremonies. The actions of these librarians during their interviews demonstrated how important it was to them for me to understand and acknowledge that they were responsible for the library's current situation and standing.

Experiencing motherhood in real life is not a prerequisite for having feelings of ownership, pride, and responsibility in an organization or project. Some of the women who selected this archetype-like role were mothers of either grown or young children, but not all had experienced motherhood. Certainly, identifying with the Mother/Caregiver archetype is not contingent on gender. Based on the comments of a male peer reviewer, men may be just as likely to view the organization or work project they originated and invested time in as "their baby." For example, the reviewer became animated when he read this section of the study, revealing feelings of loss and anger experienced after having a project that he had nurtured and spent his own money on taken away by his supervisor and given to another employee in the company.

\section{Researcher/Detective}

Another archetype-like role identified in the study and self-selected by a small number of participants is The Researcher/Detective. Like the Mother/Caregiver, The Researcher/Detective librarian archetype focuses her sights narrowly, in this case on the 
details inherent in research and the maintenance of print materials, such as repairing damaged pages, attaching protective book covers, and cataloging and classifying materials. The Researcher/Detective may not have strong interpersonal skills and in fact may be shy or even uncomfortable around other people. Instead, she finds intellectual and personal fulfillment through seeking out information for the benefit of others and demonstrates an ability for meticulous work requiring a detail-oriented mind. This archetype-like management role is characterized by librarians who:

1) enjoy researching materials and performing reference work;

2) derive a sense of purpose from helping patrons find information;

3) pride themselves on their organizational skills and abilities to catalog and classify items, and to properly maintain a print-based collection; and

4) May have some background working in an academic setting.

Almost one-third of the study participants selected The Researcher/Detective as their primary library director archetype. All but one of these librarians was soft-spoken, somewhat shy, and reluctant at some points in the interview to talk about her experiences. The remaining librarian was outspoken, gregarious, quick to volunteer information, and laughed loudly and often during her interview. A former educator, this librarian described herself as a stickler for details. When given the opportunity to correct and make changes to the transcript of her interview, this librarian telephoned to tell me she had "gotten out her red teacher's pen" to make the corrections.

One example of the Researcher/Detective archetype turned up in a bustling town of nearly 8,000 in a library building spanning 6,000 square feet (a planned renovation 
will more than double the square footage over the next year). The librarian was a creative, outgoing, and gregarious person who held both a bachelor's and a master's degree in theatre. Despite the fast-paced, busy atmosphere, the obvious evidence of heavy computer usage by both children and adults, and the enthusiastic, personable attitudes of library staff, this librarian described her true passion on the job as being researchoriented:

I'm really...into...the books. Making sure that we have the books, making sure that the books stay in good order, making sure that they're clean. Making sure that they have good covers on 'em (P05, L175-176, 180).

You know, just being able to provide people with what they need, especially if they don't think they're gonna find it. And in a lot of cases, we're able to get it to them fairly easily just because either they haven't had the opportunity to really have library skills or have research skills or know how to go about something. I, I think that's, that's the best part of it (P05, L153-157).

More than 500 miles away in a sleepy bedroom community of almost 13,000 people, a soft-spoken library director with an education and grant research work background voiced similar feelings: "With libraries, I always enjoyed the research first. I had a hard time getting to the paper because I enjoyed the research first. That part of it I was interested in" (P09, L23-26). Another librarian who has been the director for more than 30 years described the detective curiosity that keeps her job interesting and causes her to pursue reference questions even after the patron has lost interest in the topic:

I've got to find out why. And that's probably one of the reason why I, you know, [am] in the library. I've got to find out why. And if somebody comes in and asks me a question that I can't find right away, it's gonna bug me for days (P10, L450-452). 
The Researcher/Detective profile often is associated with a typical librarian personality; i.e., one who is concerned with the order and physical appearance of books, and who is strongly motivated to seek out answers to satisfy her own or others' curiosity. Of all the archetypes proposed in this study, I/ Detective most closely embodies the Librarian Archetype described by Cowden, LaFever, and Viders in their work, The Complete Writer's Guide to Heroes and Heroines: Sixteen Master Archetypes, excerpted below:

The Librarian gets things done. She does not procrastinate, she does not dither, she does not make excuses. She looks a matter over, decides how best to accomplish the task, and then she does it. Making it look easy is one of her specialties (Cowden et al. 2000, 81).

There is little doubt that these characteristics are useful personality traits for public librarians.

\section{The Visionary Leader}

The Visionary Leader archetype describes a librarian who provides a broad and long-range vision for the future. She looks at the big picture, envisions possibilities, and sets the direction for her staff to follow. The projects she takes on may be of her own making, or they may have originated under the leadership of another librarian who lacked the drive and enthusiasm to carry out the tasks. In either case, the Visionary Leader provides the energy needed to keep the project going, and inspires enthusiasm from others - staff, governing officials, library patrons, and members of the library board. She steers the project toward completion while others take care of the details of running a small community library. The Visionary Leader may lose enthusiasm for her job once the long-term project is completed, and her tenure may last only as long as the term of the 
project. Unlike the Mother/Caregiver, the Visionary Leader exhibits a sense of stewardship for rather than ownership of the library and is exemplified by a person who:

1) guides the library through a long-term project (e.g., automation or building renovation),

2) provides the vision necessary to take the library into a new era or provide a new level of service, and

3) isn't afraid to let go of the job, and in fact may look forward to having someone else take over for the next big project once her stamina and enthusiasm wane.

Three of the librarians interviewed for the current study spoke with passion and enthusiasm about the drive needed to achieve goals and complete projects that they had spearheaded for the library. Achievements ranged from establishing public access computer access to garnering support for a bond election to benefit the library to overseeing construction of a new library building. A librarian in a fast growing community of just over 9,000 people near a major metropolitan center expressed the need for enthusiastic leadership from the library director when she remarked, "You just have to work with what you have and be enthusiastic. If you're not, believe me, the other people that come in are not going to be either" (P12, L214-215). Her determination and vision also are evident in the following comment:

Soon we realized that we needed a new library. People said, "No you'll never get it. It [a bond election] has failed twice in this town." I said, "Well, we need a new library. We're going to get a new library" (P12, L58-60). 
Another librarian who had spent the past decade overseeing a large-scale automation project and the introduction of online public access computers agreed with me that "the library director sets the direction" of the library, commenting that the large-scale projects undertaken by the staff were "all done because of my initiative." Unlike the first librarian described in this section, the second library director did not instigate the large-scale project she oversaw; rather, she inherited a project already set in motion by entities outside the library. However, she did initiate changes in the library's collection that she acknowledged had given her a "good deal of satisfaction". Under her direction the library staff added new formats to the collection, including audio books, videotapes, and DVDs, anticipating patron demands.

Elsewhere in her interview, this same librarian spoke of the vision and leadership skills needed to guide the library through a major computerization project incorporating Internet access and circulation and catalog automation into the library's existing services. The resulting computerization resulted in greater demands on the library staff and increased expectations of library service by the community. The librarian and her staff found themselves on a steep learning curve as they attended the many training sessions provided by software vendors, grant foundations, the regional library system, and the state library. The librarian described their experiences as "a roller coaster ride" lasting several years. She also described a new long-term project getting underway to renovate and expand the present library building. In the quote below she speaks of her waning enthusiasm for her job and her inability to garner the energy needed to take on a new project after the demands of the previous venture: 
Like I said, it was a personally challenging and a really exciting time for me for a number of years. Now, that's '94, and we're in '05 now, so we're 11 years down the road, and, you know, <in a lower voice $>$ quite frankly, the job's not fun anymore (P02, L93-96).

Small community libraries need visionary leaders as much as their larger, urban counterparts; in some cases, the need is even greater in rural communities. Urban public libraries employing a large professional staff generally are well established and able to incorporate large-scale projects like building renovations, collection modifications (adding or eliminating formats, for example), and rearranging space to accommodate new equipment or staff. By contrast, most small community libraries in Texas are less than 100 years old. Many were established within the last 30-40 years in buildings that originally housed skating rinks, gas stations, banks, and grocery stores, or began their existence as a bookshelf housed in the city hall. Fewer than 20 are housed in Carnegie libraries built at the turn of the twentieth century. Since 1995, upwards of 400 small community libraries in Texas have received public access computers with Internet access, more than 250 have automated their collections and circulation processes, and scores have built new buildings to house expanded services and collections. The rapid technological and societal changes brought on by the Information Age demonstrate that more than ever before, leadership and long-range planning skills are vital qualities for non-MLS library directors working in small communities.

\section{The New Professional}

Small community librarianship gives many women a sense of professional identity that they are unable to achieve in other jobs. Many women living in small communities concentrate their energy and efforts on their husbands and children rather 
than their careers, so that even those with college degrees often end up working in clerical positions rather than professions such as teaching or management. The archetype-like role of the New Professional is characterized by a person who:

1) experiences a sense of professional accomplishment for the first time while working as a librarian, although she may have held other jobs in the past;

2) discovers, perhaps for the first time, an identity apart from her role as a wife and mother; and

3) gains a sense of purpose and direction from her work as a librarian that she had not gotten through educational experiences, motherhood, or other jobs.

Two library directors in the study—-both in their mid-forties — described how their job as a library director gave them a sense of fulfillment and satisfaction that they had not found in other occupations, including motherhood. Both had volunteered at their libraries before being hired, and both had previously worked in corporate business environments after earning a college degree relating to business and finance or computer science. Without being prompted, both of these study participants expressed a deep sense of personal fulfillment gained from their work as librarians. One of these librarians-after relating the story of another librarian she had met in a workshop who told that group, "I wish I'd found this [job] years ago when I first started working!"- assured me she felt exactly the same way. The other librarian elaborated on the ways in which her job as a library director allowed her to fully express the caring side of her personality, a character trait she had been unable to express while working as a purchasing agent. Just as the librarian described earlier in this section, this librarian was unable to find a business- 
related position once she reentered the job market after taking time out to raise a family. She began volunteering at the library and was asked by members of the library board to apply for the director position. During her interview, the librarian articulated her belief that a higher power had guided her to become a librarian saying, "I honestly believe it was Providence...that brought me here" (P13, L86, 88).

One of these librarians - a wife and mother with a bachelor's degree in computer sciences who had worked in one or two previous jobs — exemplified the New Professional archetype in the following quote:

When I got this [job], it was like, you know, I really feel like I'm doing something better than what I thought I was going to. Just be-you know, I'm-I enjoy being a housewife and a mother, but I really enjoy working. I really enjoy this, and I feel like maybe this is what I was supposed to do (P11, L618-621).

Managing an organization that responds to the information needs of the community, assists in educating both young people and adults, and helps to enhance the quality of life in the community gives many small community librarians a deep sense of purpose. This feeling is enhanced by taking on the responsibilities inherent in managing the operations of a public institution, and through being identified as a community leader.

\section{EVIDENCE OF Job SATISFACTION}

\section{I just love being a librarian! (P11, L1849)}

Job satisfaction is a major theme emerging from the current study, reflecting one aspect of professionalization: a positive self-image related to one's work. As the interviews progressed, a pattern of personal satisfaction related to one's job became clear. 
All of the librarians in the study expressed positive feelings associated with their work resulting from the daily variety and diversity of the job:

I have a lot of fun working here and there's just lots of things. It's never dull and [there is] always something you can laugh about everyday, and sometimes there's things that you want to cry about. But you do, you know, it's good. It's a good place to work (P08, L630-633).

Contrary to the public's perception that librarians "just sitting around reading all day," most librarians in the study spoke positively about tackling both day-to-day and long-range challenges. One librarian working in a community with a dwindling population remarked, "Well, in the thirty-two years I've been here, no two days has ever been alike" (P10, L465-466).

Study participants frequently commented that they enjoyed being librarians and had difficulty envisioning themselves doing any other kind of work. The following comment from another librarian illustrates the typical sentiments expressed by librarians in their interviews:

[Being a librarian] was the highlight of my life, besides my two kids, and my husband. I couldn't have thought of a better position. I always wanted to be a librarian, and I can't think of anything else I'd rather do (P09, L913, 917, 921, 931).

\section{Library Work as Spiritual Salvation}

Several librarians in the study described a strong attachment to their work that might be thought of as a kind of spiritual salvation. Study participants who expressed strong emotional attachments to their work also spoke of severe personal losses they had experienced, usually the death of a spouse or parent. These librarians articulated a fervent sense of gratitude for their work and, in some cases, an almost desperate desire to cling to their jobs to keep from being overwhelmed with and immobilized by grief. Comments like, "It's been real good for me. You know, my husband died, so... it, you know, it seem 
like it's become my life, you know" (P04, L712) and "It kept me sane. It kept me from going crazy. 'Cause I had that money to raise and I had that [work] to do" (P03, L230231) indicate these librarians' delicate mental and emotional states and the almost spiritual salvation they gained from their work. The quotes below clearly reveal these librarians' perceptions of their work as providing a concrete sense of purpose and a reason to continue participating in the life of the community rather than withdrawing from public view:

I don't know what I'd do without the library...during the last six years of my life if I hadn't had this library to come to... it would've been very hard. Because this was kinda my balance, this is where I could fix things where I couldn't fix [my husband's terminal illness]. So I could come down here and I could make something work (P01, L21, 273-276).

Our city manager came over the day [my husband] died, and I said, "Well, you know, you'll never get rid of me now." And he said, "Who said we wanted to?" And I said, "Well, just if you want to, you're gonna have to do it because there's just no way I'll be able to leave" (P01, L625-628).

So it's, you know, kinda my world. My husband died. That left me, you know, by myself...so, you know, my life just kind of revolves around the library. I get to where I can't talk unless they talk about books....and the library (P04, L1210-1213, 1217).

I just can't imagine not being here. I thank God every day for me being able to get up and get across here, and, as long as I can, I, you know, I want to be [at] it because I'm, I'm interested in the library (P04, L12211223).

The study participants quoted above also referred to feelings many times throughout their interviews, both their own and those of others. One librarian in a community of less than 4,000 people who had had recently lost her husband and who had suffered health problems for several years spoke about her emotions more than any of the other study participants. Several times during the interview she referred to overpowering 
feelings of grief that had lead her to tears. One example, excerpted below, describes her reactions when a trusted city council member recommended that the city hire another woman for the librarian position after she herself had applied for the job:

I sat for just a few minutes and I knew I was going to burst into tears so I just had to leave. This was right after my wreck and mother had died and everything. So I took off after a little bit and I was just crying by the time I got out the door because not so much that others had not voted for me but that he had even made the motion (P01, L90-91, 93-95).

This librarian's sorrow soon turned to joy when the city council member explained to her that he knew the other candidate would not take the job, and that he intended to offer her the job once the woman refused the low pay and long commute. At another point in the interview, she described having positive feelings of pride and happiness when she received a community service award. These feelings also resulted in tears:

And it was so neat. I mean, I cried when he gave this award to me. Because he says, "You are the keeper of the books, but you are also the keeper of..." you know, and then he named all these different things, and I got so emotional about it (P01, L480-481, 483-485).

Not everyone participating in the study agreed with the premise that library work could offer a kind of spiritual salvation to directors who were grieving over the death of loved ones. A few study participants disagreed with this premise on their Theme Verification Forms, including one librarian who had lost her mother-whom she was very close to emotionally and geographically—within the last six months. However, this particular librarian currently is happily married and enjoys a close and supportive relationship with her husband, suggesting that it is the loss of one's primary emotional support that causes her to seek solace in her work. 
The sense of spiritual salvation from library work seems to occur more often with women who have lost the person who provides the majority of their emotional support, whether this is a husband, in the case of married women, or a parent, in the case of unmarried women. Yet mourning is not the only condition that supports the sense of spiritual salvation found in one's work. Also essential to this experience are a sense of

duty and responsibility to the job on the part of the librarian, and a sense of personal satisfaction that comes from feeling she makes a difference in the community. Having a profession or vocation offers strong emotional and mental support to a person who has lost the focus of her feelings and efforts.

\section{Librarianship and the Ethic of Caring}

Librarianship often is described as both a caring and helping profession, and nowhere is this more evident that in a small town. One librarian interviewed in the current study summed up this attitude of caring by saying, "In a small town, people care so much." Another recent proclamation of this label comes from the deputy director of the Harris County Public Libraries system in Houston speaking about relief efforts by local librarians for library patrons displaced by hurricanes Katrina and Rita:

The incredible part of how well Houston area librarians responded is that they do this work every day. The extraordinary response is all in a day's work for the library community. We are a caring profession-we help people (Meraz 2005, 90).

Most of the librarians interviewed in this study articulated feelings of caring and concern for library patrons (from one-caring to one being cared for), especially children, illustrated by the following comment from a librarian working in a geographically isolated community: “And you've got to love your little town. You've got to want to help 
those kids get educated in your own town" (P08, L988-989). This same librarian also expressed strong feelings of caring for her patrons in another remark:

You get attached to your-I have a lot of elderly patrons, and you just get so attached to them. They're so nice, and you just, you just fall in love with them. Well, you get attached to a lot of the patrons and you are concerned about 'em (P08, L52-54).

The librarian quoted above clearly demonstrates the role of one-caring (librarian) for the ones-cared for (library patrons) in the following statement:

From the little kids that, that want me over there to sit down with them and read a book to the high school kids... and then the older people...that just want to talk about the day's events. You know, you get to know... who expects what from you....and it's all—combine all of that, and it makes your day (P08, L494-496, 599-601).

Many study participants described the purpose of the library as helping the community in some way, either through satisfying patrons' information needs or, more often, by improving patrons' — and by extension, the community's—social welfare. All of the librarians in the current study clearly articulated the library's helping role, and related the helping aspect of library work to their own self-esteem and sense of accomplishment:

We had one woman that came over here that can't speak English. She's using our ESL books and tapes, and she'll come in and she'll want me to talk to her in English so that she knows whether she, you know, and she'll talk to me. And she wants to know if - am I pronouncing it right and we'll discuss her, you know... and it feels real good to know that she is making progress and that she is - and that you can help. You know, you feel really good to help (P08, L687-692, 699-701).

You know, it does make you feel good when you know that [the patrons are] really working hard at [improving themselves] and that you have something in here that can help them. And that makes your day, too. It makes you feel as good as it does them (P08, L753-759). 
Well, I think it has such great rewards because you can see the people you're helping, and in life, the goal-you should always be helping somebody (P12, L1507-1508).

I just think it's a, a great way to help people and enrich them and enlighten them, or help them do all that for themselves, actually. Really, you're just giving them the mechanisms to go on and showing them how to use what's there, help them figure it out. And that's that (P13, L804-807).

Evidenced in the quotes above, library directors in the current study view their

roles as librarians in terms of caring and helping members of their communities. In one interview with a librarian working very near a large metropolitan city, the ethic of caring took on a quality of social work:

I think that being of the nature to want to help people and, interestingly enough, I'll tell you, the people that I reach out to the most and that's when they come in looking the most dejected. You know, they're obviously substance abusers, maybe they're homeless, they're, you know, their situation is worn on their person. And, you know, I just go out of the way to welcome them, let them know that we're only there because they've come needing help, and really try to show them what we have that can help them (P13, L198-207).

The librarian quoted above described herself as a very caring person. She also elaborated on how their caring roles gave her and her cstaff a sense of personal satisfaction and fulfillment:

It's the people. It's the people that come in, and they need something and, you know, we work with them individually to determine what they need and when we're able to give them that and give it to them completely and with a good attitude and that, you know, we're here to help you. That's what makes-it makes me feel good, and I must say that my entire staff embraces that (P13, L153-157).

In the comment below this same librarian articulates self-knowledge of her propensity to care for others: 
It's very personal to me, to me as a person. I really see it as a way to reach strangers' lives. You know, people that, they come to me and then it's my opportunity to show them what is here. And I...personally, I receive a lot of gratification from it. And I think I'm well-suited for it because that is in my nature, I'm giving and I enjoy people (P13, L789-790, 794-797).

Librarianship, along with the vocations of teaching and nursing, is founded on an ethic of caring. Librarians, particularly in small communities where people often know or are related to each other, often become personally involved in the lives of their patrons, sometimes unwillingly. The following quote from a former hair dresser who is now a librarian illustrates her sense of humor as she describes people's tendencies to tell the librarian all about their personal lives:

They don't really want my opinion, but they do want me to listen. I have people come in and, oh, they want to tell me about the argument they had with their husband and how they settled that or not settled it or, you know, their in-laws are complaining about their troubles, you know, and what's bothering them. They want somebody to listen to them and I, sometimes it's like I told my co-worker, "TMI," you know? "Too much information!" (P07, L319-324).

The study participants often described feelings of concern for their patrons, and the satisfaction they gained from their patrons' response to this caring behavior.

Noddings $(1984,47)$ describes situations in which people perceive bonds or relationships with others as "chains of caring," and notes that caring behavior:

...is conditioned not by a host of narrow and rigidly defined principles but by a loosely defined ethic that molds itself in situations and has a proper regard for human affections, weaknesses, and anxieties (Noddings 1984, 25).

The passage above has implications for the ways in which small community librarians interact with people in their communities in a professional capacity. The 
librarians in the study noted their willingness to remain open to each patron's needs and provide assistance on a level to best meets those needs. Additionally, most of the study participants expressed affection toward the people in their communities, in particular for people who visited the library. Study participants identified young children, the elderly, non-English speaking populations, people who actively seek their assistance in the library, and those who seem "lost" in the library as deserving special care from library staff. The attitudes of small community librarians toward their patrons may be summed up by the sentiments on a sign resting on one small community librarian's desk: "Always personable. Always professional. Forever playful!”

\section{Making a Difference in the Community}

Closely related to the ethic of caring described in the previous section, most of the study participants felt that making a difference in the community through improving the intellectual and social skills of the citizens was of paramount importance:

When you see those people it's like, well, that's why I work here, you know. I do make a difference. It's kind of like a teacher. You make a difference here. That's the way I feel. But the rewards are just-I mean, I could go on and on and on, you know, telling you stories - but it's mostly, you know, well, right, but, you know. They make me feel good about doing. Because we don't have to do those extra things (P01, L351-358).

Especially since I've been here almost 12 years, watching the kids grow up and seeing them grow, and seeing them progress, and seeing them become better citizens and better people because of their library experience and because of what they read. That type of thing. That's where the fulfillment comes in (P05, L161-165).

It's a rewarding [job]. I'll tell you that because I-most days I can go home feeling good about things. Very seldom do I not feel, you know, good about today (P08, L867-869). 
That is the goal of this library. We want to help those kids graduate from high school. How do we do that? We want them to be better citizens. How do we do that? We get them involved in reading. We get them involved in reading (P12, L1522-1525).

Almost every librarian in the study expressed feelings of satisfaction and fulfillment resulting from "having made a difference in the community." The narratives reveal that theses feelings most often arise from giving children a safe place to congregate after school or from contributing to the education of children, helping adults improve themselves by locating needed information, and acting as an intermediary who connects people in the community (usually adults) with the civic and social services provided by other agencies and organizations. Some of the study participants adamantly emphasized - through their voice inflections and choice of words - how much it means to them to have contributed to the improvement and well being of their fellow citizens. “That's why I work here...I do make a difference"(P01, L351) is a sentiment often expressed in the interviews, along with "you never know who you're gonna to touch or where they're gonna go" (P03, L924).

A few of the study participants also described the feelings that members of their communities have for library staff (from the cared-for to ones-caring), illustrated in the following comment from a 40-something librarian who emphasized the importance of reciprocal caring throughout her interview: "People come in the library, Belinda, because...they want to. So they have good attitudes. They have good, good feelings for you" (P01, L277-279). Another librarian articulated the reciprocal nature of the caring relationship between librarian and library patrons when she described the reactions of a "winter Texan" to the personal service she provided: 
And so I helped her set up her browser-I stepped her through it, which I had just learned, myself, how to do it. I stepped her through it, and then she said, "Oh, thank you so much!" And, "You went beyond the call of duty!" And so they gave me that card and a plant. They said, you know, "Hey, you were, you know, you were so nice the first time we came, and then you remembered us." And they stayed for, like, about a month. So we have a lot of that return (P11, L466-472).

It is common for a person involved in a caring profession like librarianship to feel that her work has contributed to the well-being and growth of her community, by helping one person at a time. This phenomenon is apparent in small towns where the librarian identifies herself as a member of the community and considers her patrons also to be her friends and neighbors. In small communities, “everybody knows everybody else.” This sense of closeness and relationship, coupled with the civic responsibility inherent in being a community leader and an intrinsically caring nature on the part of the librarian, engenders in her a sense of accountability for the well being of the community, both for individuals and for the community as a whole.

\section{Pride in Professional Identity - "It's the Library Lady!"}

Most of the librarians in the study expressed pleasure at being identified as the librarian by people in the community, especially children. Remarks like, "Oh, it is great 'cause, you know, whenever I'm going anywhere, they recognize me as the librarian, you know" (P04, L685-686) and "When I go to get something at the Legion or when I go to church, uh, or I'm just out and about or I'm with my son, 'Oh, you're the librarian'” (P11, L353-354) were typical. When asked to Tell me about your experiences as a person of authority in your community, study participants from all areas of the state spoke with 
pride about how children recognized them as "the library lady" during their comings and goings around town:

In the last two years the elementary school has brought the third-graders in during their library hours. At the end of the school year, they'd bring them over here on a little field trip and say, "Okay now, the library does this over here. And you can come read over this hour. Blah, blah, blah." And so, when I would see them, they were especially, "<Gasps $>$ You're the library lady. I remember" (P11, L353-359).

When I walk around the town and someone's little kid doesn't know my name, but he'll go, "There's the library lady!" It makes me feel like I've contributed to them (P12, L719-720, 728).

I'll have kids look at me and, you know, if they're by themselves they'll usually go to mamma or daddy or whoever they're with, and I see some of them tugging on slacks or skirts or whatever, and they point. And some of them will come and they'll say, "Yeah. He said it was the library lady" (P14, L2467-2471).

Several of the librarians interviewed for the current study spoke of the

responsibility they felt as a public servant to set a positive example for their community

even in their personal behavior. This is evident in the following comment:

I feel a personal...my personal life, even though I know it doesn't have anything to do with my job or anything, but my personal-who I am and how I present myself is important because I am now looked up to and a point of that community. And I will try to keep my life and who I am and my understanding in a respectable frame of mind and always try to remember that who I am-it helps you keeps your temper a little bit (P06, L983-988).

The study participant quoted above also articulated this sense of responsibility to the community when she said, "There's a trusting factor that I feel is very important" (P06, L170). Working in a town nearly 300 miles away, another librarian quietly echoed this belief when she declared that the "librarian position [is] a sacred trust and a great responsibility" (P09, Theme Verification Form response). Her comment exemplifies the 
spirit of dedication inherent in small community librarianship. Yet another librarian articulated her pleasure with the sense of authority she gained from her position as the library director:

...you know, I'm listened to. I, you know, they pay attention, so...that's good. That's a good feeling of having respect of your coworkers or your peers...so that's been a good thing (P02, L383-385).

Participants in the current study indicated that they enjoyed and appreciated being identified as librarians. Librarians in this study do not refer to themselves as information specialists, information brokers, or information architects, and are not ashamed to be identified with what the literature sometimes terms the "L-word." Rather, these librarians report gaining status and respect from others through their roles as librarians. In a small community, the librarian is as much of an icon as the teacher, the fire marshal, the mayor, the coach, and the police chief.

\section{Positive Influences on Professional Development}

The process of becoming a library professional is a complex progression that includes many facets, beginning with hiring narratives that describe how an individual came into her job as a library director. Other factors that influence professional development_ continuing education, mentoring from other professionals, and peer interaction-also are discussed in this section.

\section{Hiring Narratives}

In an effort to make the study participants more comfortable while being interviewed and recorded on audiotape, and to encourage the librarians to talk freely about their experiences, I began each interview with a general, open-ended question about the librarian's background, Tell me how you became a librarian, and how you 
became the library director. None of the participants hesitated to answer the question, and many began their narratives with a smile as they recalled the events leading up to their current employment. Several of the librarians expressed a love of books and reading that manifested at a very early age; others recounted how they had, almost serendipitously, "fallen into" their jobs as librarians. The stories of how each study participant came to be a librarian are significant in that they provides insights into the attitudes these librarians have toward their work. Attitudes may shift over time as the librarian begins to identify with her role as a library professional and perceive herself as a community leader.

\section{Accidental Librarianship}

Bushing (1995) describes the phenomenon of landing a job as a rural library director without knowing beforehand that it would become a vocation as "accidental librarianship". She observed that in many cases a woman would apply for a general job with the city or county without intentionally seeking a job as a library director. This phenomenon also occurred in the current study. Many of the participants described getting their library director position as happening "by pure accident" or by being "in the right place at the right time." One librarian in the current study commented, "Yeah, so it was like, you know, the job-I tell people the job found me. I wasn't looking for it. The job found me" (P11, L225-226). Another librarian joked, "that's how I got my job. I was just...sittin' on the corner one day and got it!"'(P01, L140-141).

Based on the content of many informal conversations with small community librarians during workshops and other continuing education events over the last decade, I 
expected to hear a number of study participants describe how they became a librarian as an accident or fluke. This assumption is supported by the narrative data gathered during the interviews, which often describe a woman applying with the city or county governing entity for part-time work in order to earn extra money or as a way to keep busy. Several study participants mentioned how their relationships with others, such as library board members or previous librarians, were instrumental in obtaining their positions. One such story came from a librarian who held a master's degree in theatre and had worked primarily in financial institutions who said, "I've always loved to read, and the lady that had been library director here for like 20 years virtually handpicked me as her successor" (P05, L17-19). Another, a warm and friendly elderly librarian working in a town of fewer than 900 people, explained, "when the librarian — the other one — was sick down there, well, they [city officials] asked me to come fill in for her" (P04, L8-9). Following are similar narratives from other librarians in the study:

I saw the position for desk clerk advertised in the local newspaper, and so I came and filled out an application just like everybody else and was hired for that position. I think probably through the influence of one of the library board members, who I knew personally, although I didn't know it at the time. I knew, I mean, that she was on the library board. But anyhow, I think that's probably how I got the job initially (P02, 11-17).

I had gone to city hall one day and just put in an application as a generaljust, as working. And they said they really didn't have any openings. But then when I turned around about two or three weeks later I was downtown and we were getting ready to build the square for Jamboree, which is a celebration, and the librarian came out of City Hall and she said, "Are you still looking for a job?" and I said, "Yes I am" and she said, "Well, I'm gonna have a part-time opening at the library." So that's how I got my job (P01, L2-8).

I had worked for the school for twelve years, and I had just quit the school and the librarian wanted to retire and she asked me if I would be 
interested. I'd come in and we'd visit and talk, and then I started substituting for her and filling in when she needed time off or whatever. And I did that for six or eight months (P08, L16-18, 34-36).

Most of the study participants recounted that they were seeking any available clerical position, and had not intended to become the library director. A few of the study participants were hired as library assistants or circulation staff and worked in the library for several years before applying for the director position when it became available. One or two librarians in the study described being pursued for the director's job by library boards or community leaders, including one library who finally relented to persistent entreaties by city officials and agreed to fill out an application "in pencil." This woman might be better described as "reluctant librarian" than as an accidental librarian.

A number of study participants described their hiring experiences as "falling into the job" or "being at the right place at the right time," indicating an element of serendipity or chance in the hiring process. One could describe this phenomenon as “occupation encountering." At least one librarian attributed landing her job to the intervention of Providence, but most of the librarians interviewed credited the assistance of others in the community with whom they had some kind of established relationship, however casual. The hiring narratives of several of the librarians in this study corroborate findings in Bushing's 1995 study concerning accidental librarians:

None...indicated that they had any particular interest in working in the library before the job opportunity was available to them. They did not seem to have any prior knowledge of what a librarian does beyond checking out books, nor did they have any ambitions to become a librarian. Their first initiation into librarianship and what a librarian is or does came only after they were hired (Bushing 1995, 79-81). 
Accidental librarianship is a common hiring experience reported by small community librarians, including the librarians in this study. Although small community library directors seem to be randomly hired by the libraries' governing entitiesprimarily city or county governments - the study participants' long tenure in their jobs (between 3 and 40 years) suggests that "accidental" librarianship may be the most advantageous means of filling library director positions in small towns.

\section{Intentional Librarianship}

Only a small number of the study participants indicated an aspiration to be librarians from an early age, although many recalled fond experiences of visiting libraries when they were children. The three librarians in the intentional librarianship category all related having positive childhood experiences with libraries or librarians. One of the participants became a librarian at the same library she went to while growing up, where her mother had been the director for 23 years. Two other librarians spoke of wanting to be librarians since their young childhood, and one described in detail the encounter with a bookmobile collection and librarian that became the defining moment of her life's direction. Still, these librarians were rare finds, and all seem to have experienced a positive encounter with a librarian at a very early age.

One librarian in the study, a woman who originally earned an education degree and went into teaching because she could not afford to move to other regions or states to go to library school, made the comment below:

I couldn't have thought of a better position. I always wanted to be a librarian...So, if I'd had a first choice, it would've been to be a librarian. So I think that worked out really well (P09, L878-879, 884). 
Another librarian explained how a negative experience with a librarian she had as a child made her determined to provide a different level of service for the children in her community:

Well, I wanted to change it because I had had a bad experience as a child and - with a librarian. I have dyslexia. I was a little behind on everything, but I loved to read, I loved to study. But I had went and took some, picked some books up that were below my- [I] was probably [in] junior high, and they were probably early chapter books, maybe even some children's books, pictures books, but it was on a specific study. I had took 'em up to the desk and she looked at me and she said, "Aren't these a little too young for you?" And I, of course, defended myself and said, "No." But at that point in time, I never went back. That didn't discourage me from learning, but it did discourage me from using the library (P06, L199-200, 204-211, 219-220).

One small community library director working in a growing bedroom community

near a large urban center described the powerful impact of her first encounter with bookmobile library services in rural Washington state:

Actually, the way I became a librarian was, when I was in kindergarten...that's when I experienced the bookmobile. One day I was out playing and the bookmobile came. And they drove up in the yard and there was this great big van and my mother came out of the house and we were invited into the bookmobile. And I was surrounded by books, it was the most exciting, truly the most exciting thing that had ever happened to me. That was my first adventure with libraries and library books and it was a focal point in my life. And I always wanted to be a person who worked on the bookmobile. (P15, L8-9, 18-19, 29-30, 34, 38, 56-57, 61$62)$.

The librarian quoted above revealed during the course of her interview that she had an MLS degree, eliminating her from the interview pool. Her story is so inspiring, however, that it is included here as an anecdotal example of one woman's compelling drive to become a librarian. 


\section{Continuing Education and Lifelong Learning}

Prior research has established that most small community librarians will not pursue master's degrees due to geographic distance, family commitments, inadequate education, limited time and funds, or for other reasons (Bushing 1995, Fitchen 1991, O’Neill 2005, Vavrek 1980, 1982a, 1982b, 1984a, 1990, 1997, 2004, 2004b, Zaltman and Duncan 1977). The experiences of one librarian in the current study reflect these findings:

I always wanted to be a librarian. But when I was going to college, it was in the '70s, and it was like, you had to go to East Texas or New Mexico. But it just wasn't accessible. So, that was the reason I went into education because I thought, well, that was pretty close. And, with being one of four children, I didn't have that option of going off that far to go to school (P9, L921-926).

Yet, many small community librarians, hired for management positions but possessing little or no practical library experience, find themselves in desperate need of training and instruction. Librarians interviewed in the present study often cited well-established continuing education programs offered by the Texas Library System and the Texas State Library and Archives Commission as being essential to their professional development. Typical comments included, "I couldn't have done this job without that training, by any means...I've learned everything I know about libraries from those workshops" (P06, L560-561, 581-582) and "But without that additional training, I could not have done it 'cause you can't, I mean, you're flying basically by the seat of your pants" (P02, L441442). This latter librarian also remarked:

Yes, undoubtedly, it's been the training I've received through the State Library and the Library Systems, the Texas Library System. Without 
that...I, I would not have been qualified to do the job that I've done (P02, L426-428).

The Small Library Management Training Program, an ongoing, basic skills program developed by the Texas State Library and Archives Commission, was singled out by many of the study participants as being a significant factor in their professional development. Responses to the program ranged from complimentary to enthusiastic:

Yes, and I got in on the first round of those [Small Library Management Training Program workshops] which I found extremely helpful. Those were all wonderful (P02, L67-68).

And I also was extremely fortunate when I came in January of '94 that in March of '94 is when the Small Library Management Program [started]. I was the first graduate from that, and it was a huge help (P05, L67-68, 80).

The small library management [program] - I felt like-I thought, "It should just have my name on it." "Dorothy, this is for you." "Dorothy, welcome! This is for you. We made this just for you" (P11, L666-667, $671,675,679)$.

Also noteworthy in the interview comments is the enthusiasm for ongoing learning shown by the small community librarians in the study. Several participants spoke of their willingness to learn through any avenue available, be it workshops, colleagues and mentors, listserv postings, library patrons, or mass media. One librarian working in a community of nearly 10,000 that is rapidly being subsumed by a major metropolitan area stated frankly, "I'm not shy about asking for help. I can really admit that I don't know. I don't have a problem with that. That I don't know and let me see what I can find out" (P13, L529-531). The quote below from another librarian working in a similar area indicates both her inner drive and willingness to learn and her ability to disseminate useful information: 
And being a small library, that's what you have to do. You have to say, "Okay, let me go to this workshop and pick something out of it." I'm always - I don't care how many times I've been there or on the subject that's going. Well, okay, what can I learn? What can this person teach me? What can this person teach me? You have to be willing to be taught (P12, L1254-1259).

\section{Mentoring and Professional Development}

Almost every librarian interviewed for the current study credited outside help for her success as a library director. The library literature identifies mentoring as a key element in the professional development of librarians working in academic, public, school, and special environments. Mentoring is especially important for non-MLS librarians working in small community public libraries, particularly for new librarians who are unfamiliar with library procedures and the professional expectations of the larger library profession. As Burrington (1993) pointed out:

...mentors teach skills, give advice, provide encouragement by example, and help those they mentor to develop sound judgement and gain confidence. They pass on their enthusiasm to those they guide. They encourage personal growth and development" (Burrington 1993, 226).

Field's (2001) observations sum up the need for mentoring for non-MLS

librarians when she states, "This rapidly changing information environment has increased the necessity for developing mentoring activities, making them more available to all information professionals" (Field 2001, 270). Although librarians in the western, northern, and southern regions of the state more often indicated that they rely on the assistance of regional system consulting staff for instruction in library procedures, small community librarians in all areas of the state cited assistance from mentors as a key element in their professional development. One librarian spoke of being "hand picked" 
by the librarian she succeeded; another credited the person who hired her with her success as a library director; still another expressed gratitude toward professional librarians and others that she could "lean on" and who would help her learn to do her job. Study participants distinguished between assistance from peers - with whom they felt themselves to be on equal footing — with assistance from mentors, those they considered to be in positions of greater knowledge and positions of authority. One librarian's comment that her mentors "treat me as an equal, and I'm not one" (P03, L431) illustrates a common type of positioning expressed by the librarians in their interviews. Study participants credited mentors with getting them their jobs, teaching them how to manage a library, and encouraging them to believe in themselves as librarians.

\section{Networking with Peers}

Networking with peers was identified by many study participants as an intrinsic component of their professional development. Small community librarians often take advantage of informal mentoring relationships with more experienced peers. Most of the peer interaction cited by the library directors in the study took place during breaks, lunches, or other informal periods scheduled during structured meetings and continuing education events. An experienced librarian who is the director of a public library that she and several other interested citizens took the initiative to establish made the following comment:

You get what the expert has to impart, and you go to lunch with the bunch, and you go talk to somebody. The best ideas in the world are the ones you steal from your colleagues because they've already tried them. They either worked or they didn't. But that's where good ideas live is among your colleagues (P03, L530-531, 535-537). 
Another long-time library worker and director voiced a similar opinion:

And typically, I learned it from the instructor, but if nothing else, you could always learn from other librarians. And I am a firm believer in the, "Don't invent the wheel," you know, just use...cheat! (P01, L426-428).

Two other librarians in the study commented on the value of informal learning

from peers and the capacity of networking to alleviate feelings of professional isolation:

I think the workshops are really good in one aspect. Even though we like our jobs here, we get exposed to how other libraries do things. And I've enjoyed that. Because you can always ask somebody else how they do it and get a little bit of input. And, and then you're gonna-your library will benefit from that (P09, L655-658).

You know, I learned so much at these workshops. And then I learn just as much sometimes at lunch as you do at the workshop. Because you learn how to network and you say-and you just hear people talking, well, about this or that, and you're going, "Well, how did you do this?" or "How did you do that?" and there's so much of that (P11, L782-792).

And then you say, "Okay, my situation," you know, you're here working by yourself, and you think, "I'm the only person that's in this situation." And you find out you're not. You know, so many people just kinda jump in and this one could be a second career for them or a first career or, you know, whatever. And you're not as isolated as you think you are (P11, L818-823).

Study participants also cited the professional benefits of networking that occurred

within the framework of the continuing education event but that was unrelated to the topic of instruction:

And it seems like in all of them [the workshops] we've had discussions to where something will come up that I'll think, "Oh, that's a good idea" and then kind of implement it from that (P09, L663-665).

I'm not even sure where all the people were from, but the networking that we did, or the information that was shared about this topic that had nothing to do with [the workshop topic] — or at least it was kind of out in left field — was really helpful to me (P02, L508-515). 
Several librarians described how they sought help for specific problems from their peers outside of continuing education events; for example, during regional and library system meetings: "You know, when there's a question or a problem or an issue, we do talk and visit and compare notes or ask for help" (P13, L317-322). Others commented that they would rather "pick up the phone and call" their colleagues in other libraries rather than communicate through listservs or email, like the librarian who stated, "I know even if I don't see them [other librarians] at workshops or if the issue doesn't come up at workshops, I can phone, you know" (P07, L200-202).

The comment below provides another example of the importance of networking with colleagues during organized events:

So those of us - and I'm referring back to when we were a cohesive group, the Dallas County Library System. And we did rely heavily on each other. We met monthly, we compared notes, anecdotes about situations and how it was handled. And that was very valuable to me in my early years when I was, you know, still trying to figure out what was going on (P13, L317322 ).

According to the study participants' narratives, networking seemed to be most effective after the librarians had a chance to become acquainted with and establish relationships with their peers. In many cases, the demonstration of caring behavior ion the part of a more experienced colleague helped establish these relationships. The following remark indicates the value study participants place on caring behavior from their peers:

[A peer] made a remark at the other library. And I needed to follow up on that. I can call her and she'll go into detail and explain to me what she's doing. She is such a cheerful person, you know, more than happy to take time out of their day and help somebody else (P08, L198-209). 


\section{Regional System Staff}

The Texas Library Systems Act, passed by the state legislature in 1969, authorized the formation of ten regional library systems to provide cooperative library and consulting services to staff working in Texas public libraries. Funded by service grants through the Texas State Library and Archives Commission, the ten regional systems vary in the size of their budgets and consulting staffs, and in the variety of services available to their member libraries. Inequalities also exist between the needs of larger public libraries, such as those in Houston and Dallas, and the smallest community libraries. Larger libraries employ many professional librarians while staffs in small community libraries often lack education, experience, and knowledge of library procedures. Consulting services provided by the ten regional system offices is crucial for staff of small community libraries. Comments like, "[System staff] are great. I can call them and ask them about anything. The System is really what makes the, this library function" (P06, L565, 569, 576) and "[The System is] what saved my life!" (P08, L78) were common responses to the interview question, What has contributed most to your professional development?

Perhaps the most heartfelt response to the assistance provided by system consulting staff comes from an elderly librarian working in a community of fewer than 900 people. This woman became the library director after substituting for the former librarian during a serious illness. She exuded warmth and friendliness to me and to members of the community both before and during the interview. She also insisted on taking me to lunch at the local senior center and introducing her to people she knew well. 
Both her actions toward me and her discourse in the interview reflected the importance this librarian placed on friendships and personal relationships. She later identified these qualities as being important personal traits for small community librarians. This librarian came into the library director position with no prior knowledge of or experience in library work. She described how consulting staff from her regional system office-whom she mentioned by name several times during the interview — personally taught her library skills and procedures such as collection weeding, purchasing and collection development, and book processing during site visits over the course of her first year on the job. Her feelings toward the consulting staff are evident in the following quote:

They've [System staff] been...I just can't tell you how good they've been to me. I just love all of them. They've all helped me so much, and I feel like I'm good friends with them all (P04, L1233-1234).

\section{Other Mentoring Relationships}

Almost every librarian interviewed for the current study credited outside help for her success as a library director. The quote below from a librarian in south Texas is typical:

That's the other thing that I will always do is I will give my boss the credit because, you know, it's just like I always thank the mayor, and I always thank [my mentor]. I will always thank [the System coordinator] and people at Texas State Library (P14, L667-670).

Study participants also emphasized the important role played by their mentors and the gratitude they felt for the assistance of the people who taught them to work in the library, while acknowledging the ongoing assistance they still receive:

I can think of mentors whose names that I will bless forever. There's no way for me to ever pay back all the people that have helped me. For instance, look at [names a workshop instructor], look at [names I], who 
offer practical advice for librarians with dusty shoes who are really gonna get out there and do it (P03, L393, 400-406).

'Course, I did have some dim idea of how to do it [manage a library] because my mentors were there, I could - had somebody to lean on, I had continuing education that I could go into and... well, it's been people who have held my hand (P03, L705-707).

The following statement, made by the experienced small community librarian quoted above, sums up the feelings of gratitude toward more experienced professionals who have taken the time to guide and educate their non-MLS colleagues: "It's just one lucky day that he [my mentor] walked into my life" (P03, L421-422).

\section{Importance of the MLS Degree}

Although I did not specifically ask study participants about their attitudes toward earning an advanced degree, several of the librarians in the study mentioned the importance of having a master's degree in library science (MLS). Some librarians in the study expressed mixed attitudes toward the MLS degree. At times, individual librarians displayed contradictory feelings in the same passage of their narrative, first citing the MLS as a necessary qualification for a professional librarian, then in the next breath assuring me that they themselves did not require the degree in order to do a professional job as a small community library director. Several study participants felt compelled to explain to I why they did not have an MLS degree, going into some detail about the life experiences (illness, childbirth, etc.) that had prevented them from earning an advanced degree. Almost all of the study participants who mentioned the MLS in their narratives said that the library director hired as their successor should hold a professional degree, although they felt that cataloging knowledge, business and management skills, and a love 
of people and willingness to provide service were adequate qualifications for the director of a small community library. The following statement is typical:

I don't have a college degree or anything. I don't think you could pay me enough to go there. And if my three years, if that's all that I've accomplished, and the person that takes over after me then can build upon that and actually maybe have a real librarian's degree (P06, L479-480).

All of the study participants who discussed the MLS were aware of state and national efforts to upgrade standards and require the MLS degree for library directors in small communities; however, none of them agreed that this was a good idea. Study participants cited inadequate compensation and the propensity of MLS librarians to become frustrated and want to move onto other, more challenging work as reasons why the MLS should not be required of small community librarians.

These same librarians went on to elaborate on the reasons they felt they did not need a master's degree to do be a competent small community librarian. The following comments typify the feelings of the small community librarians in the study about the necessity of having an MLS degree to competently manage a library:

But I don't think [the MLS degree is] really necessary. I think if you have the background - basic cataloguing and organizational skills. But, as far as the day-to-day activities, I think you can pick it up (P09, L872-880).

To get the Master's - I do believe that you can. I think you learn from that, but you really do learn on-site. You learn more, you know, there's a lot of things I figured out on my own way more than I probably would've learned there [in library school]. And I know they don't teach you everything (P01, L742-745).

There's things that I know by not having an MLS I don't, didn't know and probably don't know, but experience is a wonderful teacher, and if you have the experience, you know, I said to some people that, you know, when I retire, when I quit, I think they'll need to hire somebody with an MLS degree (P02, L432-435). 
One librarian who worked in a community of 11,000 people embedded in the suburbs of a major city pointed out the availability of alternative education opportunities for librarians without the MLS degree. This librarian had served both as a library board member and library volunteer before taking the job as the library director. In her view, continuing education is just as valuable as formal education for small community librarians:

But if you don't have a degree and you're willing to learn, there's so many avenues that you can learn from. From your State Library, the continuing education, to [the Regional Library System] for the workshops that they offer you, to going and becoming a member of [a regional group of public library administrators]. You don't have to have an MLS degree to do it [participate in continuing education]. You just have to go (P12, L834838).

Another librarian articulated what she perceived as reluctance on the part of MLS

librarians to share information or mingle with their non-MLS counterparts:

I'm a little bit surprised at how the line is drawn within the library profession among MLS and non-MLS because I really see that non-MLS, we stick together and we are more forthcoming. And it's almost as ifnow this is not - this is a general statement. This is not everybody 'cause there are - I have seen exceptions to the rule on both sides, but there seems to be a little line drawn that MLS is over here and if I'm not MLS, over here (P13, L307-312).

One librarian working in a more rural region commented favorably on the camaraderie she enjoyed with MLS librarians, while at the same time downplaying her own worth as an non-MLS librarian: "But all these people that I have talked about treat me as an equal, and I'm not one, but they have treated me as an equal" (P03, L426-427). Despite a successful career as a library director that has spanned more than 40 years, this librarian spoke with some bitterness about her inability to gain admittance to an 
accredited Texas library school in the 1950s. This negative experience galvanized her to return to her hometown and, with several other people, including her mother, establish the first public library in her community:

When I got to [the university], I was going to library school. That was my goal. And I worked for [the university] library for 6 weeks, and I found out they wanted warm bodies not...not gonna teach you anything. So I quit and went to work in a retail book store - a fine retail book store - and [the] library school down there didn't want me. So I got married and went on with my life...If I was gonna be a librarian, I was gonna have to start on square one. And so, that was the motivation [to start a community library] (P03, L41-45, 59-60).

As the interview progressed, this librarian recognized and valued her experiences as a non-MLS small community library director. Far from regretting her rejection by the library school, she dismissed the MLS degree as something that would qualify her to be only a kind of "worker bee" in a larger institution by saying, "If I had gone and had the MLS, I would have been working on the bottom of the pile somewhere, still yet" (P03, L49-50, 54).

The majority of the comments in this section show an awareness of the MLS degree as the benchmark for professional librarians. Another librarian in the study spoke of the scrutiny she felt she was under from people in the community she believed were watching and judging her performance as a library professional. In the comments below she equates professional competence with advanced education while describing her determination and self-confidence to do the best job possible without an advanced degree:

I think probably even today that there's still some that say, "Well she doesn't need that job." And so that's been my biggest problem. I knew I could do it. But it made me better. Because I knew I had these people 
watching me. And I knew they would continue to watch me. Because I didn't have an MLS. That I wasn't a certified librarian (P01, L68-70, 70, 73-76).

Other librarians in the current study echoed the study findings of earlier

researchers by pointing out how difficult it is for small community librarians to obtain master's degrees, and the lack of compensation they would receive even if they managed to obtain this level of education:

And you know, county librarians are not required to have degrees. You know, just, and for small libraries, I doubt it's, you know, pay scale being like it is, I doubt if anybody, you know, that's not fair to ask a person with a degree to take a job that wouldn't pay 'em for the time that they spent learning $(\mathrm{P} 07,147-150)$.

I know [state certification requirements are] leaning that direction [requiring the MLS]. But I'm afraid the small counties can't afford to pay the salaries that they might want. And if they had a degree, they'd probably move on to some other [community]. I think it'll hurt the small libraries (P09, L872-880).

The issue of low pay for small community librarians emerged during several of the interviews. Each of the librarians who brought up the subject mentioned they had some alternative means of support (for example, a husband with a good salary or retirement income) that allowed them to work for low wages at a job they enjoyed and from which they gained personal satisfaction. I heard comments like, "Luckily, my husband had a job where it didn't matter. I wasn't working because I needed to work. So it made a difference" (P11, 1360-1362) and "We're all women. We don't get paid what the men do. They're trying to build it up. They've tried to get us a little closer. But we don't get paid like they do." Another study participant observed:

There's been... an interesting exchange going on, uh, it's been on PUBLIB in the last few days. It's one about the high-flown ideas of librarianship, 
and I have really had to close my mouth about, you know, like, the good pay doesn't matter and all this stuff, and I want to say, "Folks, that's not where it is anymore. You've still got to live. I don't care what your highflown ideas are, somebody's gotta pay the rent" (P03, L620-621, 625$628)$.

While the small community library directors in the study recognize and acknowledge the MLS degree as a valuable credential for professional librarianship, many non-MLS library directors working in small communities remain unconvinced of the necessity for earning an advanced degree. While the non-MLS librarians' attitudes toward education in general are positive, they believe the time, expense, and effort required to earn an MLS degree far outweigh the compensation and opportunities available to use the degree as a small community library director. Yet, some librarians who have MLS degrees often are willing to take on the challenges of lower pay, smaller buildings and collections, and less staff in exchange for the personal satisfaction resulting from providing quality library service for people in small towns who might otherwise not have it, and from the chance to become part of a close-knit community.

\section{Challenges Faced by Female Librarians in Small Communities}

Nationally, women manage more than $90 \%$ of rural and small community libraries. In Texas, male librarians make up only $4.5 \%$ of the total number of small community library directors (Texas Public Library Summary for 2004). All participants in the current study are female, reflecting the predominance of women managing small community libraries. I expected to hear a number of examples of women treated as second-class citizens in their often rural and geographically isolated communities, demonstrated by the attitudes and behavior of patrons, governing officials, and others 
toward the library directors. In the interviews, I asked study participants to describe their experiences - positive or negative - as women in positions of power in their communities.

The library literature provides many examples of challenges facing small community librarians, particularly in studies conducted by faculty and staff of the Center for Rural Librarianship (Vavrek 1980, 1982a, 1982b, 1983, 1984a, 1984b, 1989, 1990, 1995, 1997). Data gathered for the current study describe three main areas, two of which—resistance from governing officials and geographic isolation—have been identified in the library literature. The current library literature does not cover genderbased discrimination — an area of challenge identified in the present study — but this phenomenon has been increasingly documented in the sociology literature over the last five years (Caprioli 2005; Gorman 2005; Jerby, Semyonov, and Lewin-Epstein 2005).

\section{Gender-Based Discrimination - Working within the Established Patriarchy}

Most of the librarians interviewed for the study insisted they were not treated differently because of their gender by people in their communities or by local (city or county) governing officials. One librarian working in a town of nearly 9,000 people who has held the director position for more than 10 years noted that there were "quite a few women in positions of authority" (P02, L339-400) in her town, including a doctor, a county judge, a curriculum director with the school district, and a human resources director. Another librarian in a town lying within 45 miles of a major metropolitan city commented almost as an afterthought on the unequal pay scales for male and female department heads in her town: "of course, we don't get paid what the men do" (P01, 
L199). The librarian made the preceding comment after first responding that that being a woman in a position of authority had "never been an issue" for her. Instead, this librarian experienced challenges to her authority because of her lack of formal education credentials (i.e., not having an MLS degree). However, another librarian in the study commented, "women are not looked at as equals in a, in a small town. It's always the [male] directors, you know, the Chief of Police or the Fire [Chief] or the Public Works [Director] (P 12, L495-497).

Murrell and James (2002) acknowledged, "one of the most widely studied areas that examines the barriers to women's career advancement are the consequences of discrimination in the workplace" (Murell and James 2002, 244). Only one library director working in a predominantly Hispanic community of just over 4,500 said she had experienced challenges and overt job discrimination because of her gender. This librarian, like most of the study participants, had grown up in the community where she now works but had gone to college in a large metropolitan city in another region of the state. After earning a bachelor's degree and working for several years in the education field, the librarian returned to her hometown to work. In the quote below she describes losing the library director position to a less-qualified male candidate who benefited from the established "good ol' boy" network in that community:

It took me a long while 'cause most of the jobs here are political. It's probably like that in most places. But here it's literally who you know or who you don't know. I have a degree. A young man that did not have a degree but had about forty relatives that vote in the county, he got the job. Okay? So, and that's what - how I really found out how the things work here (P14, L86-87, 91-92, 99-101). 
This librarian later benefited from her own "good ol' boy network" when she was hired to be the assistant library director by a male mentor she had worked with previously in a major metropolitan city. Her mentor, who was well known and respected in their small community, held a dual position as the town's City Administrator and the library director. This librarian — one of only two Hispanic women interviewed for the present study—felt strongly that women in positions of authority experienced overt discrimination in her community. It is interesting to note that the biased attitudes described in the quote below, while typical in a traditional Hispanic culture, are described in terms of gender rather than an ethnic culture by the librarian:

I think, still, people, especially in this community and rural communities, they don't like to see a woman in an authority, in a position that they're the head of a department. I think it's threatening to a lot of the male population (P14, L1652-1655).

This same librarian wryly provided specific examples of what she perceived as genderbased discrimination from local governing officials, describing the events below as "comical":

Just like at the city council, my ideas or whatever were dismissed. And I was challenged. In fact, when I became Library Director, I would submit travel reimbursements, and I would submit claims for things that I would buy for the library. Well, they pinned - two Council members, two of the ones that were always after me- not any other department, not any other department, and I was the only female head of any department (P14, L1655-1661).

And these were the two that were grilling me. In fact, one of them had, uh, saliva come out of her mouth 'cause she was so fuming she couldn't nail me for anything...Finally I asked them - I said, "Are you trying to imply that I'm trying to cheat the city out of money?" And that's when the Council members on the other end of the table said, "No. No, we don't mean"- and one of the Council members, the male Council member said, 
"Uh, no, we're doing this across the board [with] all of the city personnel," which I knew didn't happen (P14, L1684-1685, 1689-1690, 1724-1730).

The preceding quote was pared down to its main points, emphasizing the librarian's confidence in her own abilities and willingness not only to defend herself but also to go on the offensive in the face of antagonism from authority figures. One last comment reflects this librarian's perceptions of gender-based resistance to attitudes of female defiance: "And see, I think that was another thing that stuck in these male councilmen. That I would not back down" (P14, L1752, 1757). This librarian's confidence, grounded in her education and professional experience, substantiate Foster's claims that "women should be likely to act out against discrimination when their social identity as women is salient" (Foster 1999, 167).

Nearly 500 miles away in a town of just over 5,000, a soft-spoken librarian described overtly hostile behavior exhibited by some male library patrons toward the library staff:

I do have some problems - I hate to say this - mostly with males. They just don't want to, they don't wanna look at me as telling them what to do. And they get real angry. Or you can't, uh, get a certain book for them or they're not allowed to look at certain materials on the computer-different things like that. And I've, we've had one that, or two that had to be banned from the library because they were so violent toward us (P07, L72-74).

The librarian quoted above grew up in the town she worked in and had taken over the library director's job from her mother after working as a library volunteer for several years. Unlike the previous librarian, who, though small of stature, exhibited a strong, selfassured, and confident nature, the second librarian exhibited a timid, shy manner and 
unassuming personality. Seeming embarrassed, she volunteered the above information reluctantly and declined to elaborate on the experience when prompted.

\section{Resistance from Local Governing Officials}

Vavrek (1984) identified perception of low prestige from both the public and funding entities as a challenge facing librarians working in small communities. Several participants in the present study described the resistance and even antagonism they experienced from local governing officials. One librarian working in a large, wellsupported library in a town with a thriving economy lamented the perception of low prestige exhibited toward the library by its governing authorities:

I...just wish there was some way that we could figure where we could show our worth as a service to the Powers that Be. I mean, I know-like, firefighters and police with the criminals and saving lives and things - it doesn't necessarily play along that line, but we're saving people's lives by helping them live better lives and enriching the quality of what life that they have. And I wish we could make more people see that (P05, L753758).

Most of the study participants indicated that their libraries enjoyed the support of

their city and county governing officials. Several spoke of the good relationships they had established with their city managers, county commissioners, and chief financial officers, and the respect they were accorded by these officials as the library director. Only two librarians in the study described negative experiences with their governing officials. One librarian who has been on the job for more than 40 years spoke frankly about the suspicious attitude of the library staff and advisory board toward county officials over the issue of outside funding. In the passage below, she assumed my understanding since I had worked as a small community library director in the past: 
And we don't ever say much about [the private funding and donations the library receives]. Because you well know what governmental bodies do if they think you've got some money somewhere else (P03, L255-257).

This same librarian spoke also about the dismissive attitude of county governing officials toward the library, which she believes they perceive as a non-essential community institution:

My idea is to run a superb institution when the governing body doesn't care whether you do anything. They wish you would go away; they would be so happy if you would just go away. I mean, we're not painted yellow, and we don't say "Caterpillar" on the side, and we're not a pile of caliche. And therefore, we're not important (P03, L131-133).

Even the sweet, warm-hearted, elderly librarian working in the central Texas community of fewer than 900 people admitted that relations between the library board and city officials had been tense in the past, although she did not share her board's current distrust of the present city government:

We used to just kinda, didn't trust the city at all, but, you know, I've gotten along with them so well. That board wouldn't forgive 'em for the way they'd treated 'em in a way, you know. I [of] course, I, you know, could forgive and forget (P04, L291-294).

The study data gathered indicate that some small community librarians in Texas do not perceive themselves as experiencing gender-based discrimination from people in their communities or from their city or county governing entities. At the same time, the librarians in the study are aware of their governing entities' prejudice in favor of male department heads regarding pay and political influence. This bias also may be the result of the perception that certain departments, such as police, fire, and public worksgenerally staffed and directed by men - provide more essential city services than the library. Study data also indicate that some small community librarians experience strong 
resistance to their authority from men in their communities. The accounts of genderbased discrimination by one of the study participants are difficult to substantiate, as the actions she described could be based on personal rather than gender discrimination. Nevertheless, this librarian's perceptions of discrimination based on her gender are genuine. More study is needed to determine if gender-based discrimination is prevalent in small Texas communities.

\section{Geographic Isolation}

Geographic isolation was cited by several of the study participants as a factor negatively influencing their ability both to take advantage of continuing education opportunities and to elicit assistance from their more experienced colleagues and peers. Texas is well known for its geographic distances and varied population areas with terrain ranging from dense forests along the Louisiana border to the high plains of the Panhandle and the flat grasslands and sandy seashores of the coastal bend. In the western half of the state, most communities lie more than 40 miles apart. Due to the semi-arid and, in some cases, mountainous environments in the far western reaches, some of the larger counties in these areas have only two or three small towns. It is common for librarians in this region to travel more than 200 miles to attend continuing education workshops or to shop at large urban centers. By contrast, the eastern half of the state is more densely populated and small communities in this region rarely lie further than 10 or 15 miles from one another.

Several librarians expressed their unwillingness to travel over long distances to attend training workshops that lasted only two hours or for half a day. Librarians working 
in less populated areas of the state expressed frustration because their travel time often was twice as long as the duration of the continuing education event they wanted to attend. Some study participants spoke of feeling isolated from other librarians. Several librarians told the interviewer that early in their careers they often felt they were the only ones experiencing certain problems and situations. This sense of "being the only one" to experience problems tends to disappear once the librarians have an opportunity to meet with and share information with their peers at workshops and regional meetings. One study participant working in the western region of the state described how geographic distances precluded her from networking with colleagues in other communities. Her comment below also reveals the importance she places on face-to-face relationships with peers:

I communicate with the lady that is the director in [a town 30 miles away], but since we're so far apart, it's hard for us to communicate with the other librarians in our system...It's hard for us to get together and just talk (P08, L225-227, 35).

The well-established political tradition of local governance in Texas, coupled with variations in population, ethnicity, and topography, contributes to the vast differences in building size and condition, quality of materials collections, and local support of public libraries in small Texas communities. Librarians working in these communities may or may not have the resources or, in some cases, permission from their governing officials to attend workshops and professional conferences. Many librarians, particularly those who are new to the library field, experience a strong sense of isolation from their colleagues in other areas of the state and from the larger library profession. Although most small community librarians recognize the need for continuing education and are willing to 
travel to attend workshops, the comments below demonstrate an unwillingness to spend more time traveling than in training:

Part of the problem here is the isolation, and you're a good many miles from the next workshop...because to go to a workshop here, you're talking four hours [driving time] (P03, L462-464, 714-715).

[Geographic distance] is...it is a challenge. Because they put on a twohour workshop in Abilene, I'm not driving an hour and a half and back to go to a two-hour workshop (P03, L476-477, 481).

In contrast, continuing education workshops and programs that were centrally

located so that librarians from several regions could attend and that lasted for one day or longer received high praise from study participants:

It was so, you know, kind of centrally located for a lot of libraries and easy to get there, and I liked the idea of the two days in a row because you could, if you missed anything or didn't understand anything that first day, you could get caught up on it or ask questions. I loved it. And being new to the-everything, I needed that (P08, L98-103).

Most of the small community librarians participating in this study, particularly those in less populated areas of the state, experience a sense of geographic isolation from their colleagues and peers and from the larger library profession that negatively impacts their professional development. Study participants indicated a preference for meeting with their colleagues in person rather than communicating online, and favored telephone conversations over email correspondence. Although librarians in western areas of the state have fewer opportunities to meet in groups than librarians in more populated regions, library directors in all areas of the state would benefit from structured and unstructured opportunities to exchange information with each other in person, which could be scheduled during meetings and continuing education workshops. 


\section{GUIDELINES FOR SUCCESS}

In her interviews with 24 rural librarians in six states, Bushing (1995) concentrated a portion of her study on identifying the characteristics of effective rural librarians. The current study concerns the broader parameters of professional development for small community librarians, which include the assumption that the study participants have gained enough professional experience to offer advice to new library directors. One component of professionalization covered in this study is the participants' perceptions of which job skills and knowledge are important for managing a small community library. In the course of each interview, study participants were asked, "What advice would you give to someone coming into a small community library as the director for the first time? " Responses revealed the librarians' attitudes toward their jobs, but also indicated either a broad (social) or narrow (personal) perception on the part of each individual toward librarianship.

\section{Understanding the Community}

Every librarian in the current study cited understanding the social construction of small communities - in particular, the tendency of people in small communities to be suspicious of and resist change_ — as being important to successful librarianship.

Resistance to sudden change was most often cited by study participants as the reason for a new librarian to get to know her community. Eighty percent $(80 \%)$ of the library directors interviewed for the study were raised in the communities they currently work in. Although some of these women moved away from their communities for a few years either to attend school or to work, all eventually returned there to live. Consequently, 
their experiences provided insight into the dynamics of small community life. The following advice from one librarian embodies the study participants' belief that librarians must try to understand the communities they serve: "That [new] person needs to know their patronage, know the area, feel the, the atmosphere of it, and really take that into consideration" (P06, L798-800). Another study participant advised new librarians to:

Learn your community. Be a part of your community. You may have worked for a place and know all about libraries. The most important thing you need to know is all about your community (P12, L1449-1452).

Many of the librarians interviewed for this study emphasized that people in small communities are resistant to and suspicious of change. Most of the study participants cautioned new library directors not to make any changes when first coming into their jobs, and spoke of their communities' resistance to change:

Get to know the people and don't bulldoze things at your patrons. Take it easy. I know with this community, you don't bring things up; you ease it in. You ease it in. We had a guy here that was director for about nine months, and he tried to shove it down everybody's throats. That's one reason why he didn't last as long as he did. And then, the next guy that came along, he was a little more patient with it. He was here for 14 years (P10, L631-640).

I think the biggest mistake a person can make is when they move to a new community or a new area, just to go in and try to change everything that's been done in the past. Maybe small towns are more...they want things kept the same more than big towns do. I'm not sure, I've never lived in a big town. I don't know what they're like. But small communities, they don't like [change]. I still get complaints about the automation (P8, L400405).

Before you start making your mark, learn everything that you can however it's done. First, before you start changing things. I think that's what worked for me is that I didn't go in and try to change everything right away to fit mine. You know, I'm the one that's in charge. I was, like, no, I'm going at this, and I need to learn all that I can learn from whoever I 
can learn it from before I could put my mark. And so, I really, I didn't change anything for like the first year (P11, L1042-1047).

The study data clearly indicate that a new library director working in a small community should spend several months becoming acquainted with the needs, attitudes, and opinions of the people in the community before implementing any changes in library structure or operations. Even librarians who have lived and worked in their communities for a number of years should take time for others to become comfortable with them in their new roles as library managers. A small community library director who wishes to keep her position for a period of more than two years needs to gain the support and trust of her coworkers and patrons. Taking the time to do this will help ensure that the community will accept the librarian's suggestions and alterations to the library's materials and services.

\section{Becoming Part of the Community}

Another recommendation from study participants closely aligned with their advice to get to know the community is for a librarian to become part of her small community. Study participants recommended activities such as shopping in the community, going to church, participating in community functions, and taking every opportunity to become acquainted with people in the town where the library resides, even if they did not live in the town itself.

Nearly every study participant mentioned at some point in her interview how vital it is for librarians to become part of their local communities. As one librarian put it, "If I were, did not know anybody, I'd certainly try to get acquainted in town. 'Cause you need to know people" (P04, L922-923). Another energetic and dynamic librarian who 
successfully championed her community's new library building described how her strategy of becoming part of the community led to a successful vote in the general bond election:

So I decided, number one, to win the staff in the city. Whatever it took, I was going to win those people, to get 'em on my side, and then I was going to win the City Council...We just became involved in everything the town did-very supportive and got out to people who didn't know us...And so, the library just became the focal point of the town (P12, L7577, 90-91, 85-86).

This same librarian encouraged her employees to take part in community activities to further raise the library's profile among the townspeople:

I work to involve [the library] in the comminuty. So we have, you know, these big celebrations. I tell my staff to go. And, and the reason is, I want people to know them, who they are. Some of them don't have the incentive to go, maybe. It may cost you a few hours. You may have to work a little harder, but I'd rather you be out in the community, at a community function, where people can see you than sitting at home going, "Oh, no, I don't want to do that" (P12, L687-692).

Two librarians working in different regions of the state exhibited their awareness that the library would benefit from maintaining a positive image in the community, stating, "You need to know the community. Know what you can get away with and what you can't" (P10, 683-684) and "Get to know your people. And keep it as flexible as you can, because that goodwill is more important than even worrying about losing a piece of material" (P06, L729-731). Other study participants advised new librarians to network in their communities and become acquainted with people who can offer assistance in an effort to establish themselves as a community leader. The belief that participation in community affairs leads to positive feelings toward the library and its staff is illustrated 
in the following comments. These remarks also illustrate the librarians' political astuteness:

Just become involved in your community. Remember that you're not trying to reach the world. Your job is to reach your community. So whatever your community is, find out what they do and do it with them. And then, you can get them to come do what you want them to do. You've got to be willing to do what they do first, whether you like it or not (P12, L1459-1463).

The first piece of advice that I would give [a new director] really does not have much to do with the science of administration of the library. It would be to network within the community, get to know people, you know. Let yourself be known and find out who exactly it is that can help you, and start moving toward establishing yourself as a community leader. And then all that other stuff kind of comes with it (P13, L546-550).

Establishing herself as a member of the community can be advantageous in

several ways for the small community librarian. Being active in the community can help the librarian gain support for her projects and promote good will toward the library, acting as a kind of marketing strategy for the small community librarian. Political networking is vital if the librarian is to become a leader in her community. People who are personally acquainted with the librarian are more inclined to offer their time and energy to support library causes and are more likely to become library advocates. The small community librarian's active participation in community activities demonstrates her interest in and caring for the town, which in turn will encourage others to care for the library.

\section{Making the Library the Heart of the Community}

Tangential to the idea that the community's needs come before the wishes of the librarian is the concept that the library is an extension of the community in which it 
resides. The small community librarians in this study perceive the library as a public institution and feel strongly that people in the community should guide the library's services and operations. Librarians who perceive the library as being a vital part of their community will try to create an inviting and welcoming environment and encourage library use among all members of the community. An outgoing and sociable librarian working in a recreational community said, "I feel like libraries are a vital part of the community and especially in a small community. Because, I mean, we're the hub" (P11, L1511-1512). In the comment below, a soft-spoken librarian working in a of fewer than 500 people articulates her belief that the library not only belongs to the community, but also is the very center of community life, a place to exchange news and visit with neighbors:

The midday is the - that's the time the mothers come in. Their kids may be in school and they needed a little time, maybe it's computer time or whatever, and they don't wanna have to, you know, watch their little kids. And sometimes that's the only place they have to visit. They don't see their neighbor, so they'll visit in here a lot of times. They'll — and I'll be going on about my business and two or three of them will sit and get caught up on the latest news, you know? So, it's a place for that, too. And, I think that's important, you know, to keep contact with what's going on in your community. And this is a good place for it (P08, L791-809).

Other comments from study participants echoed this belief:

I think that no matter what's going on everywhere else, a library should be the one place they [people in the community] can come in and feel comfortable. And that it belongs to them. It's their library. Not...how they want it, not how I want it so much (P08, L529-531, 535).

The people that are here and involved with the community, this is an important part of it because not everybody goes to the same church, not everybody belongs to the civic center, not everybody belongs to the Legion. But see, this is a place that people can come (P11, L1514-1518). 


\section{Business and Managerial Skills}

Leaders in the library field have long emphasized the importance of business and managerial skills for women in librarianship. A paper presented at the 14th American Library Association annual conference in 1892 insisted that "the librarian must be both a good business woman and an educator in the highest sense of the word" (Proceedings 1892, 1976, 13). Six years earlier, Melvil Dewey warned that female librarians were handicapped compared to their male counterparts, in part because "women lack business and executive training" (Dewey1886, 1976, 10). Librarians interviewed for the current study also are convinced that business skills — which may include bookkeeping experience, organizational skills, personnel management, and budgeting skills — are valuable in their work. One librarian remarked, "I think getting any kind of bookkeeping experience you can get is important with all the state reports, and organizational skills" (P09, L850-852). Another library director echoed this sentiment: "If you don't have some experience with preparing and administering budgets, that is very, very important" (P02, L662-663). Others commented:

I think a lot of times, sometimes librarians that wind up being in small libraries like this get into it for the love of the books and things like that, but if they don't have a whole lot of business experience, I think that sometimes that can hamper them (P05, L78-82).

Well, but that also takes, you know, business skills. I mean it takes some sort of management and budgeting skills, too. So, you know, you can't just make it up without knowing (P10, L702-704).

Additionally, several of the library directors credited their business-related backgrounds and skills with making them better library managers: 
I had worked in banks and things like that - and handling money and different things like that in the real world, and then coming in and being able to appreciate all the different aspects of librarianship plus the fact that it's a business. I think that made it easier, in some ways, to handle the money from the grants, to handle all these different things (P05, L83-86).

I had a business. I had been in private business all my life. I am businessminded, so therefore, they wanted - our library had gone down to about 900 people coming in a month. It had really decreased. It just didn't have the excitement. You know, you just have to have someone generating that. And that's what I am. I'm a promotor/generator. Marketing is kinda my deal, so that's one reason they hired me - and I can use power tools (P06, L104-109).

I've been in the book business all my life. I run a library on the side and do research and write a little bit...I've been in rare book business, I've been in retail book business, I've been in the library business. You have to have a little piece of all of 'em, keep it all going, because it's so interrelated (P03, L773-774, 787-788, 796-797).

I was a terminal manager for the seventh largest trucking company in the United States. I worked as, uh, supervisor of the maintenance department in the warranty section - didn't even know enough to put gas in my car. ..But I soon collected over a million dollars in warranties my first year. So anyway, so when I got the [library director] job, I said, "Okay, what do you need to know?" You need to know who your patron is, what they like to read, and how you can service them. Because there's not much difference between moving freight than there is in moving books ( $\mathrm{P} 12$, L40-41, 47-48, 52-56).

Several study participants had managed, worked in or owned their own businesses, or had completed a two-year business school certification program. Evidenced by the comments above, even librarians who did not have corporate work experience or business backgrounds were cognizant of the value of business skills such as budgeting, supervising, and planning in their roles as library managers. The librarians with knowledge of business procedures described instances in which they were able to transfer this prior knowledge to specific situations in the library. Those who lacked these 
skills initially realized their need and sought out learning opportunities early in their careers as library directors.

\section{People and Customer Service Skills}

Interacting with people - the public, governing officials, state and system staff, and other librarians, is an essential part of small community librarianship. Without exception, every librarian in the current study emphasized the importance of developing people skills for managing a small community library. Weingand (1997) asserts that:

The nature of a public library...creates an environment that tends to be rather personal in terms of public relations. Many customers are regular users and become very well known to the staff. It is a milieu in which a high standard of customer service can flourish (Weingand 1997, ix).

One enthusiastic, vivacious librarian working in a retirement and recreational

community described her own interpersonal skills with frank good humor:

And, you know, I've never-I haven't met any of the librarians that weren't helpful. You know? And talk about the stereotype of, you know, everybody's shy and, you know. Well, I haven't met one yet. And, in fact, I got so much grief from my friends and family. And I got, "You're a librarian now? You're gonna, you? I just can't see it." And then my brother - one of my brothers said, "You're a librarian? Oh, how many times a day do the patrons tell you to shush?" (P11, L827-829, 841-842, 846-847).

Perhaps the most vital qualification is simply enjoying being around people, articulated by the same librarian: "You know, I love to read. I love people. And I try to make-when people come in - a warm and inviting place for kids as well as adults" (P11, L428-430).

Study participants described in their interviews what they considered good customer service skills. Foremost among the qualities articulated was friendliness and the ability to maintain personal relationships with library patrons. One librarian in the study 
remarked that library patrons had described her to her supervisor in the following way:

"She's really friendly. She always got a smile for you" (P11, L585-586). Other comments included:

At the beginning when I was working, I was real shy, and I've slowly come out of that shyness because of the patrons that come in, like I said, [they] need more than just a librarian. They need you to be [their] friend (P07, L108-110).

You're just not a librarian, you listen to their stories and their problems. And I guess that's one of the advantages of being in a small library in a small community 'cause you know everybody (P07, L52-57).

Small communities are completely different than, like, a large town, so I would say that you definitely have to make it personable. You can't just be, "Okay, here's your book. Here, check this out." And, you know, you do have to make it a personal place to come (P01, L609-702).

Several librarians added comments to their Theme Verification Form reiterating that people skills were the most important qualities for a small community librarian to have, including comments like, "To know your people, be friendly and helpful" and "Openness to interact with people; approachability."

Customer service skills or "people skills" are essential for anyone working in an environment that requires greeting and interacting with the public.

The table following summarizes all of the study themes described earlier in this chapter as "indicators of evidence": 
Table 10: Themes and Sub-themes Identified in the Study.

Themes

Sub-Themes

\begin{tabular}{|c|c|}
\hline $\begin{array}{l}\text { 1. Archetypal Management Roles for } \\
\text { Library Directors }\end{array}$ & \\
\hline & The Mother/Caregiver \\
\hline & The Researcher/Detective \\
\hline & The Visionary Leader \\
\hline & The New Professional \\
\hline 2. Evidence of Job Satisfaction & \\
\hline & Library work as spiritual salvation \\
\hline & Librarianship and the ethic of caring \\
\hline & Making a difference in the community \\
\hline & Pride in professional identity \\
\hline $\begin{array}{l}\text { 3. Positive Influences on Professional } \\
\text { Development }\end{array}$ & \\
\hline & Hiring narratives \\
\hline & Accidental librarianship \\
\hline & Intentional librarianship \\
\hline & Continuing education and lifelong learning \\
\hline & Mentoring and professional development \\
\hline & Networking with peers \\
\hline & Regional library system staff \\
\hline & Other mentoring relationships \\
\hline & Importance of the MLS degree \\
\hline $\begin{array}{l}\text { 4. Challenges Facing Small } \\
\text { Community Librarians }\end{array}$ & \\
\hline & Gender-based discrimination \\
\hline & Resistance from local governing officials \\
\hline & Geographic isolation \\
\hline 5. Guidelines for Success & \\
\hline & Understanding the community \\
\hline & Becoming part of the community \\
\hline & Making the library the heart of the community \\
\hline & Business and managerial skills \\
\hline & People and customer service skills \\
\hline
\end{tabular}




\section{Chapter Five: Summary, Conclusions, and Recommendations}

\section{SUMMARY OF RESEARCH}

The purpose of the current study is to discover elements in educational events, personal experiences, or job circumstances that a selected group of library directors without MLS degrees working in small Texas communities believed to be significant in contributing to their professional development. Much of the previous research about rural librarians, in particular studies conducted by the Center for Rural Librarianship at Clarion University, focused on the needs of and challenges inherent in rural communities; i.e., communities of 2,500 or fewer people. Additionally, prior studies relied mainly on survey data to determine the circumstances within which small community libraries operate and challenges facing library staff. To date less than a handful of qualitative studies, including the one conducted by Bushing in 1995, have explored the attitudes and perceptions of the librarians working in small communities. None were conducted in Texas prior to the current study.

I used naturalistic, qualitative methods to conduct on-site interviews investigating experiences relating to the professional development of non-MLS female library directors in 14 small Texas communities. Librarians in the study were selected using a random stratified sampling method from a cross-section of rural and urban communities of varying sizes, and were of varying ages, educational backgrounds, economic standing, and ethnicity. Using an interview protocol, I asked each librarian in the study about her experiences using open-ended questions. Topics of inquiry included hiring experiences, job satisfaction, challenges experienced as a woman in a position of authority, events that 
influenced her professional development, what advice she would give to first-time small community library directors, and what it meant to her to be a librarian.

After an independent transcriber transcribed each interview, both I and the study participants reviewed the interviews for errors and omissions. I analyzed the interview data to determine patterns and themes relating to the study objectives, which resulted in the coding of 250 quotations. The interview narratives further revealed the study participants' approaches toward their work as archetypal roles. After an initial data analysis, I developed two separate verification forms listing themes, sub themes, and archetypes emerging from the narrative data. Study participants were asked to review each of these verification forms for agreement and to give additional input. Study participant feedback included indicating agreement or disagreement with each of the themes and sub themes, identifying with a particular archetype or archetypes, and adding further comments relating to both themes and archetypes.

The study findings provide a conceptual framework for understanding the attitudes and perceptions of 14 small community librarians in Texas. The findings both corroborate and expand on earlier findings by researchers studying the professional development of rural librarians in other states. These findings are summarized in three sections following: 1) Archetypes as Metaphors for Library Management, 2) The Importance of Personal Relationships, and 3) Positive Factors in Professional Development. This chapter closes with summary conclusions and suggestions for implementation in practice. Recommendations for further research follow these conclusions. 


\section{Archetypes as Metaphors for Library Management}

The term "archetype" is used as a metaphor in the current study to describe various job approaches exhibited by study participants. Archetypes represent complex patterns of behavior that exhibit deep, perhaps even unconscious, leanings in a primordial form. Yet unlike stereotypes which are rigid and limited sets of characteristics, archetypes can shift and evolve over time, allowing for variation and paradox within one individual (Pratt et al. 1981, 3). For example, the librarian stereotype remains prevalent in modern culture: a middle-aged or elderly spinster who wears sensible shoes with her hair in a bun, who possesses a timid, sour, or nasty disposition. Yet the librarian archetype used in literature reveals a more complex and conflicted personality:

The librarian is earnest about things she cares about...she does have a sense of humor, but don't look for her to laugh off important issues...count on this woman. She never leaves anyone in the lurch...the lady has a stubborn streak, and if pushed too hard, she turns into a formidable obstacle... The Librarian hides behind her intelligence, creating her own safe world. She wonders what the outside world is like, but is too scared to jump in. (Cowden, LaFever, and Viders 2000, 81-82)

While many of the archetypes utilized in current organizational management practices embody traditionally masculine traits (e.g., "The Hero", "The King", "The Warrior"), the psychology literature provides many examples describing feminine hero archetypes, sometimes related to the Greek and Roman goddesses (Noble 1991, Polster 1992). Sociology literature includes discussions of female archetypes in literarure (Pratt 1978, Pratt et al. 1981), art (Lauter 1976), education (Meiners 2002), and media (Caputi 2004, Hedly 2002). Business management practices have incorporated archetypes for both men and women over the last decade (Pearson 1991, 1998, Mark and Pearson 1998). 
Other female archetypes represented in the literature are the wild woman (Tovar Ramirez 1996) and the triple goddess images delineated by the Virgin (Hall 1980), Mother/Caregiver (Kaplan 1994, O'Neill 2002, Whitehead 1995), and the Crone (Bussmann 1987, Eschle 2005, Lewis McCabe 2005, Walker 1985).

Librarians in the current study articulated strong feelings about their roles as library directors. In many cases, the interview narratives included distinct references to archetypal profiles. Archetypes identified in this study are 1) the Mother/Caregiver, exemplified by a person who feels a sense of nurturing towards and has made a personal investment in the library; 2) the Researcher/Detective, someone who prefers to search for information and maintain a physical collection; 3) the Visionary Leader, a person whose broad vision allows them to guide the library through one or more long-term projects; and 4) the New Professional, a woman who previously saw herself as a wife and mother, but who perceives herself as a professional career person through her position as the library director.

Although not all of the profiles identified in this study correspond to classic archetypes identified in the literature of psychology and mythology (for example, the New Professional), the librarians' tendencies to identify with these roles suggests that complex patterns of perception guide the management styles of small community librarians. Future research will determine whether the management archetypes identified in the current study are exemplified by librarians in other venues (academic, school, special), and identify additional library management roles. 


\section{The Importance of Personal Relationships}

The ability to establish and maintain personal relationships with patrons is a major factor in the small community librarian's sense of job satisfaction. As revealed in the sections titled Making a Difference in the Community (p. 101) and Librarianship and the Ethic of Caring (p. 97), relationships with others are of paramount importance to librarians working in small communities. Librarians in the study who articulated a deep love for and enjoyment in their work during their interviews were more likely to enjoy interacting with people from all walks of like and working with the public on a daily basis.

In contrast to libraries in larger cities which experience a much higher volume of visitors and librarians often are not personally acquainted with their patrons, libraries in small communities are able to offer more personalized service. Personalized service may be a leading reason that small community libraries continue to exist and even thrive in the age of iPods, instant messaging, and Internet access. The caring relationships between library staff and people in the community also may be the small community library's best asset to emphasize when seeking community support for building expansions, bond elections, and increased funding.

Findings in the current study reveal that small community libraries in Texas exist within complex social environments that are supported by caring relationships between the librarian and people in the community in which the library is embedded. These caring relationships are based on trust and, in many instances, affection. Caring relationships allow small community librarians to determine the information and library services 
needed by the people in their communities on a case-by-case basis. At the same time, the establishment of prior relationships and acquaintanceship are not necessary for the librarian to exhibit caring behavior toward library users. Several librarians in the study described their concern for strangers, especially those who exhibited a need for assistance through their words, body language, or behavior, and for children of all ages.

A willingness to establish relationships with the public, and even feeling some affection toward people in general, were cited by almost every study participant as vital skills for librarians working in small communities. Librarians in the current study provided numerous examples of their interaction with adults and children. Further, during their interviews several study participants were interrupted by their staff, patrons, or members of the public either in person or over the telephone. In every instance, the librarian apologized to me and spent the necessary time to assist or visit with the person who interrupted the interview while the recording equipment was turned off. This behavior demonstrated as well as any narrative the value that small community library directors place on human relationships and interactions with members of the community.

The importance of relationships extends to the professional arena as well. Small community librarians, particularly those working in geographically isolated areas of the state, rely on informal networking opportunities with peers for problem solving and to gain insights into their work. Thus, the professional development of small community librarians is positively influenced by the advice and information shared with peers. However, despite having access to email and online discussion or news groups, small community librarians would rather communicate with others in person or "with a real 
voice" over the telephone. Even so, the librarians in the study indicated that they tend to only contact people they have established relationships with or who work in towns nearby.

The attitudes expressed by librarians in many of the interviews reflect a predilection for personal, relationship-based interactions with others over text-based electronic communication. One reason for this bias may be that the regional computerbased listservs subscribed to by Texas public librarians are not active discussion venues; instead, they are used mainly to relay announcements about grant and continuing education opportunities. Discussion on national library listservs — which generally includes between 20 and 50 postings per day—often is driven by a handful of outspoken individuals. To date, this phenomenon has not taken hold among small community librarians in Texas. The preference for establishing personal relationships and the reluctance to use electronic communication exhibited by the study participants may indicate prevailing attitudes among small community librarians. These attitudes may negatively influence small community librarians' willingness to participate in online learning venues, which can have an impact on the kinds of continuing education programs developed by CE providers.

\section{Positive Influences on Professional Development}

Many times, small community librarians are women who are already members of the community, are willing to work for low pay, and have no expectations about the job other than a vague idea that libraries are quiet and safe places and that librarians spend most of their time reading, stamping out books, and shushing noisy patrons. The 
remarkable transformation from library worker to librarian occurs only after these women make connections with other librarians and mentors, are identified as "the librarian" in their community, and, perhaps most importantly, gain a sense of personal satisfaction from providing library services.

Rather than being unaware of "what competent library service should be" (Luchs $2001,54)$, the narratives used to gather qualitative data for the current study reveal that small community librarians are motivated by their understanding of their communities' needs for quality library service to gain the necessary expertise and skills. Small community librarians in Texas seek training in areas like budgeting, collection development and maintenance, Internet and database searching, handling intellectual freedom challenges, establishing programming for children and youth, providing business services, and maintaining computer hardware and software. Findings from the current study reveal that some small community librarians in Texas feel they have received adequate training and education to qualify as library professionals, if not as professional librarians. Study participants identified four main sources of professional development:

1) continuing education events such as workshops organized by the Texas State Library and Archives Commission and the Texas Library System, and offered during the annual conference of the Texas Library Association;

2) information shared by more experienced peers and colleagues during formal and informal meetings, and hands-on instruction from previous librarians or library staff; 
3) assistance provided by regional library system consulting staff, especially through on-site training and offering advice on issues affecting day-to-day and long-term library operations; and

4) personal experience gained after years working in a small community library as a desk clerk or library director.

Without exception, all of the participants in the current study identified their participation in continuing education events as a major factor in their professional development. Most credited the workshops developed and provided by their regional library systems and the Texas State Library and Archives Commission—especially the Small Library Management Training Program—with providing the necessary skills and knowledge for managing a small community library. Most of the study participants also expressed a willingness, and even eagerness, to take advantage of every available organized learning opportunity. One librarian, concerned about the challenges of working in a rapidly changing profession, expressed a sense of urgency when she said, "the industry is moving, and you can't do it like you did it 10 years ago. And I have gotten behind again, and I need to be up there" (P03, L461-462). Her comment reflects Abbott's assertion that "the major cultural force affecting librarianship is internal intellectual change" (Abbott 1998, 437) and indicates an awareness of a professional's responsibility to continually gain new knowledge and expertise.

The small community library directors participating in the current study were well aware of the need for skills relating to fiscal management, supervising staff, project management, and planning. Data indicate that librarians with management certification or 
prior experience in business-related industries such as accounting or who have managed their own businesses have an advantage over their less experienced colleagues. The wide gaps in experience and education among library small community library directors indicates that continuing education programs targeting non-MLS librarians should include a substantial management component. Study data indicate that small community librarians in Texas learn about the issues facing small community libraries and begin to identify with the larger library profession by attending continuing education events, visiting with more experienced colleagues, and through the mentoring of regional library system consulting staff, colleagues, and experts in the field.

It is interesting to note that only one librarian interviewed for the current study expressed a belief that training should specifically relate to small community library issues. In the following quote, this director cites time constraints imposed by her job responsibilities as the reason for her unwillingness to attend continuing education events not directly related to her situation: 'It's hard to get out of here, you know, so it's gotta be-it must be something that is gonna apply to what we are doing or want to do or plan to do" (P13, L291-292). By contrast, one experienced librarian with more than ten years of experience as a library director wrote on her Theme Verification Form that continuing education is "valuable even when not applicable to small libraries" (P05, Theme Verification Form). This librarian also telephoned me three months after her interview to express her beliefs about the benefits of continuing education. During this conversation, the librarian emphasized how important she felt it was for small community librarians to take advantage of every training opportunity because "you never know when you'll learn 
something you can use" and "even if it's [the training] geared toward larger libraries, you take what you can use and apply it to your situation."

Study data indicate that continuing education programs and events provided by the Texas Library System and the Texas State Library and Archives Commission are essential to the professional development of small community library directors in Texas. Whether through printed flyers mailed out by the regional system offices and the state library or through email announcements posted by the consultants working in these organizations, small community librarians seem well informed about the number and variety of continuing education opportunities available in their areas. Small community library directors are motivated to attend continuing education workshops by two primary needs: 1) a desire to learn basic library procedures and 2) a need to gain organizational and management skills. It should be noted that the data gathered in this study only concern small Texas community library directors' attitudes toward on-site continuing education events and do not reveal any insights about their willingness to take part in online training.

All of the study participants working in the western and southern areas of the state cited assistance from regional library system consulting staff as a major factor in their professional development. The interview narratives indicated that consulting staff in the West Texas, Texas Trans-Pecos, Texas Panhandle, North Texas Regional, and South Texas Library Systems ${ }^{19}$ often made site visits to instruct new librarians on library

\footnotetext{
${ }^{19}$ The regional library systems in the western part of the state have fewer member libraries than their counterparts in the eastern half of the state, but cover much broader geographic areas. These systems also have only one or two consulting staff, where more populated systems often employ three or more consulting staff.
} 
procedures such as collection development, weeding, and filling out reports mandated by the system office or the state library. Interview data also revealed that system consulting staffs in these regions provide extensive telephone, email, and, in some cases, Web-based assistance to both new and experienced librarians in a variety of areas including computer problems, difficult reference questions, and grant writing. Study participants in the western, southern, and northern regions of the state articulated a high level of comfort when approaching their regional library system consulting staff with questions on routine matters or to help solve minor problems.

The assistance provided by regional library system consulting staff is vital to the professional development of small community librarians, particularly in areas of the state where librarians are geographically isolated. While continuing education workshops provide necessary training and opportunities for networking with peers, on-site assistance and training provided one-on-one between consulting staff and librarians are essential for many small community librarians to gain hands-on knowledge of library operations. Inperson visits also help to establish personal relationships between system staff and small community library directors, which in turn encourage the librarians to ask for help when it is needed. Librarians in the study who have benefited from mentoring articulated a better understanding of the roles and responsibilities of a public library director.

For some small community library directors, guidance provided by more experienced colleagues, supervisors, governing officials, and others is key to their professional development. Mentors not only provide instruction in day-to-day library operations, but also inspire the small community librarian to believe in herself, instilling 
in her a sense of confidence and helping her perceive herself as a library director. Psychology literature has established that professional development is enhanced by mentoring; for example, in a qualitative study conducted by Chovwen (2004) it was determined that:

...although [the] protégé/mentoring relationship was not formally constituted in most organizations it was found to be a significant predictor of growth and participants with mentors perceived they experienced higher growth than those without mentors (Chovwen 2004, 126).

Librarians in the current study who mentioned the influence of mentors also exhibited proactive leadership and a high degree of self-confidence in their abilities as librarians. For example, one librarian overcame personal disappointment to found a library in her hometown. In succeeding years, she became very active in the state's library association and established herself as a historian by publishing several historical indexes and writing for a professional history journal. Another librarian overcame serious injuries sustained in a car accident to establish her authority in the face of overt resistance from city officials, and later launched a successful campaign to open branch libraries in two nearby towns in the county. A third librarian spearheaded a successful effort to build a new, state-of-the art library building, and later participated on a statewide public library task force. Mentorship played a fundamental role in the professional development of these small community librarians.

\section{ReCOMMENDATIONS fOR PraCtice}

The attitudes and perceptions expressed in face-to-face interviews with the 14 library directors in the study can help educators and continuing education providers 
develop programs that will encourage and enhance the professional development of small community librarians. Library-related literature acknowledges the need to train and educate librarians working in small communities, but there is little cooperation or synthesis among existing programs in various U.S. states. Understanding what is important to non-MLS library directors may persuade educators to reach out to these librarians and find ways to facilitate small community librarians' involvement in the larger profession. The data gathered in this study also may encourage other small community library directors to seek out opportunities for professional development.

1) Many non-MLS library directors deserve acknowledgment as library professionals within the larger library profession. Certification requirements should take into account life experience, prior work experience, and the individual's involvement in state and local professional organizations, such as participation in city or county planning committees or serving as an officer or active member in organized groups within the state library association, in addition to participation in other continuing education events.

2) The state library agency or the state library association might establish formal mentoring programs pairing new small community library directors with more experienced colleagues, regardless of the mentor's MLS degree status. Participation in a formal mentoring relationship could be required as part of the small community librarian's accreditation requirements. Mentoring should include frequent communication via telephone, email, and on-site visits. Mentors and mentees should be required to visit each other's libraries at least once, and to attend the state library association's annual conference together. 
3) State and regional continuing education providers in Texas need to provide more opportunities for informal networking among small community librarians during face-to-face meetings and events. Asking each librarian to share a tip or programming idea during an "idea slam," scheduling lunches on site, posing discussion topics, or simply providing unstructured time for librarians to visit with their colleagues during the meeting or workshop would contribute to the professional development of non-MLS library directors.

4) Distance learning events such as videoconferencing and online class instruction for small community library directors need to provide some way of establishing acquaintance and relationship among the participants. Adult learning techniques such as ice breaking activities, team and small group work, and opportunities for participants to introduce themselves to their peers in a non-threatening environment are a few ways to encourage social contact among the participants.

\section{RECOMMENDATIONS FOR FURTHER RESEARCH}

In developing this study, I assumed that understanding the perceptions and attitudes of small Texas community librarians about their professional development could be useful to planners and developers of both academic courses and continuing education events. Researchers interested in information-seeking behavior, the dynamics of adult learning, the ways in which women learn, and the social constructs involved in establishing and maintaining relationships in a small town will find a rich source of study data in the small community library environment. Little work exists on the social impact of rapid technological changes implemented in small community libraries during the last 
decade or on the information-seeking behavior of non-MLS librarians. The current study identifies continuing education as a vital component in the professionalization of nonMLS librarians. Yet, almost no documentation or assessment exists in the literature of regional, state, and national continuing education programs. Coordinated efforts by educators and continuing education providers will not be possible unless researchers document and evaluate these programs.

1) Organizational management uses archetypes to help identify and understand the motivations of workers. Library management literature would benefit from an exploration of the archetypes prevalent within the library field. Building on the current study to develop a list of library management archetypes, researchers can explore implications for librarians working in public, school, academic, and special libraries.

2) Both the current study and Bushing's 1995 study have identified elements important in the professional development of select groups of non-MLS library directors working in small communities. These data can be instrumental in creating a national survey instrument, perhaps using Web technology, which may confirm and broaden the findings of the two existing studies.

3) To date, only a partial catalog of national continuing education programs targeting small community librarians exists. A national group of continuing education providers working in state library agencies could be tapped to provide data on existing continuing education programs, including evaluation responses and comments. A survey and evaluation of national continuing education programs would aid in identifying the components of successful continuing education for non-MLS librarians. 
4) Librarianship would benefit from sociological and cultural studies concerning small community life and the role played by the library and librarian in a community's development as a gatekeeper and provider of information.

5) Exploring the relationship dynamics between non-MLS library directors working in small communities and professional librarians both in rural and urban areas would provide an understanding of what constitutes a profession. Documenting the attitudes and perceptions of non-MLS and professional librarians toward each other may help to promote collegiality and cooperation between the two groups.

6) The current study touches on political issues affecting libraries in small communities. A broader understanding the political process at work in small communities and the role the library plays within that process would contribute to the literature concerning municipal governance structures.

7) Researchers need to explore the ways in which women learn or whether female library directors in small communities and elsewhere process knowledge in ways consistent with current feminist theory, particularly the findings in Women's Ways of Knowing (Belenky et al., 1984). A study utilizing feminist pedagogy to determine the learning patterns of female librarians would explore a previously undocumented population and contribute to the literature on women's studies.

\section{CONCLUSiOnS}

Exploring the perceptions and beliefs of non-MLS librarians working in small communities through qualitative case study methods has confirmed findings in previous studies relating to professional development and identified motivations not previously 
recognized. The current study reveals that small community library directors are motivated to improve their knowledge, skills, and abilities by a number of factors, including:

1) A strong service orientation.

2) A love of and devotion to literacy, libraries, and learning.

3) A willingness to learn from more experienced and knowledgeable individuals, including colleagues, outside experts, and regional library system consulting staff.

4) A sense of ownership for the library building, collection, and services.

5) A feeling of pride in being identified as a person of authority in the community.

6) A feeling of professional achievement gained from having a career rather than a job.

7) A sense of civic responsibility toward improving the quality of the community and contributing to the education and self-actualization of all individuals, particularly children and adults with less education and fewer life skills.

8) Caring relationships among the library's community of users and within the community where the library is embedded.

These motivations, coupled with positive experiences related to professionalizationsuch as gaining knowledge and skills from continuing education events and guidance from mentors - contribute to the process of transformation inherent in professionalization that distinguishes a worker from a working professional. 
Despite dire warnings in the literature that small community public libraries will cease to exist without the direction of MLS librarians (Luchs 2001; Vavrek 1992, 1997), public libraries continue to be established in areas that are unserved and underserved by larger institutions. This study suggests that the librarians participating in the study are dedicated and caring individuals who recognize the value of building and maintaining personal relationships. Most of the librarians are women are over the age of 40 who draw from their life and occupational experiences to guide their current work. Librarians who have at least one year of experience in their jobs, who have participated in some kind of library management training, and who have been mentored by regional system consulting staff or by their more experienced colleagues exhibit a strong professional identity. Faceto-face continuing education programs and events appear to be the most valuable tools for professional development, but hands-on assistance from regional library system consulting staff, mentoring by more experienced colleagues, and networking with peers also greatly contribute to the professionalization process.

Since the MLS degree remains the standard measurement of professional ability, small community librarians are not acknowledged as professionals in the library field. Yet all of study participants exhibit traits associated with professional librarians: knowledge of information sources and tools, research skills, business and management skills, and customer service skills. Further, the librarians in the study articulated their awareness of a sense of duty inherent in being a public servant, the seriousness of the responsibility for maintaining trusting relationships with library patrons, and a willingness to act as a community leader. As Weingand (1992) observed, "In these 
smaller towns, 'professional' must rightly apply to dedication and attitude, regardless of educational preparation" (Weingand 1992, 362). Some of the study participants perceive themselves as visionary leaders whose responsibility it is to guide the library staff and community through rapid technological and sociological changes. Others view their work on a more personal, immediate level, and relish the personal satisfaction that comes from helping one individual to achieve her goals. All expressed a belief that they were performing rewarding work that made a difference in their communities. For some, what began as a job has become a vocation.

The small community librarian is on call 24 hours a day. She supplies information; provides a comfortable environment for children and adults to visit with each other or to pursue intellectual interests; teaches patrons how to use the library's resources, including computer skills such as database searching and email; repairs broken steps and furniture using her own power tools; and, on occasion, rescues small rodents from toilets. She is accustomed to having people give her lengthy explanations about why they have not returned their library materials while standing in line at the grocery store, and having neighbors and relatives ask her to let their child into the library after hours so he can finish a school report. The small community librarian will forever be known as "the library lady" in her community, and she wears this title as a badge of honor.

The current study establishes that non-MLS library directors working in small communities have much to offer the larger library community. Unfortunately, many small community librarians operate almost invisibly on the fringes of the library profession, and their voices remain absent from discussions held on national listservs and 
at state and national committee meetings and conferences. Library leaders, particularly those working in state library agencies, state library associations, large urban libraries, and on college and university faculties should make more efforts to mentor non-MLS public librarians, and to include them in the mainstream profession. 
Appendix A: Map of the Texas Regional Library System

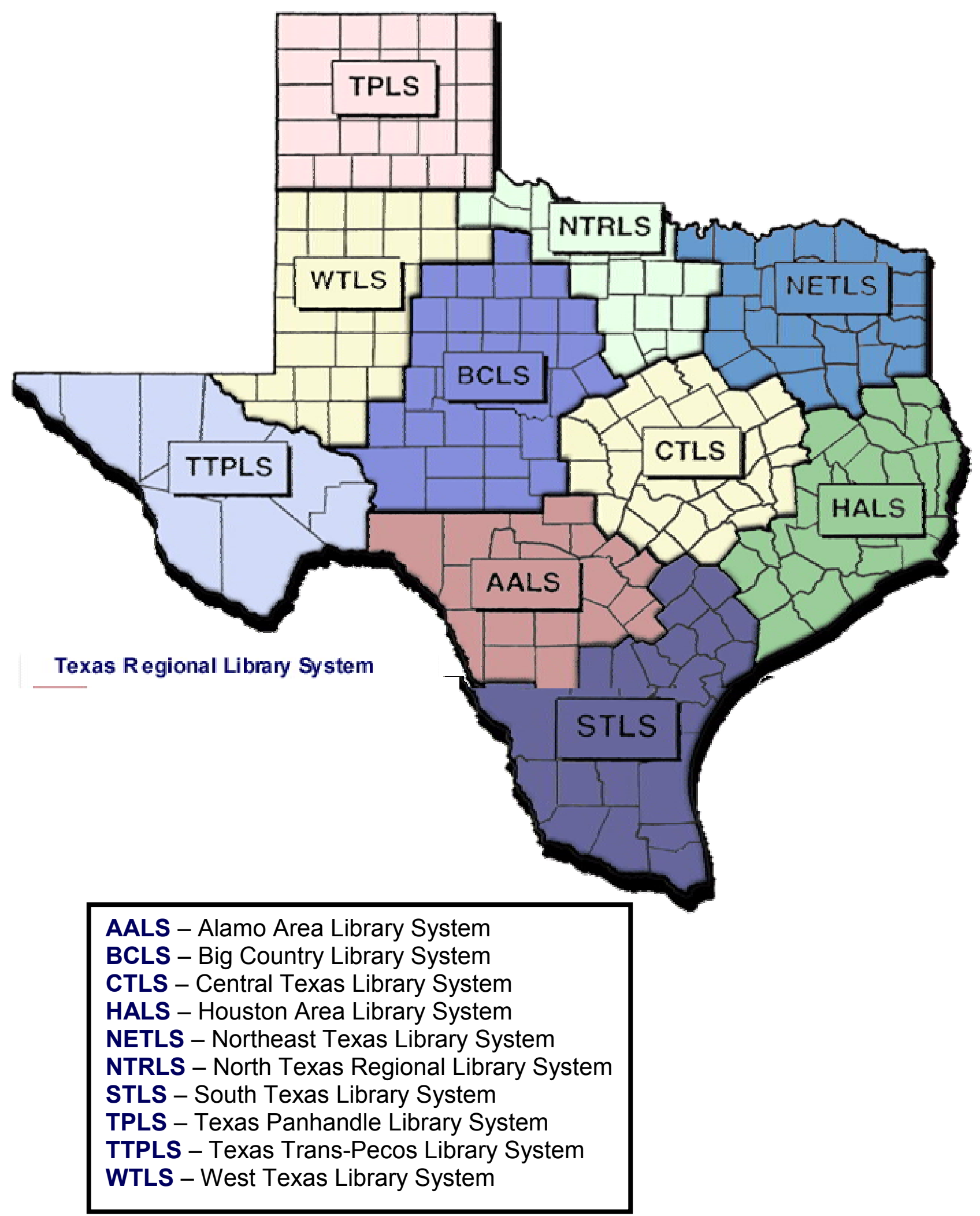


Appendix B: Map of the Texas Geographic Regions

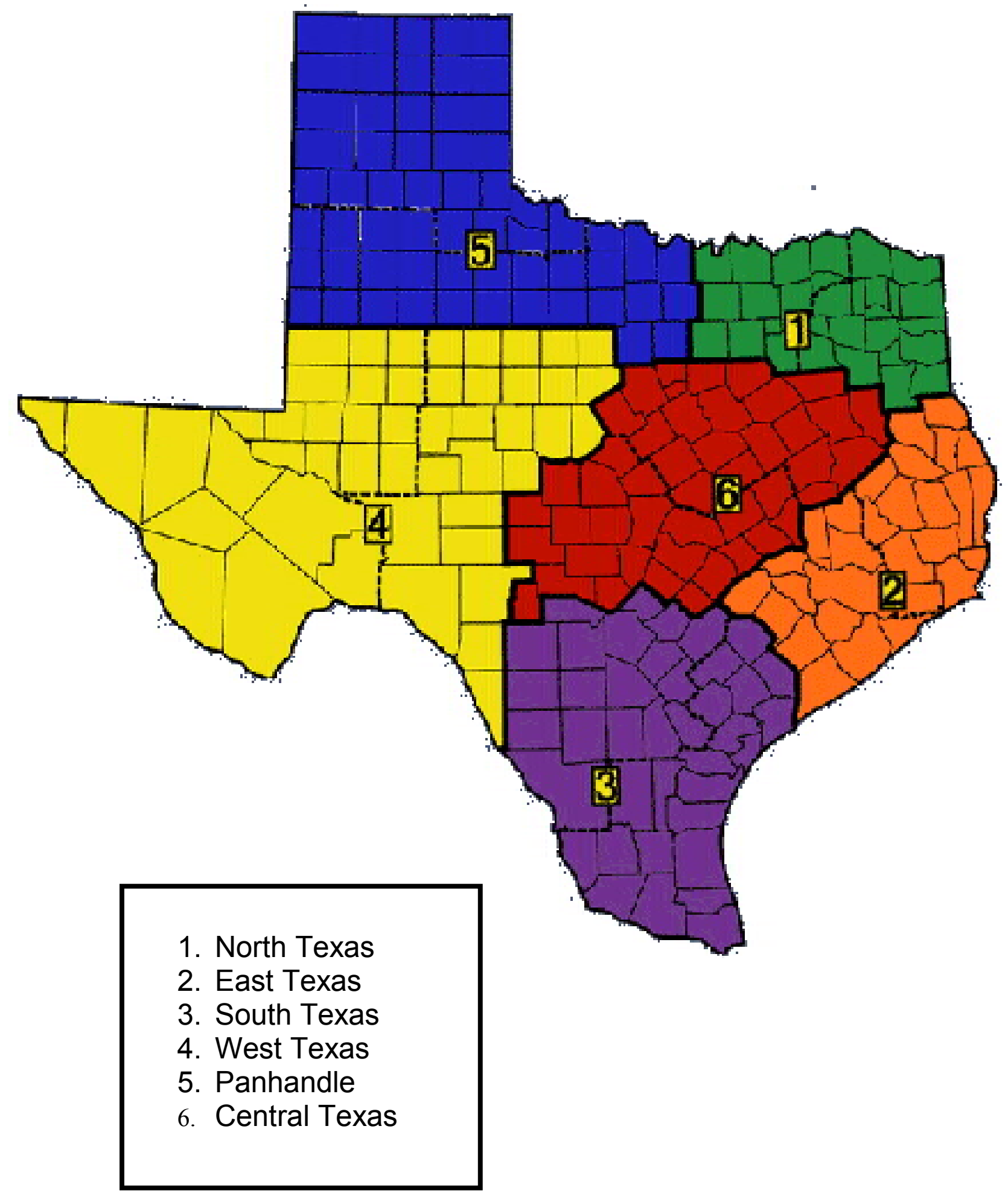




\title{
Appendix C: Informed Consent Form
}

\author{
The University of Texas at Austin
}

You are being asked to participate in a research study. This form provides you with information about the study. The Principal Investigator (the person in charge of this research) or his/her representative will also describe this study to you and answer all of your questions. Please read the information below and ask questions about anything you don't understand before deciding whether or not to take part. Your participation is entirely voluntary and you can refuse to participate without penalty or loss of benefits to which you are otherwise entitled.

Title of Research Study:

The Female Experience in Small Community Texas Public Libraries: Implications for Continuing Education

Principal Investigator

Belinda Boon, Doctoral Student

UT School of Information

815 Great Britain Blvd.

Austin, TX 78748

512-292-8341

bboon@ischool.utexas.edu
Faculty Sponsor

Barbara F. Immroth, Ph.D.

UT School of Information

Mail Code: D7000

512-471-3875

immroth@ischool.utexas.edu

\section{Funding source:}

N/A

What is the purpose of this study?

1) To determine what experiences influence the professional development of female library directors working in public libraries in small Texas communities.

2) To provide data for dissertation research.

\section{What will be done if you take part in this research study?}

Data gathered during the interview will be recorded on audiotape to avoid misinterpretation or misquotes by the Principle Investigator (PI). The PI is the only person who will listen to the tape. The study participant's identity and the location of her library will be kept confidential, and no information will be shared with other researchers or the general public without the written permission from the study participant.

\section{What are the possible discomforts and risks?}

There are no physical, psychological, social, or legal risks associated with this pilot study. The only potential risk is the loss of confidentiality. To ensure the confidentiality of research data, no identifying information (e.g., names of participants or the libraries 
they work in) will be used in the final study. Study participants will only be referred to by categories of age and ethnicity (towns by their population and region) in the final report.

What are the possible benefits to you or to others?

Understanding the experiences of female library directors working in small Texas communities will 1) inform others who may be considering similar positions; 2) assist staff in agencies responsible for library training and continuing professional education to develop curriculum, and to develop and administer effective assessment tools and criteria; and 3) contribute to the development of both feminist and learning theory.

If you choose to take part in this study, will it cost you anything?

No

Will you receive compensation for your participation in this study? No

What if you are injured because of the study? N/A

If you do not want to take part in this study, what other options are available to you?

Participation in this study is entirely voluntary. You are free to refuse to be in the study, and your refusal will not influence current or future relationships with the PI, the University of Texas at Austin, or any other library agency or organization.

How can you withdraw from this research study, and who should you call if you have questions?

You are free to withdraw your consent and stop participation in this research study at any time without penalty or loss of benefits for which you may be entitled. If you wish to stop your participation in this research study for any reason, you should contact: Belinda Boon at (512) 292-8341 or (512) 517-1003, or bboon@ischool.utexas.edu. Throughout the study, I will notify you of new information that may become available and that might affect your decision to remain in the study.

In addition, if you have questions about your rights as a research participant, please contact Clarke A. Burnham, Ph.D., Chair, The University of Texas at Austin Institutional Review Board for the Protection of Human Subjects, 512/232-4383.

How will your privacy and the confidentiality of your research records be protected? Authorized persons from The University of Texas at Austin and the Institutional Review Board have the legal right to review your research records and will protect the confidentiality of those records to the extent permitted by law. Otherwise, your research records will not be released without your consent unless required by law or a court order. 
If the results of this research are published or presented at scientific meetings, your identity will not be disclosed.

\section{Will the researchers benefit materially from your participation in this study?}

No.

\section{Interview Data}

All interviews will be recorded on audiotape. The cassettes will be coded so that no personally identifying information is visible on them; they will be kept in a secure place (e.g., a locked file cabinet in the investigator's office); and they will be heard only for research purposes by the investigator and her associates. Audiocassettes will be kept by the Principal Investigator so that the she may review them for additional analyses at a later time.

I hereby give permission for the audiotape made for this research study to be also used for educational purposes. I understand that by signing this document I am agreeing to be recorded on audiotape only for research purposes, and that the confidentiality of the information on that tape will be maintained by the Principal Investigator.

\section{Signatures:}

As a representative of this study, I have explained the purpose, the procedures, the benefits, and the risks that are involved in this research study:

\section{Signature and printed name of person obtaining consent Date}

You have been informed about this study's purpose, procedures, possible benefits and risks, and you have received a copy of this Form. You have been given the opportunity to ask questions before you sign, and you have been told that you can ask other questions at any time. You voluntarily agree to participate in this study. By signing this form, you are not waiving any of your legal rights.

Printed Name of Subject

Date

Signature of Subject

Date 


\section{Appendix D: Interview Protocol and Questions}

\section{Introduction}

Thank you for agreeing to be interviewed today. I want to reiterate that this interview is part of a formal research study, and that your participation in this project is entirely voluntary; you are free to stop at any time. I also want to assure you that no one will profit materially from this study, and that there are no physical risks involved.

With your permission, the interview will be recorded digitally or on audiotape to avoid my misinterpreting or misquoting your words after the fact. I am the only person who will listen to the tape besides the transcriptionist, and although I will identify you at the beginning of the interview for my records, I will refer to you, your library and community by descriptive characteristics (age, education, region, population) in the study. Your identity and the location of your library will be kept confidential, although the library will be described in general terms (e.g., population, geographic region), and no information will be shared with other researchers or the general public without your written permission. You will also have an opportunity to look over a summary of our interview, and to add or modify any of the information. If you agree to all these terms, please take a moment to read and sign the Informed Consent Form. Thank you.

As a researcher I am interested the kinds of experiences that have influenced your professional development. During the interview I will ask you about your backgroundhow you became a librarian, for example — and also about your present situation. I have several questions written down, but please feel free to tell me anything you think is relevant to this topic. 


\section{INTERVIEW QUESTIONS}

1. Tell me how you became a librarian, and became the director here.

2. Describe what it is like to be a woman in a position of authority in your community.

3. How has your job given you a sense of personal or professional satisfaction or accomplishment?

4. What has contributed most to your professional development?

5. What advice would you give to someone coming into a small community library?

6. What does being a librarian mean to you?

7. Is there anything else I should have asked, or that you would like to share?

Thank you for your time and willingness to be involved with my research project. Even though I will touch base with you over the next several weeks, please feel free to call or email me if you think of anything else that might be relevant, or if you would like to add to any of the topics we discussed. 


\section{Appendix E: Theme Verification Form}

Below are several themes I identified during our interviews. Please indicate whether you agree or disagree with each, and feel free to add your own themes on page 2. (You may want to rank the lettered items in \#6, 7 and 8 from most important to least important.) I welcome your input!

\begin{tabular}{|c|c|c|c|}
\hline \multicolumn{2}{|r|}{ Themes } & Agree & Disagree \\
\hline 1. & $\begin{array}{l}\text { Becoming a small community librarian/library director } \\
\text { often happens by accident or through serendipitous } \\
\text { circumstances, but it eventually becomes a vocation. }\end{array}$ & & \\
\hline 2. & $\begin{array}{l}\text { Assistance from others (mentors, library board, Friends, } \\
\text { colleagues, System and TSLAC staff, foundations) } \\
\text { contributes greatly to the success of libraries and librarians } \\
\text { in small communities. }\end{array}$ & & \\
\hline 3. & $\begin{array}{l}\text { Continuing education is valuable when it is practical and } \\
\text { applicable to the small library situation. }\end{array}$ & & \\
\hline 4. & $\begin{array}{l}\text { Networking with other librarians is one of the best ways to } \\
\text { learn and grow professionally. }\end{array}$ & & \\
\hline 5. & $\begin{array}{l}\text { Working at the library can become a kind of "spiritual } \\
\text { salvation", giving direction and purpose to one's life after } \\
\text { the loss of a loved one. }\end{array}$ & & \\
\hline $\begin{array}{l}6 . \\
\text { a. } \\
\text { b. } \\
\text { c. } \\
\text { d. }\end{array}$ & $\begin{array}{l}\text { Small community librarians gain the most satisfaction } \\
\text { through: } \\
\text { Helping children and adults find information. } \\
\text { Helping children and adults improve their lives. } \\
\text { Making a difference in the community. } \\
\text { Receiving both formal and informal recognition from } \\
\text { the } \\
\text { community. }\end{array}$ & & \\
\hline $\begin{array}{l}7 . \\
\text { a. } \\
\text { b. } \\
\text { c. } \\
\text { d. } \\
\text { e. }\end{array}$ & $\begin{array}{l}\text { The biggest challenges facing small community libraries } \\
\text { are: } \\
\text { Geographic isolation. } \\
\text { Lack of funding. } \\
\text { Rapid changes in the field. } \\
\text { Rapidly changing technology and low computer skills. } \\
\text { Being undervalued by city and county officials. }\end{array}$ & & \\
\hline
\end{tabular}


8. Important characteristics for small community librarians to have include:

a. Business and management (people and money) skills.

b. Knowledge of library procedures and organization.

c. Getting to know and being active in the community.

d. A love of books and reading.

e. Vision and leadership skills.

f. Political savvy.

g. People skills and a willingness to help others.

\section{OTHER THEMES/SALIENT POINTS?}

Becoming/being a librarian:

Continuing education:

On the job:

Job satisfaction:

Challenges and frustrations:

Essential characteristics:

Other: 
Appendix F: Participant Responses to Theme Verification Form

\begin{tabular}{|c|c|c|c|c|c|c|c|c|c|c|c|c|c|c|c|}
\hline & Themes & PO1 & $\mathbf{P O 2}$ & PO3 & P04 & P05 & P06 & P07 & P08 & P09 & P10 & P11 & P12 & P13 & P14 \\
\hline 1. & $\begin{array}{l}\text { Becoming a small } \\
\text { community } \\
\text { librarian/library } \\
\text { director often happens } \\
\text { by accident or through } \\
\text { serendipitous } \\
\text { circumstances, but it } \\
\text { eventually becomes a } \\
\text { vocation. }\end{array}$ & N/A & N/A & A & $\mathrm{A}$ & A & N/A & $\mathrm{A}$ & N/A & $\mathrm{D}$ & A & A & $\mathrm{A}$ & A & $\mathrm{A}$ \\
\hline 2. & $\begin{array}{l}\text { Assistance from } \\
\text { others (mentors, } \\
\text { library board, Friends, } \\
\text { colleagues, System } \\
\text { and TSLAC staff, } \\
\text { foundations) } \\
\text { contributes greatly to } \\
\text { the success of } \\
\text { libraries and librarians } \\
\text { in small communities. }\end{array}$ & N/A & N/A & A & A & A & N/A & A & N/A & A & A & A & A & A & A \\
\hline 3. & $\begin{array}{l}\text { Continuing education } \\
\text { is valuable when it is } \\
\text { practical and } \\
\text { applicable to the small } \\
\text { library situation. }\end{array}$ & N/A & N/A & A & A & D & N/A & A & N/A & A & A & A & A & A & A \\
\hline 4. & $\begin{array}{l}\text { Networking with } \\
\text { other librarians is one } \\
\text { of the best ways to }\end{array}$ & N/A & N/A & A & A & A & N/A & A & N/A & A & A & A & A & A & A \\
\hline
\end{tabular}




\begin{tabular}{|c|c|c|c|c|c|c|c|c|c|c|c|c|c|c|c|}
\hline & $\begin{array}{l}\text { learn and grow } \\
\text { professionally. }\end{array}$ & & & & & & & & & & & & & & \\
\hline 5. & $\begin{array}{l}\text { Working at the library } \\
\text { can become a kind of } \\
\text { "spiritual salvation", } \\
\text { giving direction and } \\
\text { purpose to one's life } \\
\text { after the loss of a } \\
\text { loved one. }\end{array}$ & N/A & N/A & N/A & A & D & N/A & D & N/A & A & A & A & D & A & A \\
\hline 6. & $\begin{array}{l}\text { Small community } \\
\text { librarians gain the } \\
\text { most satisfaction } \\
\text { through: }\end{array}$ & $\mathrm{N} / \mathrm{A}$ & N/A & A & A & A & N/A & A & N/A & A & A & A & A & N/A & A \\
\hline a. & $\begin{array}{l}\text { Helping children and } \\
\text { adults find } \\
\text { information. }\end{array}$ & & & 3 & & & & & & & & 1 & 3 & & 3 \\
\hline b. & $\begin{array}{l}\text { Helping children and } \\
\text { adults improve their } \\
\text { lives. }\end{array}$ & & & 4 & & & & & & & & 3 & 2 & & 2 \\
\hline c. & $\begin{array}{l}\text { Making a difference } \\
\text { in the community. }\end{array}$ & & & 1 & & & & & & & & 2 & 1 & & 1 \\
\hline d. & $\begin{array}{l}\text { Receiving both formal } \\
\text { and informal } \\
\text { recognition from the } \\
\text { community. }\end{array}$ & & & 2 & & & & & & & & 4 & 4 & & 4 \\
\hline 7. & $\begin{array}{l}\text { The biggest } \\
\text { challenges facing } \\
\text { small community } \\
\text { libraries are: } \\
\text { Geographic isolation. }\end{array}$ & N/A & N/A & A & A & A & N/A & A & N/A & A & A & A & A & A & A \\
\hline
\end{tabular}




\begin{tabular}{|c|c|c|c|c|c|c|c|c|c|c|c|c|c|c|c|}
\hline b. & Lack of funding. & & & 4 & & & & & & & & 1 & 1 & & 1 \\
\hline c. & $\begin{array}{l}\text { Rapid changes in the } \\
\text { field. }\end{array}$ & & & 5 & & & & & & & & 5 & 2 & & 4 \\
\hline d. & $\begin{array}{l}\text { Rapidly changing } \\
\text { technology and low } \\
\text { computer skills. }\end{array}$ & & & 2 & & & & & & & & 2 & 5 & & 3 \\
\hline e. & $\begin{array}{l}\text { Being undervalued by } \\
\text { city and county } \\
\text { officials. }\end{array}$ & & & 1 & & & & & & & & 3 & 4 & & 5 \\
\hline 8. & $\begin{array}{l}\text { Important } \\
\text { characteristics for } \\
\text { small community } \\
\text { librarians to have } \\
\text { include: }\end{array}$ & $\mathrm{N} / \mathrm{A}$ & N/A & A & A & A & N/A & A & $\mathrm{N} / \mathrm{A}$ & A & A & A & A & A & A \\
\hline a. & $\begin{array}{l}\text { Business and } \\
\text { management (people } \\
\text { and money) skills. }\end{array}$ & & & 2 & & & & & & & & 1 & 6 & & 3 \\
\hline b. & $\begin{array}{l}\text { Knowledge of library } \\
\text { procedures and } \\
\text { organization. }\end{array}$ & & & 1 & & & & & & & & 6 & 5 & & 2 \\
\hline c. & $\begin{array}{l}\text { Getting to know and } \\
\text { being active in the } \\
\text { community. }\end{array}$ & & & 6 & & & & & & & & 7 & 2 & & 4 \\
\hline d. & $\begin{array}{l}\text { A love of books and } \\
\text { reading. }\end{array}$ & & & 3 & & & & & & & & 3 & 3 & & 7 \\
\hline e. & $\begin{array}{l}\text { Vision and leadership } \\
\text { skills. }\end{array}$ & & & 4 & & & & & & & & 5 & 4 & & 5 \\
\hline f. & Political saavy. & & & 5 & & & & & & & & 4 & 7 & & 6 \\
\hline g. & $\begin{array}{l}\text { People skills and a } \\
\text { willingness to help } \\
\text { others. }\end{array}$ & & & 7 & & & & & & & & 2 & 1 & & \\
\hline
\end{tabular}




\section{OTHER THEMES/SALIENT POINTS?}

\section{Becoming/being a librarian:}

You have to love books and people; you need to know what books and authors are popular. (P04)

To become a librarian a person has to possess a love of books and people. They also have to have good organization and people skills. Librarian positions a sacred trust and a great responsibility. There are few librarian positions and are hard to secure. (P09)

\section{Continuing education:}

You need to know the latest thing in library work, to see how other people do it. (P04)

Can be valuable even when NOT applicable to small libraries. (P05)

\section{On the job:}

You should be on the job regularly; they count on you. (P04)

\section{Job satisfaction:}

If you do a good job, you are proud. (P04)

Being a librarian is a joy and a wonderful way to make a living. (P09)

\section{Challenges and frustrations:}

Under appreciation for things that are not quantitative but qualitative, such as providing a comfortable place to interact with patrons. (P12)

Challenges and frustrations happen every day. You have to learn to deal with it. (P04)

Time, space, funding, adequate number of staff positions and efficient staff are the top of challenges and frustrations that I have to deal with. (P09)

\section{Essential characteristics:}

Openness to interact with people; approachability (P11)

To know your people, be friendly and helpful. (P04)

Other:

N/A 


\section{Appendix G: Librarian Archetype Verification Form}

Please indicate one or two (first and second choice) librarian archetypes from the list below that BEST describe your approach to job. Feel free to add additional criteria, or to add your own archetype(s) at the end of the list. Please email (bboon@ischool.utexas.edu) or call (512-292-8341) me if you have any questions.

\begin{tabular}{|c|c|}
\hline ARCHETYPE & CHOICE 1 OR 2 \\
\hline $\begin{array}{l}\text { The Mother/Caregiver } \\
\text { A. Feels responsible for the establishment, organization and/or } \\
\text { operation of the library. } \\
\text { B. Contributes own resources to purchase materials, supply } \\
\text { furniture and/or facility. } \\
\text { C. Feels responsibility toward patrons, especially children. } \\
\text { D. Identifies closely with the library, and is pleased to be } \\
\text { identified that way by others (i.e., as the Librarian). } \\
\text { E. Reluctant to retire/turn over the reins to a new director who } \\
\text { doesn't 1) know the history of how the library was built up } \\
\text { over the years, and/or 2) understand the extent/significance } \\
\text { of the current librarian's contributions. } \\
\text { Other criteria: }\end{array}$ & \\
\hline $\begin{array}{l}\text { The Social Conscience } \\
\text { A. Feels a social responsibility to the community, especially } \\
\text { children. } \\
\text { B. Feels a responsibility to "give back" to the community in } \\
\text { gratitude for personal blessings and advantages. } \\
\text { C. Works for the pleasure of the job and chance to make a } \\
\text { positive difference, rather than for the money. } \\
\text { Other criteria: }\end{array}$ & \\
\hline
\end{tabular}


The Researcher/Detective

A. Enjoys researching materials and performing reference work.

B. Gets a sense of purpose from helping patrons find information.

C. Believes the library has a responsibility to provide education, especially for children.

D. Usually some background working in an academic setting. Other criteria:

The Visionary Leader

A. Sees the library through a long-term project (e.g., automation, renovation).

B. Provides the vision necessary to take the library into a new era or provide a new level of service.

C. Isn't afraid to let go of the job; looks forward to having someone else take over for the next big project.

Other criteria:

\section{The Businesswoman}

A. Relies on business skills (management, financial planning) to manage the library.

B. Takes a business approach to the job rather than viewing it as a social service.

C. Views herself as a businesswoman or philanthropist.

D. Views the job as a stepping stone to or time marker until her next business venture.

E. Acknowledges her own career ambitions.

F. Acknowledges and admires business acumen in others.

Other criteria: 


\section{The Politician}

A. Demonstrates political savvy.

B. Views the job as a platform that facilitates relationships with people of influence.

Other criteria:

\section{The Storyteller}

A. Refers to stories (both general and specific) and storytelling in the narrative.

B. Uses colorful euphemisms and phrases to illustrate points.

C. Liberal use of metaphor and other poetic devices (e.g., oxymorons) in the narrative.

Other criteria:

\section{The New Professional}

A. Job gives a sense of professional accomplishment, perhaps for the first time.

B. Discovers an identity apart from the wife/mother role.

C. Gains a sense of purpose and competence from the job.

Other criteria:

Other Archetypes: 
Appendix H: Participant Responses to Archetype Verification Form with Researcher Opinion*

\begin{tabular}{|c|c|c|c|c|c|c|c|c|}
\hline & $\begin{array}{c}\text { Mother/ } \\
\text { Caregiver }\end{array}$ & $\begin{array}{c}\text { Social } \\
\text { Conscience }\end{array}$ & $\begin{array}{c}\text { Researcher/ } \\
\text { Detective }\end{array}$ & $\begin{array}{c}\text { Visionary } \\
\text { Leader }\end{array}$ & Businesswoman & Politician & Storyteller & $\begin{array}{c}\text { New } \\
\text { Professional }\end{array}$ \\
\hline \multicolumn{9}{|l|}{ P01 } \\
\hline \multicolumn{9}{|l|}{ P02 } \\
\hline P03 & $\mathrm{A}$ & & & & & & & \\
\hline P04 & $\mathrm{A}$ & $\mathrm{B}$ & & & & & & \\
\hline P05 & & $\mathrm{B}$ & $\mathrm{A}$ & & & & & \\
\hline \multicolumn{9}{|l|}{ P06 } \\
\hline P07 & $\mathrm{A}$ & $\mathrm{B}$ & & & & & & \\
\hline \multicolumn{9}{|l|}{ P08 } \\
\hline P09 & $\mathrm{A}$ & & $\mathrm{B}$ & & & & & \\
\hline P10 & $\mathrm{A}$ & & $\mathrm{B}$ & & & & & \\
\hline P11 & $\mathrm{A}$ & & & $\mathrm{B}$ & & & & \\
\hline P12 & & & $\mathrm{B}$ & $\mathrm{A}$ & & & & \\
\hline P13 & & A & & $\mathrm{B}$ & & & & \\
\hline P14 & & & & $\mathrm{A}$ & & & & \\
\hline Researcher & $\begin{array}{l}\text { P01, P04, } \\
\text { P08 }\end{array}$ & P07, P13 & $\begin{array}{l}\text { P05, P09, } \\
\text { P10 }\end{array}$ & P02, P12 & P06 & P14 & P03 (A) & P11 \\
\hline
\end{tabular}

$A=$ first choice

$\mathrm{B}=$ second choice

*Participants 1, 2, 6, and 8 did not respond 


\section{Appendix I: Description of Study Participants}

\begin{tabular}{|c|l|l|l|r|r|l|}
\hline $\begin{array}{c}\text { Interview } \\
\text { Participant }\end{array}$ & $\begin{array}{c}\text { Type of } \\
\text { Jurisdiction }\end{array}$ & $\begin{array}{c}\text { Regional } \\
\text { System }\end{array}$ & $\begin{array}{c}\text { Geographic } \\
\text { Region }\end{array}$ & $\begin{array}{c}\text { Service } \\
\text { Population }\end{array}$ & $\begin{array}{c}\text { Librarian } \\
\text { Age }\end{array}$ & $\begin{array}{c}\text { Librarian } \\
\text { Education } \\
\text { Level }\end{array}$ \\
\hline P01 & Municipal & CTLS & Central & 16,196 & $50+$ & Some College \\
\hline P02 & Municipal & CTLS & Central & 7,207 & $60+$ & Bachelor \\
\hline P03 & County & BCLS & Central & 8,766 & $70+$ & Bachelor \\
\hline P04 & Municipal & STLS & South & 969 & $70+$ & Bachelor \\
\hline P05 & Municipal & HALS & East & 7,830 & $50+$ & Masters \\
\hline P06 & County & TTPLS & West & 2,211 & $30+$ & High School \\
\hline P07 & County & WTLS & West & 6,892 & $40+$ & Bus. School \\
\hline P08 & County & TTPLS & West & 1,727 & $60+$ & High School \\
\hline P09 & County & WTLS & Panhandle & 22,838 & $50+$ & Some College \\
\hline P10 & County & TPLS & Panhandle & 8,075 & $50+$ & High School \\
\hline P11 & Non-profit & AALS & South & 5,067 & $40+$ & Bachelor \\
\hline P12 & Municipal & NTRLS & North & 8,174 & $50+$ & Bachelor \\
\hline P13 & Municipal & NETLS & North & 11,239 & $40+$ & Bachelor \\
\hline P14 & Multi & STLS & South & 12,811 & $50+$ & Bachelor \\
\hline
\end{tabular}




\section{Bibliography}

1st Congress: What is the Shelf Life on the MLS?." American Library Association. 2005. http://www.ala.org/ala/hrdrbucket/1stcongressonpro/1stcongresswhat.htm (Accessed 23 June, 2005).

Abbott, Andrew. 1998. Professionalism and the Future of Librarianship [revision of a paper presented at the 1993 ALA Conference]. Library Trends, 46(3) (Winter 1998), 430-443.

Abbott, Andrew. 1988. The System of Professions. University of Chicago Press.

Ahern, Mary Eileen. 1899, 1977. The Business Side of a Woman's Career as a Librarian. In Kathleen Weibel and Kathleen M. Heim with assistance from Dianne J. Ellsworth eds. The Role of Women in Librarianship 1876-1976: The Entry, Advancement, and Struggle for Equalization in One Profession. Oryx Press.

Andrew Abbott. 1988. The System of Professions: An Essay on the Division of Expert Labor. University of Chicago Press.

Appleton, L. 2004. Informal Mentoring in Library and Information Services. Impact, the Journal of the Career Development Group, 7(3), 54-58.

Archetypes Around Us and Within Us: A Conversation with Carol Pearson. 2003. New Dimensions World Broadcasting Network. http://www.newdimensions.org/onlinejournal/articles/archetypes.html (Accessed 8 August, 2005).

Asp, William G., Suzanne H. Mahmoodi, Marilyn L. Miller, Peggy O’Donnell, Elizabeth W. Stone. 1985. Continuing Education for the Library InformationPprofessions. Library Professional Publications.

Bates, M. E. 2003. That Darned L-word. Online, 27(3) (May/June2003), 80.

Bates, Marcia J. 1989. The Design of Browsing and Berrypicking Techniques for the Online Search Interface." Online Review, 13 (October 1989), 407-424.

Bates, Marcia J. 1999. The Invisible Substrate of Information Science. Journal of the American Society of Information Science and Technology, 50(12), 1043-1050. 
Bates, Marcia J. 1999. The Role of the PhD in a Professional Field. http://www.gseis.ucla.edu/faculty/bates/phdrole.html (Accessed 4 October, 2005).

Baum, Christina D. 1992. Feminist Thought in American Librarianship. McFarland \& Company, Inc.

Belenky, Mary, Blythe Clinchy, Nancy Goldberger, Jill Tarule. 1996. Women's Ways of Knowing: The Development of Self, Voice and Mind. $10^{\text {th }}$ Anniversary Edition. HarperCollins.

Bell, V. 2003. Mentorship: Is It for Me? Impact, the Journal of the Career Development Group, 6(3/4), 38.

Bergman, B. J. 2005. Looking at Electronic Resources Librarians: Is There Gender Equity Within This Emerging Specialty? New Library World, 106(3/4), 116-127.

Berry, J. N. et al. 2000. University of Washington SLIS Drops L-word. Library journal, 125(18) (November 1, 2000), 13.

Bonnette, A. E. 2004. Mentoring Minority Librarians Up the Career Ladder. Library Administration and Management, 18(3), 134-139.

Brand, B. E. 1983. Librarianship and Other Female-Intensive Professions. Journal of Library History, 18(4), 391-406.

Brooks, Ann K. 2000. Transformation. In Elisabeth Hayes and Daniele D. Flannery with Ann K. Brooks, Elizabeth J. Tisdell, and Jane M. Hugo eds., Women as Learners: The Significance of Gender in Adult Learning. San Francisco: Jossey-Bass.

Brooks, Jacqueline Grennon and Martin G. Brooks. 1993. In Search of Understanding: The Case for Constructivist Classrooms. Association for Supervision and Curriculum Development.

Brugh, Anne E. and Beede, Benjamin R. 1976. American Librarianship. Signs: A Journal of Women in Culture and Society, 1 (Summer 1976), 943-955.

Burrington, G. 1993. Mentors - A Source of Skill, Strength and Enthusiasm. Library Association Record, 95(4), 226-227. 
Bushing, Mary Catherine. 1995. The Professionalization of Rural Librarians: Role Modeling, Networking and Continuing Education. (Doctoral dissertation, Montana State University Bozeman). UMI® Dissertation Services.

Bryne, D. 2003. Mentoring: Enabling, Empowering, Inspiring. Library \& Information Update, 2(4), 38-39.

Bussmann, A. 1987. The Wise Old Woman: Cultural History-Symbolism-Archetype. Soziologische Revue, 10(supplement 2), 36-38.

Caprioli, M. 2005. Primed for Violence: The Role of Gender Inequality in Predicting Internal Conflict. International Studies Quarterly, 49 (June 2005), 161.

Caputi, J., \& Sagle, L. 2004. Femme Noire: Dangerous Women of Color in Popular Film and Television. Race, Gender \& Class, 11(2), 90-111.

Chatman, Elfreda A. 1992. The Role of Mentorship in Shaping Public Library Leaders. Library Trends, 40(3), 492-512.

Chennell, Frank. 1902, 1977. Lady Assistants in Public Libraries. In Kathleen Weibel and Kathleen M. Heim with assistance from Dianne J. Ellsworth eds. The Role of Women in Librarianship 1876-1976: The Entry, Advancement, and Struggle for Equalization in One Profession. Oryx Press, 45-47.

Childers, T. 1989. Adventures with the "L" word: The Drexel Chronicle. Library Journal, 123 (February 14, 1998), 112-13.

Chovwen, C. O. 2004. Mentoring and Women's Perceived Professional Growth. IFE Psychologia: An International Journal, 12(1), 126-132.

Coats, R., Goodwin, J., \& Bangs, P. 2000. Seeking the Best Path: Assessing a Library's Diversity Climate. Library Administration and Management, 14(3), 148-154.

Cooper, E. A., \& Barrett, G. V. 1984. Equal Pay and Gender: Implications of Court Cases for PersonnelPpractices. Journal of Library Administration, 5(4), 71-89.

Cowden, Tami, Carol LaFever and Sue Viders. 2000. The Complete Writer's Guide to Heroes and Heroines: Sixteen Master Archetypes. Lone Eagle Publishing Company.

Crawford, Walt. We Call Them Libraries: What the "L" Word Means to Me. American Libraries, 30(10) (November 1999), 38+.

Creswell, J. W. 1998. Qualitative Inquiry and Research Design: Choosing Among Five Traditions. London: Sage Publications, 1998. 
Cronin, B. 2001. The Dreaded "L” Word. Library Journal, 126(5) (March 15, 2001), 58.

Dewey, John. 1938, 1998. Experience and Education: The 60th Anniversary Edition. West Lafayette, IN: Kappa Delta Pi, 1938, 1998.

Dewey, Melvil. 1886, 1976. Women in Libraries: How They are Handicapped. In Kathleen Weibel and Kathleen M. Heim with assistance from Dianne J. Ellsworth es. The Role of Women in Librarianship 1876-1976: The Entry, Advancement, and Struggle for Equalization in One Profession. Oryx Press, 10-12.

Engle, Michael. 1993, 1998. Remythologizing Work: The Role of Archetypal Images in the Humanization of Librarianship. Paper presented at the Fall Conference of the Eastern New York Chapter of the Association of College and Research Libraries, Plattsburgh, New York, 7-8 October 1993, revised February 12, 1998.

Eschle, C. 2005. "Skeleton Women": Feminism and the Antiglobalization Movement. Signs, 30(3), 1741-1769.

Fairchild, Salome Cutler. 1904, 1976. Women in American Libraries. In Kathleen Weibel and Kathleen M. Heim with assistance from Dianne J. Ellsworth eds. The Role of Women in Librarianship 1876-1976: The Entry, Advancement, and Struggle for Equalization in One Profession. Oryx Press, 48-55.

Farmer, J., and Campbell, F. 1998. Identifying the Transferable Skills of Information Professionals Through Mentoring. Education for Information, 16(2), 95-106.

Ferguson, A. W. 1996. The "L" Word. Against the Grain, 8 (April 1996), 90+.

Fernald, Dodge. 1996. Psychology. New Jersey: Prentice Hall College Division, 1996. http://www.prenhall.com/fernald/chapter/fern3.html (Accessed 12 December, 2005).

Field, J. 2001. Mentoring: A Natural Act for Information Professionals? New Library World, 102(1166/1167), 269-273.

Fisher, B. 1994. Mentoring. Journal of Librarianship and Information Science, 26(4), 233-234.

Fisher, B., Nankivell, C., Norry, J., Trickey, K., \& Tuffin, S. 1997. Mentoring: Do As I Do. Library Association Record, 99(10), 544-546. 
Fisher, W. 1997. The Question of Gender in Library Management. Library Administration and Management, 11(4), 231-236.

Fitchen, J. M. 1991. Endangered Spaces, Enduring Places: Change, Identity, and Survival in Rural America. Boulder, CO: Westview Press.

Foster, Mindi D. 1999. Acting Out Against Gender Discrimination: The effects of Different Social Identies. Sex Roles, 40(3/4), 167-186.

Freedman, Janet. 1970. The Liberated Librarian? A Look at the "Second Sex" in the Library Profession. Library Journal 95 (May 1, 1970), 1709-1711.

Garrison, Dee. 1972. The Tender Technicians: The Feminization of Public Librarianship, 1876-1905. Journal of Social History, 6(2), 131-159.

Gilbert, Mizpah. 1915, 1976. The Position of Women in Public Libraries. In Kathleen Weibel and Kathleen M. Heim with assistance from Dianne J. Ellsworth eds. The Role of Women in Librarianship 1876-1976: The Entry, Advancement, and Struggle for Equalization in One Profession. Oryx Press, 67-72.

Gilligan, Carol. 1979. Woman's Place in Man's Life Cycle. Harvard Educational Review, $49,440$.

Gilligan, Carol. 1982. In a Different Voice: Psychological Theory and Women's Development. Cambridge, MA: Harvard University Press.

Golian, L. M. and Galbraith, M. W. 1996. Effective Mentoring Programs for Professional Library Development.

Gorman, G. E. and Corbett, B. J. 2002. Core Competencies in Information Management Education. New Library World, 103( 11-12) (November 2002), 436-445.

Gorman, M. 2005. The Greatest Challenge. American Libraries, 37(3) (March 2006), 5.

Grossman, D. 2006. Beyond the 'L' Word. Searcher, 14(2) (February 2006), 29-31.

Gustafson, Barbro. 2005. Confirming Mentoring. Journal of Nursing Management, Vol 13(4) (July 2005), 312-321.

Hall, Eleanor L. 1980. The Moon and the Virgin: Reflections on the Archetypal Feminine. Harper \& Row. 
Hedley, M. 2002. The Geometry of Gendered Conflict in Popular Film: 1986-2000. Sex Roles, 47(5-6), 201-217.

Heim, Kathleen M. 1982. Factors Contributing to a Continued Status Differentiation Between Male and Female Librarians. In Weingand, Darlene E. (Ed.) Women and Library Management: Theories, Skills and Values, Pierian Press, 3-13.

Hernández, Adriana. 1997. Pedagogy, Democracy and Feminism: Rethinking the Public Sphere. State University of New York Press, 1997.

Hildenbrand, Suzanne. 2000. Library Feminism and Library Women's History: Activism and Scholarship, Equity and Culture. In Wertheimer, Andrew B. and Davis, Jr., Donald G. (Eds.) Library History Research in America: Essays Commemorating the Fiftieth Anniversary of the Library History Roundtable. Libraries \& Culture: A Journal of Library History. 35(1), (Winter 2000), 51-65.

Hoadley, I. B. 1999. Management Morphology: How We Got to Be Who We Are. Journal of Academic Librarianship, 25(4), 267-273.

Hunt, David Marshall and Michael, Carol. 1984. Worth Repeating from the Management Literature. Ournal of Library Administration, 5(1), 77-95.

Jensen, Gary. "Library Education: Guiding Principles,” OLA Quarterly, 3(3) (Fall 1997).

Jerby, Iris, Semyonov, Moshe, and Lewin-Epstein, Noah. 2005. Capturing Gender-Based Microsegregation: A Modified Ratio Index for Comparative Analyses. Sociological Methods \& Research, Vol. 34(1), 122-136.

Kaplan, L. D. 1994. Woman as Caretaker: An Archetype that Supports Patriarchal Militarism. Hypatia, 9(2), 123-133.

Kaufman, Paula T. 1993. Library Leadership: Does Gender Make a Difference? Journal of Library Administration, 18(3/4), 109-128.

Kehde, Ned. 1999. The Tyranny of Professionalism. American Libraries, 30(8) (September 1999), 43.

Kennedy, T., and Okrent, M. 1993. Managing Diversity: Some Practical Tips for Managers. New Jersey Libraries, 26(4), 15-18.

Knowles, Malcolm. 1998. The Adult Learner: The Definitive Classic in Adult Education and Human Resources Development, $5^{\text {th }}$ ed. Gulf Publishing Co.

Knowles, Malcolm. 1984. Andragogy in Action. Jossey-Bass. 
Laird, D. 1985. Approaches to Training and Development, $2^{\text {nd }}$ ed. Addision-Wesley.

Lauter, E. 1976. Homage to Anima: Some Psychological and Cultural Implications of Willem de Kooning's Images of Woman. Soundings, 59(4), 426-446.

Law, M. 2001. Mentoring Programs: In Search of the Perfect Model. Feliciter, 47(3), 146-148.

Lewis McCabe, G. C. 2005. Morphing the Crone: An Ethnography of Crone Culture, Consciousness and Communities. Dissertation Abstracts International, A: The Humanities and Social Sciences, 66 (1), 363-A

Library Systems Act and Rules for Administering. 2005. http://www.tsl.state.tx.us/ld/pubs/libsysact/libsysact2005.pdf (Accessed 3 Aug, 2005).

Lowenthal, Helen. 1971. A Healthy Anger. Library Journal, 96 (September 1, 1971), 2597-2599.

Luchs, Manda. 2001. The Education of the Rural Librarian: Advantages and Obstacles. Rural Libraries, 21:1, 51-64.

Madden, Karl and Bob Grover. 2001. Current Trends in Library Support Staff Continuing Education Programs: A Report for the Western Council of State Librarians Education Task Force. October 2001. http://msl.state.mt.us/LDD/WesternCouncilRevisedReport.htm. (Accessed May 2005 through October 2005).

Mark, Margaret and Carol S. Pearson. 2001. The Hero and the Outlaw: Building Extraordinary Brands Through the Power of Archetypes. McGraw-Hill.

Marshall Hunt, D., Michael, C., and Hunt, D. M. 1984. Mentorship: A Career Training and Development Tool. Journal of Library Administration, 5(1), 77-95.

McDermott, E. 1994. Researching Women. Assistant Librarian, 87(3), 40-41.

Meiners, E. R. 2002. Disengaging from the Legacy of Lady Bountiful in Teacher Education Classrooms. Gender and Education, 14(1), 85-94.

Meraz, Gloria. 2005. In Times of Trouble. Texas Library Journal, 81(3), 90.

Miles, Mathew B. and Michael Huberman. 1994. An Expanded Sourcebook: Qualitative Data Analysis, Second Edition. London: Sage Publication. 
Murrell, Audrey J. and James, Erika Hayes. 2001. Gender Diversity in Organizations: Past, Present, and Future Directions. Sex Roles, 45(5/6), 243-257.

Nadler, L. and Nadler, Z. 1994. Designing Training Programs: The Critical Events Model, $2^{\text {nd }}$ ed. Gulf Publishing Co.

Nankivell, C. and Shoolbred, M. 1997. Mentoring in Library and Information Services: A Literature Review and Report on Recent Research. New Review of Academic Librarianship, 3, 91-114.

National Council for Education Statistics. 2002. Public Libraries in the United States: Fiscal Year 2001. U.S. Department of Education, 2002. http://nces.ed.gov/pubs2003/2003399.pdf (Accessed May 2005 through October 2005).

Noble, Kathleen. 1994. The Sound of a Silver Horn: Reclaiming the Heroism in Contemporary Women's Lives. Fawcett Columbine.

Noddings, Nel. 1984. Caring: A Feminine Approach to Ethics and Moral Education. University of California Press, 1984.

O'Neill, J. 2002. Marcuse's Maternal Ethic: Myths of Narcissism and Maternalism in Utopian Critical Memory. Journal of Classical Sociology, 2(1), 5-24.

O’Neill, Lauren. 2005. A Small Public Library and Its Community: Case Study of Churchill County Library. PNLA Quarterly, 69(4), 12, 32.

Pearson, Carol. S. 1991. Awakening the Heroes Within : Twelve Archetypes to Help Us Find Ourselves and Transform Our World. Harper San Francisco.

Pearson, Carol S. 1998, The Hero Within: Six Archetypes We Live By. Harper San Francisco.

Pessen, Edward. 1978. Jacksonian America: Society, Personality, and Politics. Dorsey Press.

Poland, F., Curran, M., and Owens, R. G. 1996. Women and Senior Management. A Research Study of Career Barriers and Progression in the Library and Information Sector. Library Association. 
Polster, Miriam F. 1992. Eve's Daughters. Jossey-Bass.

Pratt, Annis. 1978. Aunt Jennifer's Tigers; Notes Toward a Preliterary History of Women's Archetypes. Feminist Studies, 4(1), 163-194.

Pratt, Annis with White, Barbara, Loewenstein, Andrea, and Wyer, Mary. 1981. Archetypal Patterns in Women's Fiction. Indiana University Press.

Proceedings of the 14th American Library Association Conference: The Woman's Meeting. 1892, 1976. In Kathleen Weibel and Kathleen M. Heim with Assistance from Dianne J. Ellsworth eds. The Role of Women in Librarianship 1876-1976: The Entry, Advancement, and Struggle for Equalization in One Profession. Oryx Press, 13-17.

Putnam, Herbert. 1912, 1976. The Prospect: An Address Before a Graduating Class of Women. In Kathleen Weibel and Kathleen M. Heim with Assistance from Dianne J. Ellsworth eds. The Role of Women in Librarianship 1876-1976: The Entry, Advancement, and Struggle for Equalization in One Profession. Oryx Press, 1976, 56-66.

Regan, J. 2003. Mentoring Schemes: Raising the Standards. Library \& Information Update, 2(4), 36-37.

Redwood, Rachel. 1999. "Information Point: Narrative and Narrative Analysis" in Journal of clinical nursing. Volume 8, 1999, p. 674.

http://www.blackwellpublishing.com/specialarticles/jen 8 674.pdf (Accessed 26 June, 2005).

Reissman, Cathy. 1993. Narrative Analysis. London: Sage Publications.

Riggs, D. E., and Sykes, V. M. 1993. The Time for Transformational Leadership is Now! Journal of Library Administration, 18(3/4), 55-68.

Ritchie, A., and Genoni, P. 1999. Mentoring in Professional Associations: Continuing Professional Development for Librarians. Health Libraries Review, 16(4), 216-225.

Rooks, D. C. 1994. Terms for Academic Library Directors. Library Trends, 43(1), 47-61.

Rossman, Gretchen B. and Sharon F. Rallis. 2003. Learning in the Field: An Introduction to Qualitative Research. Sage Publications. 
Sable, Arnold. 1969. The Sexuality of the Library Profession: The Male and Female Librarian. Wilson Library Bulletin, (April 1969), 748-751.

Schiller, Anita R. 1976. Women in Librarianship. Academic Press.

Smith, Duncan. 1999. What is the Shelf Life of the MLS? American Library Association, 1999. http://www.ala.org/congress/smith.html (Accessed 17 June, 2005).

Somerville, M. (1995). Yin Management in a Yang World. Wilson Library Bulletin, $69(8), 30-32$.

Studwell, W. E. 2002. Mentoring and the Future of Library and Information Science. Technicalities, 22(4), 3, 6 .

System Orientation Manual. Library Development Division, Texas State Library \& Archives Commission, 1999. http://www.tsl.state.tx.us/ld/pubs/som/ (Accessed 23 June, 2005).

Texas Public Library Summary for 2004. 2005. Texas State Library and Archives Commission.http://www.tsl.state.tx.us/ld/pubs/tpls04/ (Accessed 23 December, 2005).

Tisdell, Elizabeth J. 1995. Creating Inclusive Adult Learning Environments: Insights from Multicultural and Feminist Pedagogy. ERIC Clearninghouse on Adult, Career, and Vocational Education.

Tisdell, Elizabeth J. 2000. Feminist Pedagogies. In Elisabeth Hayes and Daniele D. Flannery with Ann K. Brooks, Elizabeth J. Tisdell, and Jane M. Hugo, eds., Women as Learners: The Significance of Gender in Adult Learning. Jossey-Bass, 2000.

Todaro, Julie B. 2000. Small Library Management Online Tutorial on Professionalism. http://www.tsl.state.tx.us/ld/tutorials/professionalism/print.html (Accessed 10 August, 2005).

Tovar Ramirez, A. 1996. Women Who Run with the Wolves. Myths of the Wild Woman Archetype. Acta Sociologica, 16, 291-292.

Usherwood, R. C. 1998. Staunch Defenders of the 'L' Word. Library Association Record, 100(9) (September 1998), 463. 
Vavrek, Bernard. 1980. Information Services and the Rural Library. Library Trends. 1980, 563-578.

Vavrek, Bernard. 1982. Profession Needs a New Entry Level: Non-MLS Workers in Rural Libraries are Isolated from the Mainstream. In American Libraries, 1984; 13(4), 271-272.

Vavrek, Bernard. 1982. Reference Service in Rural Libraries. School of Library Science, Center for the Study of Rural Librarianship, Clarion State College.

Vavrek, Bernard. 1983. A Struggle for Survival: Reference Services in the Small Public Library. Library Journal, 108, 966-969.

Vavrek, Bernard. 1984. Reference Service in Rural Libraries. Center for the Study of Rural Librarianship.

Vavrek, Bernard. 1984. Rural Library Services. The Bookmark, 42, 245-248.

Vavrek, Bernard. 1989. Rural library Service. Wilson Library Bulletin, 63, 29-31, 34-38, 40-47.

Vavrek, Bernard. 1990. Assessing the Information Needs of Rural Americans. Center for the Study of Rural Librarianship.

Vavrek, Bernard. 1992. Educating Rural Library Staff. Library Mosaics, 3 (1), 7-9.

Vavrek, Bernard. 1995. Rural Information Needs and the Role of the Public Library. Library Trends, 41(1), 21-48.

Vavrek, Bernard. 1997. A National Crisis No One Really Cares About. American Libraries, 28, 37-38.

Vavrek, Bernard. 2004. The Challenge of Starting a Rural Library. American Libraries, 35(3), 77.

Vavrek, Bernard. 2004. Rural and Small Libraries: Providers for Lifelong Learners. http://www.ala.org/ala/olos/outreachresource/servicesrural.htm (Accessed 22 Nov, 2005). 
Voelck, J. 2003. Directive and Connective: Gender-Based Differences in the Management Styles of Academic Library Managers. Portal: Libraries and the Academy, 3(3), 393-418.

Walker, Barbara G. 1985. The Crone: Woman of Age, Wisdom, and Power. HarperCollins.

Ward, Patricia Layzell. 1966. Women and Librarianship: An Investigation of Certain Problems of Library Staffing. London: Library Association.

Weingand, Darlene E. 1992. Continuing Professional Education. In T. W. Sineath ed. Library and Information Science Education Statistical Report, 1992. Chicago: American Library Association, 343-362.

Weingand, Darlene E. 1997. Customer Service Excellence: A Concise Guide for Librarians. American Library Association.

Whitehead, J. 1995. Modernising the Motherhood Archetype: Public Health Models and the Child Marriage Restraint Act of 1929. Contributions to Indian Sociology, 29(12), 187-209.

Wolcott, H. F. 1994. Transforming Qualitative Data: Description, Analysis, and Interpretation. Thousand Oaks, CA: Sage Publications.

Wood, Wendy, Christensen, P. Niels, Hebl, Michelle R., Rothgerber, Hank. 1997. Conformity to Sex-Typed Norms, Affect, and the Self-Concept. Journal of Personality and Social Psychology, 73(3), 523-525.

Yapp, C. (2000). The Knowledge Society: The Challenge of Transition. Business Information Review, 17(2), 59-65.

Young, Jr., Terrance E. 2004. No School Library Media Specialist Left Behind: Professional Development. Knowledge Quest, 32(3) (January/February 2004), 49-50. http://www.ala.org/ala/aasl/aaslpubsandjournals/kqweb/kqreviews/networth/young.pd f. (Accessed 24 January, 2006).

Zaltman, Gerald and Duncan, Robert. 1977. Strategies for Planned Change. John Wiley and Sons. 
Zuga, Karen F. 1999. Addressing Women's Ways of Knowing to Improve the Technology Education Environment for S1l Students. Journal of Technology Education, 1999; 10(2), 57-71.

\section{Web Resources}

National Center for Education Statistics Library Statistics Program http://nces.ed.gov/surveys/SurveyGroups.asp?Group=5

Gates Foundation U.S. Library Program http://gatesfoundation.org/Libraries/USLibraryProgram/

Texas State Library and Archives Commission http://www.tsl.state.tx.us/ld 


\section{Vita}

Belinda Boon was born on July 29, 1961 in Houston, Texas to Carolyn and Herb Boon. She attended Southwest Texas State University and the University of Texas at Austin where she graduated in 1983 with a Bachelor of Arts degree in English Literature. After working for two years in corporate and retail environments, Belinda returned to graduate school at the University of Texas at Austin and earned a Master's in Library and Information Science there in 1987. After working for three months as an intern in the Archives of the Ford Foundation in New York City, she began her library career as a children's librarian in the Harris County Public Libraries in Houston, working there until 1990. From 1991 to 1993, Belinda served as the director of the Bastrop Public Library, a small community library in central Texas. In 1993, she became the continuing education consultant at the Texas State Library and Archives Commission (TSLAC), where she coordinated a statewide continuing education program and developed the Small Library Management Training Program. While at the TSLAC, Belinda authored The CREW Method, a nationally recognized manual for weeding library collections. She served as the Manager of Continuing Education and Consulting at the TSLAC from 2000 to 2003.

Belinda has been an independent consultant since 2002, and has conducted more than 100 workshops for school, public, and academic library staff in eight states. She currently resides in Austin, Texas, and expects to assume a faculty position at Kent State University's School of Library and Information Science in the fall of 2006.

815 Great Britain Blvd., Austin, TX 78748.

This dissertation was typed by Belinda Boon. 